\title{
SYSTEM IDENTIFICATION OF A BRIDGE-TYPE
}

\section{BUILDING STRUCTURE}

\author{
A Thesis \\ presented to \\ the Faculty of California Polytechnic State University, \\ San Luis Obispo
}

\author{
In Partial Fulfillment \\ of the Requirements for the Degree \\ Master of Science in Architecture with a Specialization in Architectural Engineering \\ by \\ Pablo De La Cruz Ramos Jr. \\ March 2013
}


(C) 2013

Pablo De La Cruz Ramos Jr.

ALL RIGHTS RESERVED

ii 
TITLE:

AUTHOR:

DATE SUBMITTED:

COMMITTEE CHAIR:

COMMITTEE MEMBER:
System Identification of a Bridge-Type Building Structure

Pablo De La Cruz Ramos Jr.

March 2013

Dr. Graham Archer, Ph.D., P.Eng., Professor, Architectural Engineering

Dr. Cole McDaniel, Ph.D., P.E., Associate Professor, Architectural Engineering

COMMITTEE MEMBER: John Lawson, M.S., S.E., Assistant Professor, Architectural Engineering 


\begin{abstract}
System Identification of a Bridge-Type Building Structure
\end{abstract}

Pablo De La Cruz Ramos

The Bridge House is a steel building structure located in Poly Canyon, a rural area inside the campus of California Polytechnic State University, San Luis Obispo. The Bridge House is a one story steel structure supported on 4 concrete piers with a lateral force resisting system (LFRS) composed of ordinary moment frames in the N-S direction and braced frames in the E-W direction and vertically supported by a pair of trusses. The dynamic response of the Bridge House was investigated by means of system identification through ambient and forced vibration testing. Interesting findings such as diaphragm flexibility, foundation flexibility and frequency shifts due to thermal effects were all found throughout the mode shape mapping process. Nine apparent mode shapes were experimentally identified, N-S and E-W translational, rotational and 6 vertical modes. A computational model was also created and refined through correlation with the modal parameters obtained through FVTs. When compared to the experimental results, the computational model estimated the experimentally determined building period within $8 \%$ and $10 \%$ for both N-S and E-W translational modes and within $10 \%$ for 4 of the vertical modes. 


\section{ACKNOWLEDGEMENTS}

I would like to thank the previous Bridge House senior project team, Brian Planas, Megan Hanson, Dave Martin, Emma Ronney, Charles Weir, and Nick Herskedal for converting the Bridge House into a structural dynamic laboratory, without your hard work this thesis would not been possible. I would like to thank Ray Ward for fixing the linear mass shaker when it was necessary. I would like to thank my brother from another mother Sabino Tirado, thank you for traveling to Cal Poly with me and extending your helping hand through the experimentation process. I would like to thank my mother Flora Reyes for always giving me her love and support throughout my college education, after

9 years of college I graduated with a Master's degree. I would like to thank my wife and daughter Erika and Jazlene Ramos, thank you for your understanding, patience and continuous motivation on completing this thesis. Finally, I would like to thank my advisors Dr. Graham Archer, Dr. Cole McDaniel, and Mr. John Lawson for your continuous help throughout the production of this thesis as this would not have been possible without your time and expertise. 


\section{Table of Contents}

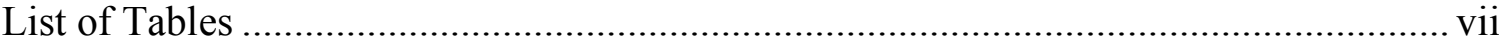

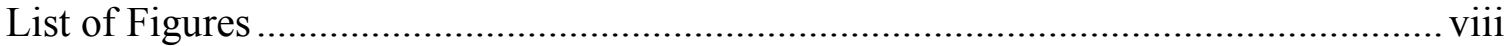

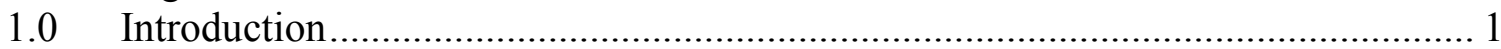

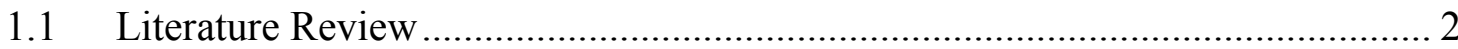

$1.2 \quad$ The Test Building ................................................................................. 5

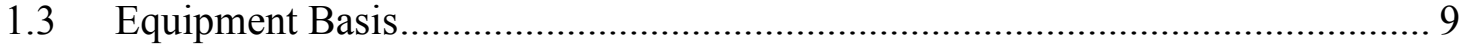

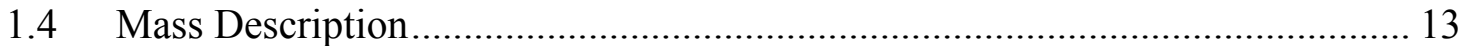

1.5 Stiffness Approximations of Lateral Resisting Elements …………………....... 16

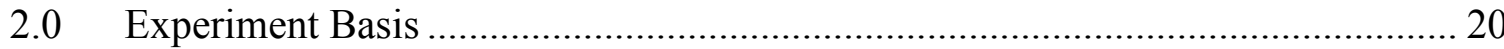

2.1 Theoretical Validation of the Experimental Readings ……………………....... 20

2.2 Experimental Determination of Apparent N-S Mode Shape ............................ 24

2.2.1 Ambient Vibration Testing …………………................................... 24

2.2.2 Forced Vibration Testing .................................................................. 26

2.3 Experimental Determination of First E-W Mode Shape ……………………..... 31

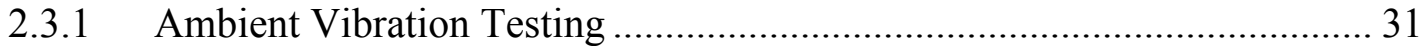

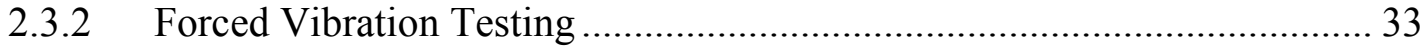

2.4 Experimental Determination of First Vertical Mode Shape ............................... 37

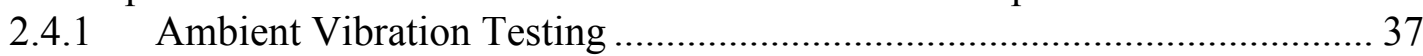

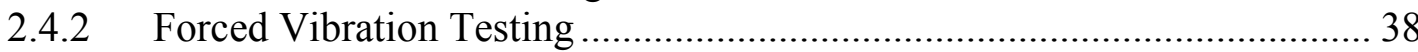

2.5 Modal Orthogonality of Experimental Mode Shapes ...................................... 46

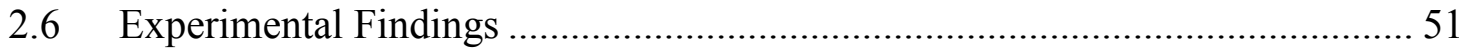

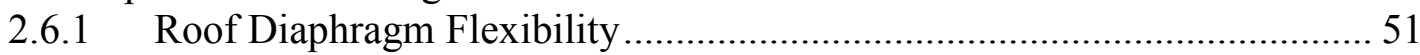

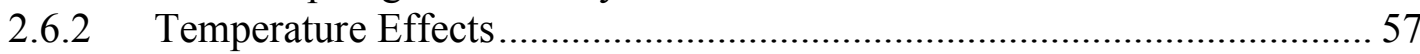

2.6.3 Vertical Anomaly on the Floor Diaphragm in First N-S Mode .................... 62

2.6.4 Foundation Flexibility.............................................................................. 64

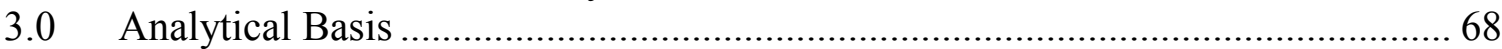

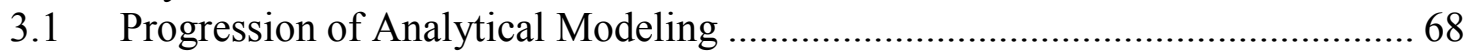

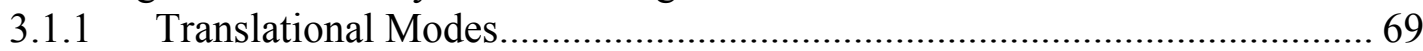

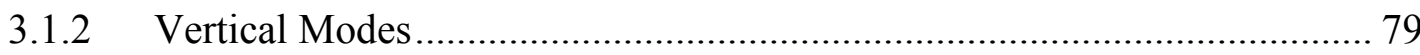

3.2 Comparison of Analytical to Experimental Mode Shapes .................................... 80

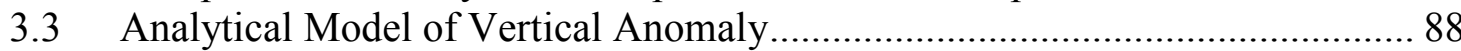

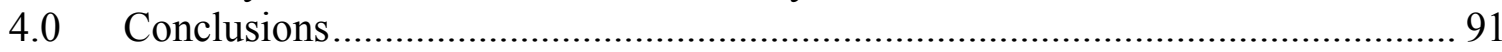

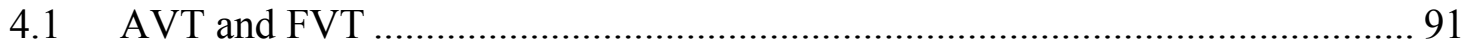

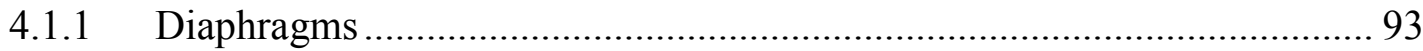

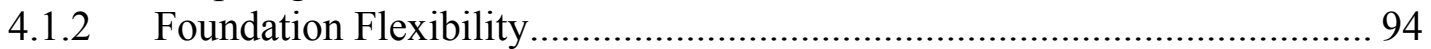

4.1.3 Frequency Shift Due to Thermal Effects ……………………………….... 95

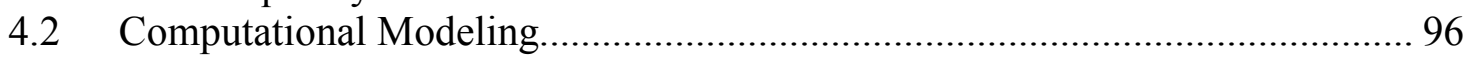

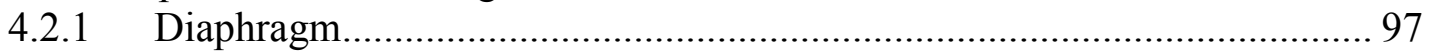

4.2.2 Foundation Flexibility........................................................................... 97

4.2.3 Comparisons of Analytical to Experimental Mode Shapes ......................... 98

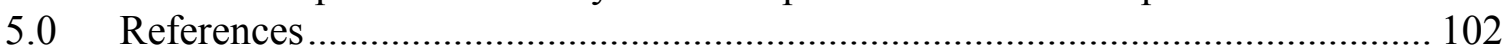

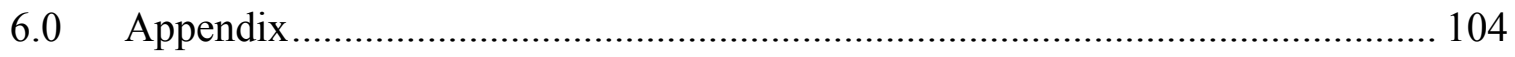




\section{List of Tables}

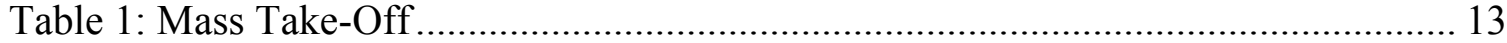

Table 2: Stiffness Approximations of Lateral Resisting Elements ................................ 19

Table 3: Experimental vs. Computational Accelerations .............................................. 24

Table 4: Summary of Experimental Mode Shapes ...................................................... 43

Table 5 Continued: Summary of Experimental Mode Shapes...................................... 44

Table 6: Mass Weighted Correlation Numbers Comparing Experimental Mode

Shapes

Table 7: Diaphragm Stiffness and Natural Frequency of the Analytical E-W Mode

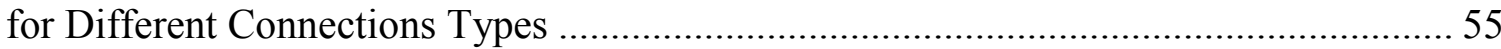

Table 8: Flexible Roof Diaphragm vs. Experimental Results .................................... 71

Table 9: Hybrid Roof Diaphragm vs. Experimental Results ....................................... 72

Table 10: Hybrid Diaphragm Model with Foundation Flexibility vs. Experimental

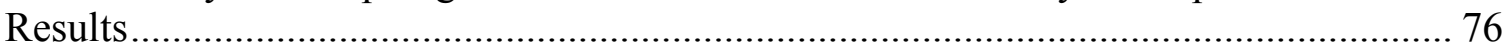

Table 11: Flexible Roof Diaphragm Model with Diagonal Bracing vs. Experimental

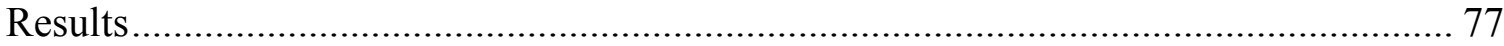

Table 12: Analytical Vertical Modes vs. Experimental Vertical Modes ........................ 80

Table 13: MAC Numbers Comparing Un-Swept-Apparent Results to Analytical

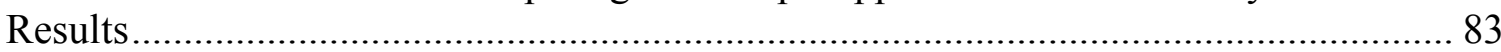

Table 14: MAC Numbers Comparing Swept-Experimental Results (Modes 1, 5, 2, 3, 8, 6, 4, 9, 7) to Analytical Results ............................................... 85

Table 15: MAC Numbers Comparing Swept-Experimental Results

(Modes 1, 5, 2, 3, 8, 7, 4, 6, 9) to Analytical Results 


\section{List of Figures}

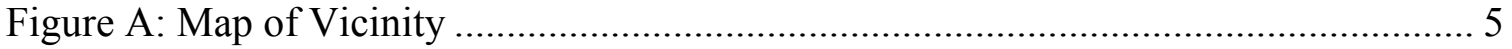

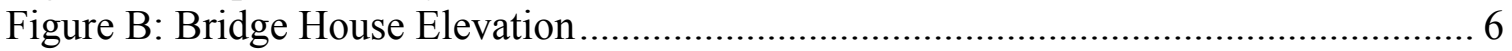

Figure C: Exterior Welded Connections.................................................................. 7

Figure D: Beam to C-Channel Connection .................................................................. 7

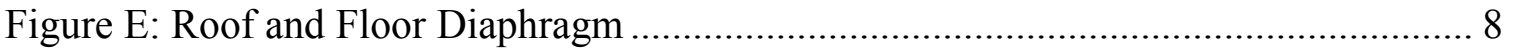

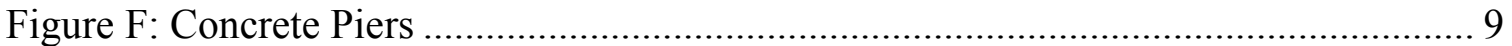

Figure G: Test Setup L) Computer, Amplifier and Signal Generator,............................. 10

Figure H: Vertical Shaker Used to Capture Vertical Modes .......................................... 11

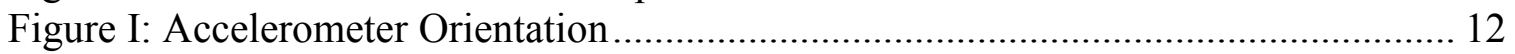

Figure J: Weight Verification of a 1-ft x 1-ft Square Hole on the Roof.......................... 14

Figure K: Tributary Area per Degree of Freedom for Construction of Mass Matrix ....... 15

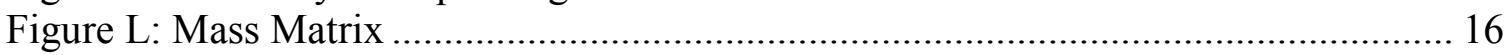

Figure M: Approximate Soil Spring Stiffness of Actual Conditions............................... 18

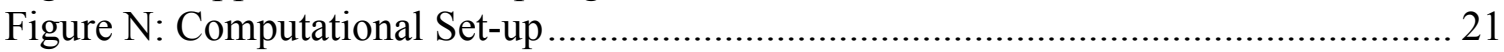

Figure O: First Ambient Vibration FFT Response ……………………...................... 25

Figure P: Second Ambient Vibration FFT Response ………....................................... 26

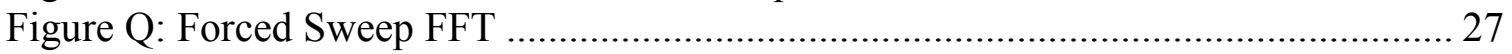

Figure R: Frequency Response Curve ................................................................... 28

Figure S: Definition of Half Power Band Method......................................................... 29

Figure T: First Experimental N-S Mode Shape …………......................................... 30

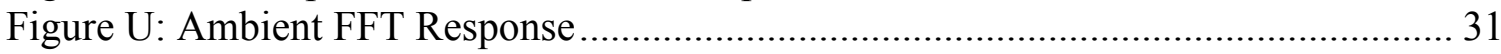

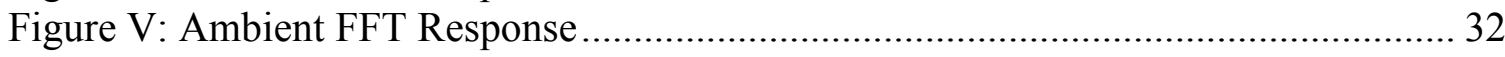

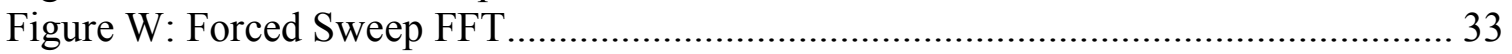

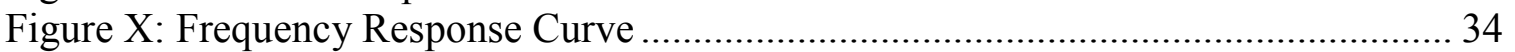

Figure Y: First Experimental E-W Mode Shape.......................................................... 35

Figure Z: Vertical Accelerations of the Floor and Roof Diaphragm ................................ 36

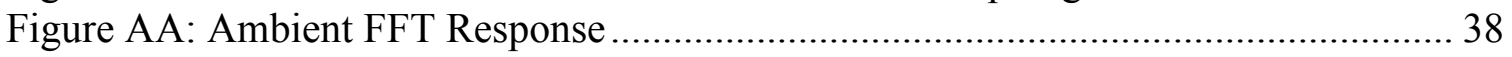

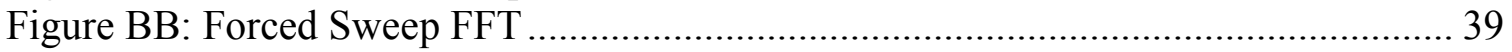

Figure CC: Frequency Response Curve.................................................................... 40

Figure DD: First Experimental Vertical Mode Shape ................................................. 41

Figure EE: Future Placement of Vertical Shaker to Optimize Apparent Mode 6 ............ 50

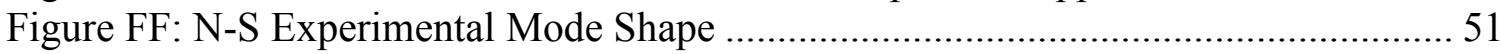

Figure GG: E-W Apparent Mode Shape..................................................................... 52

Figure HH: Steel Deck Panel Connections A) Seam Weld B) Button Punch C) Screw .. 53

Figure II: Roof Steel Deck Panel Configuration........................................................... 55

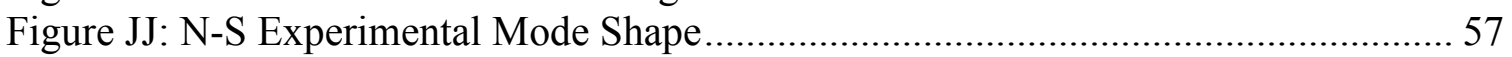

Figure KK: Isometric on Site View of the Bridge House.............................................. 58

Figure LL: Frequency Response Shift Due to Thermal Phenomena ………………….... 59

Figure MM: Surface Temperature vs. Natural Frequency................................................ 60

Figure NN: Compression Stresses Due to Thermal Expansion .............................................. 61

Figure OO: East Elevation of First N-S Analytical Mode Shape ........................................ 61

Figure PP: Mass Normalized Vertical Floor Accelerations of the N-S Mode.................. 63

Figure QQ: Mass Normalized Translational Floor Accelerations of the N-S Mode ........ 63 


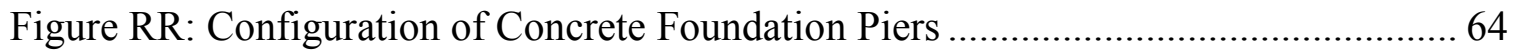

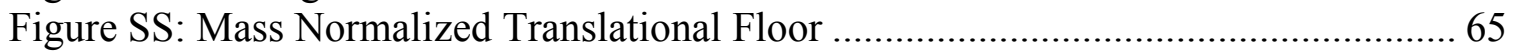

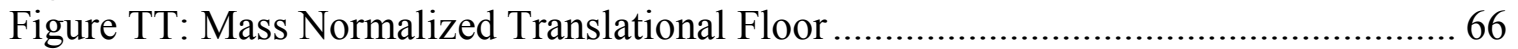

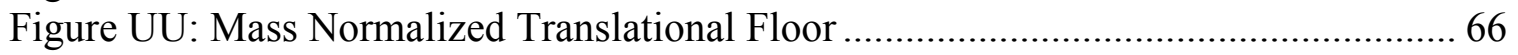

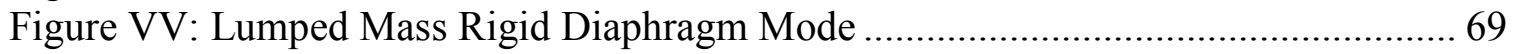

Figure WW: Flexible Roof Diaphragm .................................................................... 70

Figure XX: Experimental vs. Analytical N-S Roof Mode Shape .................................. 71

Figure YY: Hybrid Roof Diaphragm ........................................................................ 72

Figure ZZ: Experimental vs. Analytical N-S Roof Mode Shape................................... 73

Figure AAA: Experimental vs. Analytical E-W Roof Mode Shape ............................... 73

Figure BBB: Analytical Model with Foundation Flexibility ….................................. 74

Figure CCC: Flexible Roof Diaphragm Model with Diagonal Bracing .......................... 77

Figure DDD: Experimental vs. Analytical Flexible Roof Diaphragm Model with

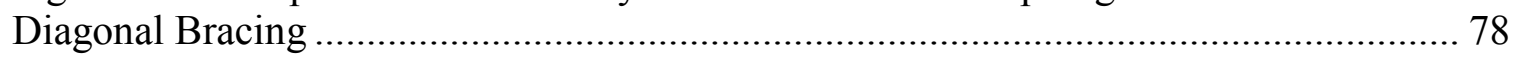

Figure EEE: Analytical vs. Experimental Rotational Mode ........................................ 79

Figure FFF: Experimental Vertical Floor Response of First N-S Mode ....................... 88

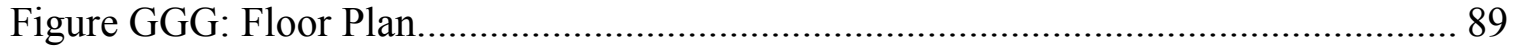

Figure HHH: Analytical of Model with Unconnected Beam (B7) ............................. 89 


\subsection{INTRODUCTION}

The purpose of this thesis is to capture the dynamic response of the Bridge House through a process known as system identification. System Identification is the development of an analytical model through its comparisons with experimentally determined natural frequencies, mode shapes, and damping ratios.

The Bridge House, the structure investigated in this thesis is a one story steel structure that is supported by 4 concrete piers. Its lateral force resisting system (LFRS) is composed of ordinary moment frames in the N-S direction and braced frames in the E-W direction. The structure is also similar to a bridge and spans $48 \mathrm{ft}$ over a seasonal creek, it is vertically supported by a pair of trusses.

To get a feel for the natural frequencies of the Bridge House in one of the N-S, E-W, and vertical directions, ambient vibration tests (AVT) were first performed. The results of AVT can be influenced by inconsistent noise (mainly due to wind gusts) and produce variable results; thus, to better determine the natural frequency, AVT were followed by forced vibration tests (FVT). Force vibration amplifies the response of the structure through the use of a linear mass shaker with a sinusoidal output force of $30 \mathrm{lbs}$. For translational modes the shaker was most effective when placed on the roof in its respective direction while for vertical modes it was most effective when placed in the vertical direction on the floor. A more precise frequency of the mode of interest was determined by performing a micro sweep. A micro sweep was done by exciting the structure at a small range of frequencies while simultaneously recording the steady state accelerations. The results of the micro sweep were used to create frequency response 
curves used to determine modal parameters such as the natural frequency and damping ratio. Once the natural frequency was established, the shaker was then set up to continuously oscillate at the determined natural frequency and the steady state the N-S, E-W, and vertical accelerations were recorded. For this particular structure, accelerations at 70 locations throughout the floor and roof were recorded, a process also known as mode shape mapping.

An analytical model was developed to capture the dynamic behavior of the Bridge House. The process of generating an accurate computational model required a series of subsequent refined computational models. The analytical modeling process began with a simple hand analysis and ended with a complex computational model. The computational modeling was focused on the refinement of the model based on comparisons with experimental results.

\subsection{Literature Review}

The Bridge House was investigated using forced vibration testing (FVT) and exhibited a flexible roof diaphragm response in the E-W direction. Thus a literature review was conducted on similar research topics that were performed using FVT. Other research papers were investigated for their estimation of the flexible diaphragm stiffness and its effect on the overall response of the structure.

In a research study that utilizes the same experimental equipment, (Jacobsen 2011) explored the behavior of two nearly identical concrete-shearwall buildings with flexible diaphragms, one of which that had been seismically retrofitted to strengthen the 
moment connections and add braces to the perimeter walls in the east/west direction. Forced vibration testing (FVT) was used to detect the effect of the dynamic modal properties resulting from the retrofit. The first two natural frequencies for both the buildings were found through FVT and were experimentally determined to be $3.35 \mathrm{~Hz}$ and $6.31 \mathrm{~Hz}$ for the unretrofitted building (URB) and $2.66 \mathrm{~Hz}$ and $5.63 \mathrm{~Hz}$ for the retrofitted building $(\mathrm{RB})$. The first NS mode consisted of in-plane bending of the diaphragm with the maximum deflection at mid span. The second mode shape, also NS was expected to be double bending; however, the tested shape showed differential movement between the north and south side of the building. From the FVTs it is apparent that the retrofit did not have an effect on the NS mode and the natural frequency shift between the URB and the RB was a result of the URB having no gravel on the roof and the RB having several inches of gravel, adding significant amount of additional mass to the RB. It was believed that the natural frequencies in the EW direction were outside the range of testing equipment $(2 \mathrm{~Hz}$ to $10 \mathrm{~Hz}$ ) thus the effect of the retrofit was not documented during this research. This is relevant to this thesis because FVT will also be implemented in the experimental determination of the Bridge House's modal parameters.

In a similar study (Rendon 2011) determined the modal parameters of a 5 story reinforced concrete structure through ambient and forced vibration tests. This research was focused on computational model refinement based on comparisons with experimental results. The computational model began as a simple hand analysis and evolved into a complex model. To effectively excite each mode, multiple locations were examined to determine the optimal shaker locations. For translational modes it is 
typically ideal to excite a structure at the center of mass. However, this structure features a large opening at the center of mass on all 5 floors, thus making it challenging to effectively excite the structure. The first three natural frequencies recorded and their respective modes were mapped out. The diaphragms in the 5 story structure behaved as rigid diaphragms for the $1^{\text {st }} 2$ modes while the third mode displayed a semi rigid diaphragm response. This is relevant to this thesis because this research highlights that forced vibration testing can be effectively used to validate computational models.

Trembley and Stiemer (1996) investigated the dynamic behavior of low-rise steel buildings that rely on metal roof deck diaphragm response for lateral seismic resistance. A parametric study in the preliminary phase of the research showed that typical structures designed according to modern building code provisions can have a fundamental period of vibration that is much longer than that assumed in the calculations. The study also indicated that roof diaphragm flexibility in the direction parallel to the stiff lateral frames increases the natural period of a structure in its respective direction. This is relevant to this thesis because the bridge house's roof diaphragm behaves flexible in the E-W direction whereas it is essentially rigid diaphragm in the N-S direction. As a result, diaphragm flexibility must be accounted for when analyzing the Bridge House, specifically in the E-W direction.

In order to calculate the natural period of a low rise steel building with a flexible diaphragm, the stiffness of the diaphragm needs to be estimated. The stiffness of a corrugated steel deck diaphragm is a direct indication of how the diaphragm distorts under the influence of in-plane shear forces (Luttrell 1995). Some factors that affect 
diaphragm stiffness are the geometry of the corrugated steel element and the type of side lap connections. Corrugated steel decks have standard geometry with minimal variation. However, when a button punch is alternatively used instead of seam weld, the diaphragm stiffness can be significantly reduced. This is relevant to this thesis because the equations provided by the Steel Deck Institute Diaphragm Design Manual will be used to estimate the diaphragm stiffness, and empirical equations derived by researchers that incorporate diaphragm flexibility will be applied to estimate the natural period of the Bridge House.

\subsection{The Test Building}

The structure investigated in this thesis was-built in 1965 by a group of students as a senior project. It is located on the northeast campus of the California Polytechnic State University, San Luis Obispo. See Figure A below.

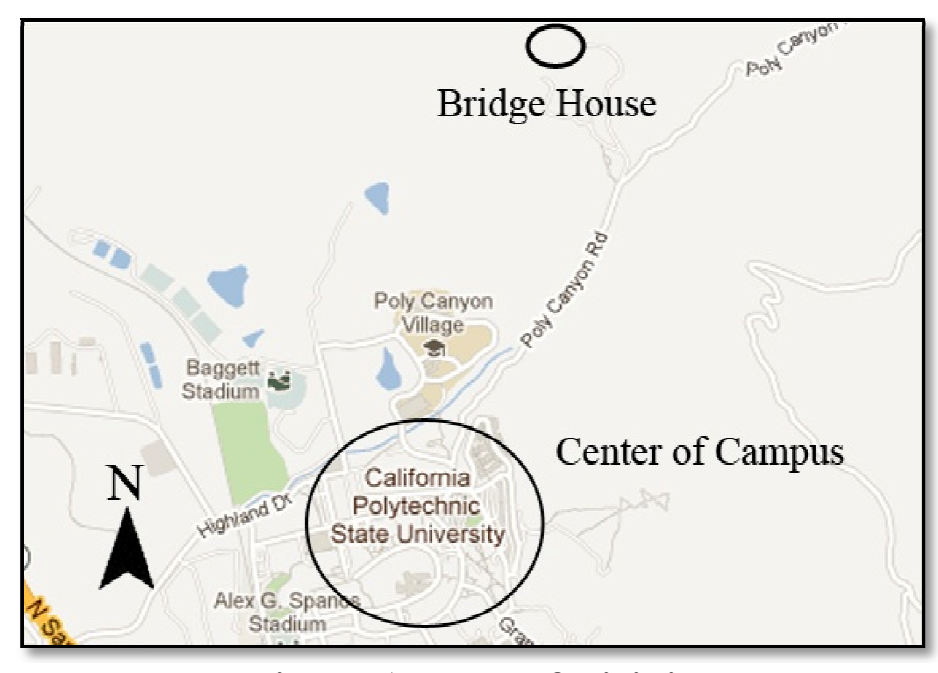

Figure A: Map of Vicinity

(Google Maps) 
The Bridge House is located in a remote area known as the outdoor experimental construction laboratory inside of Poly Canyon and it is approximately 1.2 miles away from the center of campus.

It is a one-story steel structure with a lateral force resisting system (LFRS) composed of ordinary moment frames in the N-S direction and braced frames in the E-W direction. See Figure B below.

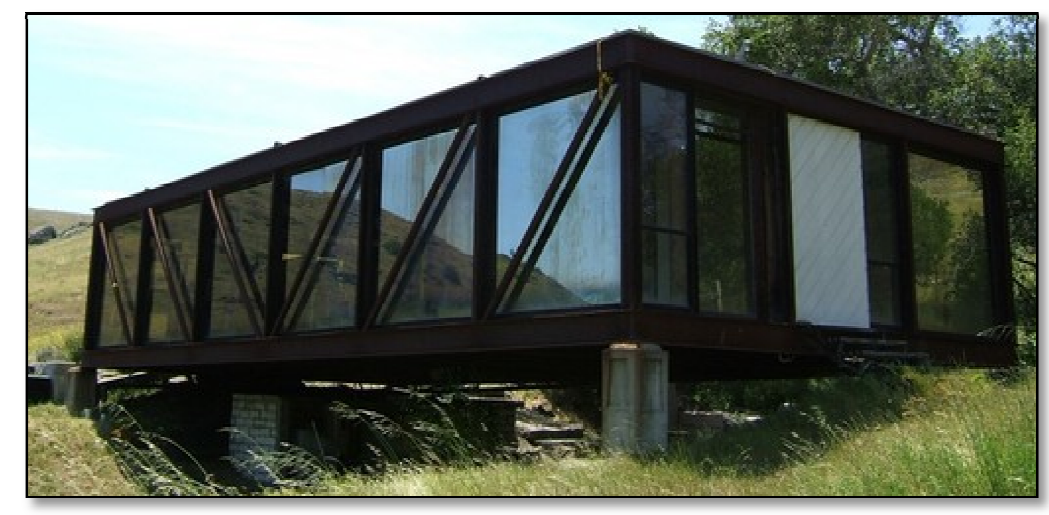

Figure B: Bridge House Elevation

(Nelson)

The structure is similar to that of a bridge and spans 48 - $\mathrm{ft}$ in the longitudinal direction and 24-ft in the transverse direction. It is vertically supported by a pair of trusses along the longitudinal direction. The façade of the building is a combination of large glass windows and plywood sheathing. The plywood sheathing is a temporary replacement for windows that were broken as a result of vandalism.

The columns and braces on the exterior of the building are hollow structural sections (HSS3X3X1/4) that are welded in between two c-channels (C12X20.7). The cchannels are also the chord members of the truss system. See Figure C below. 


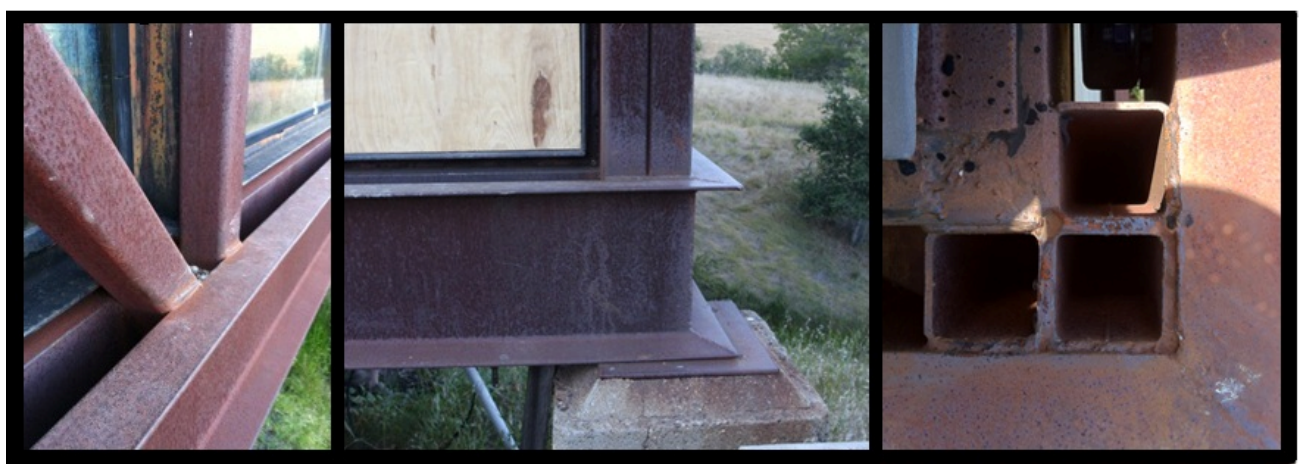

Figure C: Exterior Welded Connections

The corner columns of the building are built up sections composed of (4) HSS3X3X1/4 tubes as seen in the Figure C above. Only three HSS tubes can be seen in Figure C; the fourth tube lies underneath the inside c-channel. A typical weld connection for a brace or column to the truss chord consists of four 12-inch-long fillet welds, one for each corner of the HSS.

The interior roof and floor beams are wide flange sections spaced at $8 \mathrm{ft}$ on center and are connected to the web of the truss chords via steel tabs. See Figure D below.

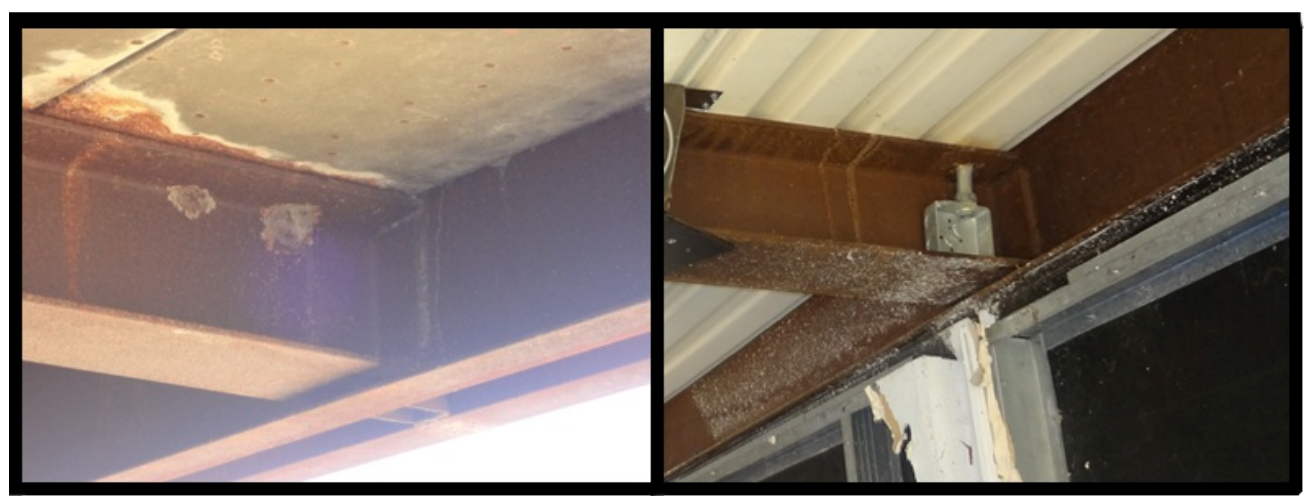

Figure D: Beam to C-Channel Connection

The steel tabs are located on both sides of the beam web and are connected with fillet welds. 
The roof diaphragm is made up of rigid insulation topped with gravel-on-metal deck, while the floor diaphragm is composed of $3 \frac{1}{2}$ - inch thick lightweight concrete also supported by metal deck. See Figure E below.

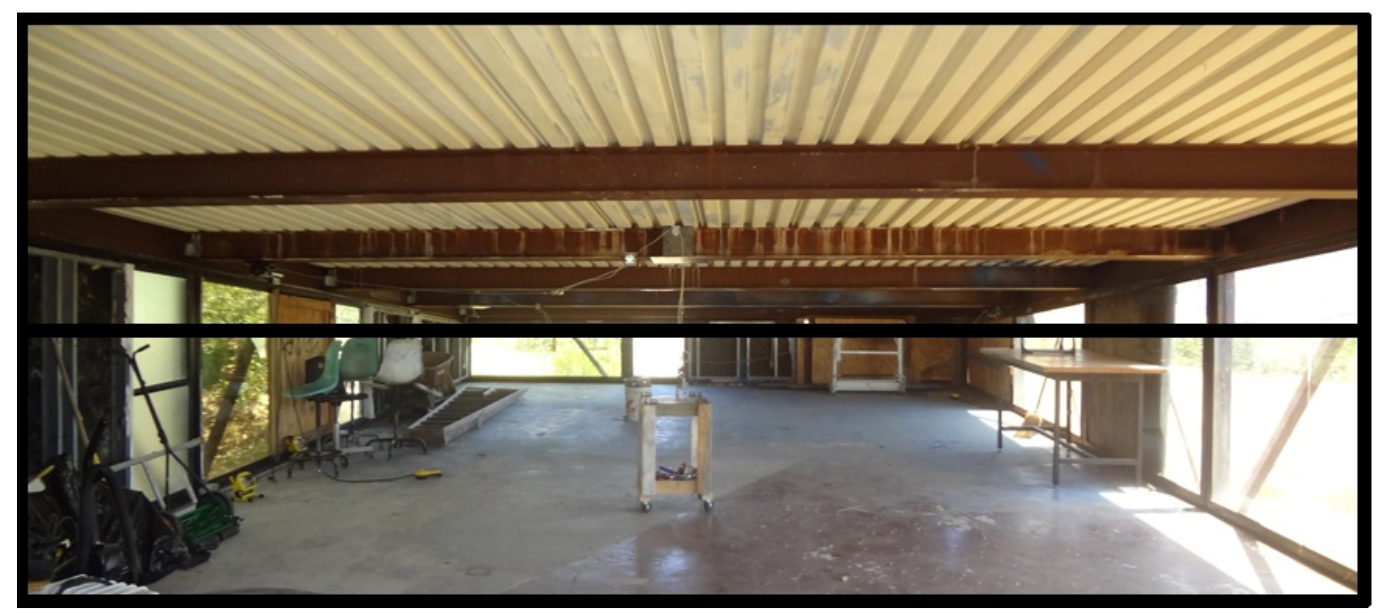

Figure E: Roof and Floor Diaphragm

The metal decks spans 8 - $\mathrm{ft}$ and as common practice, it is reasonable to assume that the roof deck panels and roof beams are interconnected through intermediate spot welds. In the original senior project report of 1965, the floor beams were designed non composite (Bridge House, 1966); thus, the connections between the floor diaphragm and floor beams are also assumed to be intermediate spot welds.

The building rests on four 18-inch x 18-inch concrete piers, one for each corner of the building. See Figure F below. 


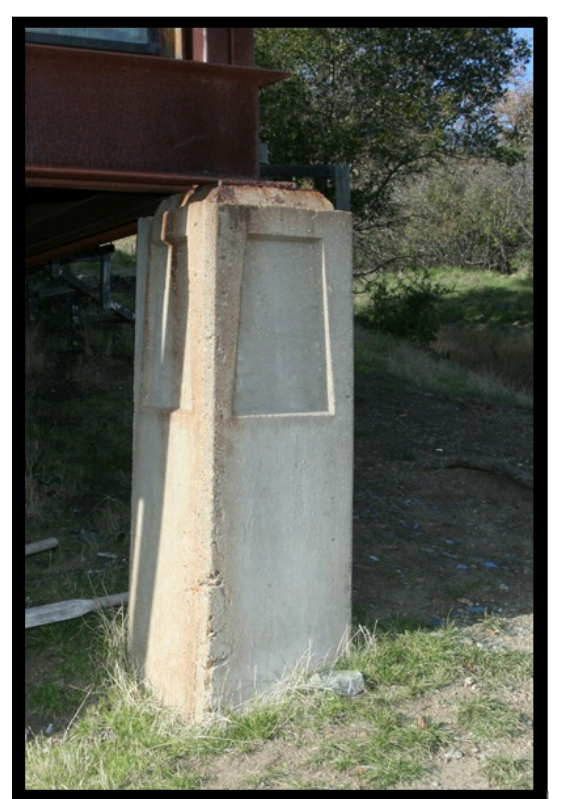

Figure F: Concrete Piers

The embedment and exposure of each pier differs at each corner. It is assumed (verified through experimental testing) that the floor diaphragm is pin connected to the concrete piers via embed plates, rebar, and fillet welds. A soils report is not available to determine the current site conditions; however, the soil contains some cohesion with granular material; therefore the soil is in the range of clayey sand.

\subsection{Equipment Basis}

Forced Vibration Testing (FVT) (McDaniel and Archer 2010) was used in this thesis to experimentally determine the natural frequencies and mode shapes of the Bridge House. To document the resonant frequencies and mode shapes, the following equipment was used:

- Accelerometers

- Data Acquisition (DAQ)

- Dell Computer with Lab View Software

- Electronic Signal Generator 
- Amplifier

- Linear Mass Shaker

This equipment can also be seen in Figure G below.

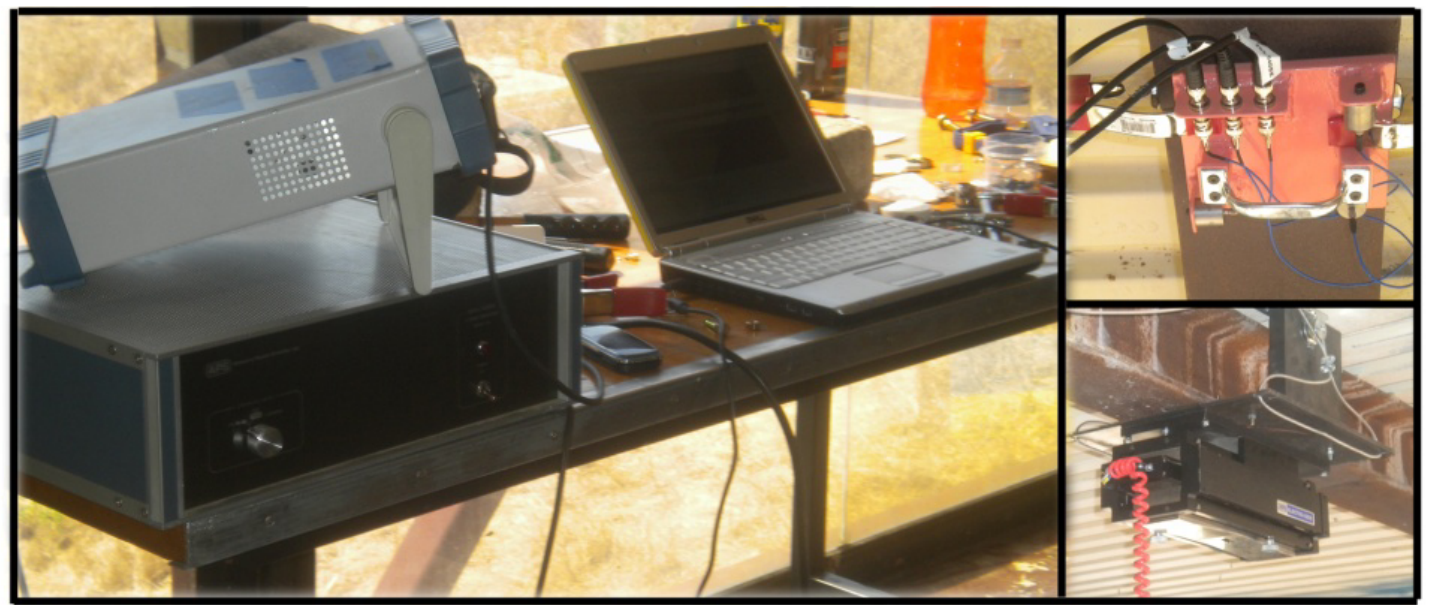

Figure G: Test Setup L) Computer, Amplifier and Signal Generator, TR) Accelerometers, BR) Linear Mass Shaker

The linear mass shaker is an $80-1 \mathrm{~b}$ machine that oscillates at various frequencies and amplitudes that can generate a sinusoidal force up to $30 \mathrm{lbs}$. Generally friction between the base of the shaker and the floor is sufficient to transfer the force generated from the shaker onto the structure, thus no additional anchoring devices are needed. Designed for scale structures, the linear shaker, when properly placed, has been proven to excite buildings under 4 floors, and under 30,000 square feet (McDaniel and Archer 2010). The same linear shaker was used to excite the Bridge House, a structure that is far within the limitations of the equipment, as it is a 1-story steel structure with a square footage of 1,152 sq-ft. and an approximate weight of 41 tons.

In 2011 the Bridge House was renovated and converted into a structural dynamics laboratory (Rehabilitation, 2011). The senior project team fabricated shaker mounts at 
the roof level to easily hoist and fasten the linear mass shaker to the roof. The Bridge House is a 1-story structure, thus exciting the structure at the roof ideally maximizes response of the first translational modes. The linear mass shaker fastened to the roof can also be seen in the test setup depicted in Figure G on page 10.

A vertical shaker was also used to capture the vertical modes. See Figure H below.

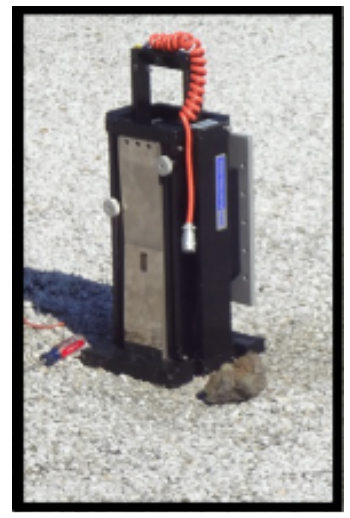

Figure H: Vertical Shaker Used to Capture Vertical Modes

The floor diaphragm supports over half of the structures mass in the vertical direction, thus the mass participation of the floor in each vertical mode is about half of the total sum for that particular mode. Theoretically, similar results can be achieved by exciting either the roof or the floor. Thus, for simplicity the vertical shaker was placed on the floor.

Piezoelectric flexural accelerometers with an advertised broadband resolution of 1-3 $\mu \mathrm{g}$ rms and a frequency range of less than $1 \mathrm{~Hz}$ and up to greater than $200 \mathrm{~Hz}$ were used to capture the structure's accelerations. For most of the experimental mode shapes the accelerometers were oriented similar to accelerometers A, B and C in Figure I below. 
The 3 accelerometers were mounted to a steel plate, one for each direction along the $\mathrm{X}, \mathrm{Y}$ and $\mathrm{Z}$ coordinates.

An additional accelerometer was introduced to capture the rotational mode of vibration about the vertical axis. Accelerometer D as in Figure I below was set 48 -ft away from accelerometer $\mathrm{A}$ and the rotation was calculated using equation 1 below.

$$
\frac{A-B}{x} \times g
$$

Equation 1

Where $A$ and $B$ are the accelerations from the two accelerometers (g),

$g$ is the acceleration due to gravity $\left(\mathrm{ft} / \mathrm{sec}^{2}\right)$, and

$x$ is the distance between accelerometers $\mathrm{A}$ and $\mathrm{B}(\mathrm{ft})$.

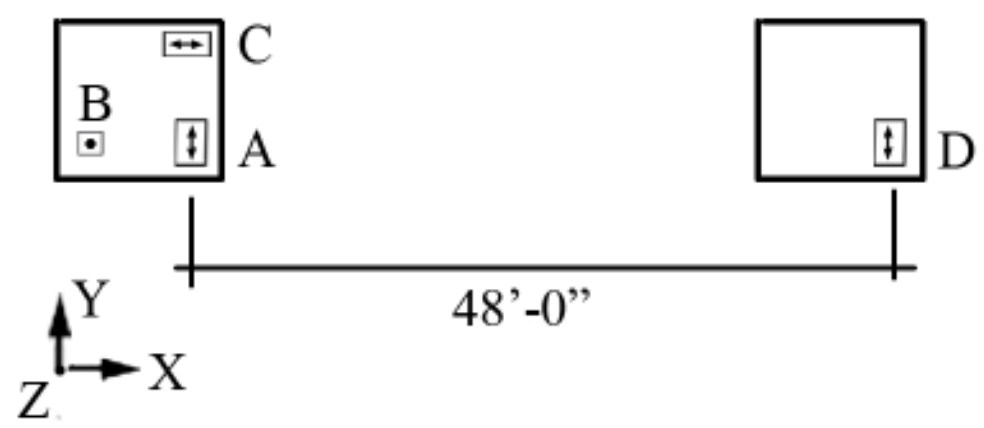

Figure I: Accelerometer Orientation

A 24-bit analog to digital converter was used to process the signals from the accelerometers. These signals were processed further using the standard lab software, LabView (McDaniel and Archer 2010). The software was set up to scale the readings from each accelerometer and provide a time history of the accelerometer readings as well as perform a Fast Fourier Transform (FFT) of the data to provide frequency information. (Rendon, 2011) 


\subsection{Mass Description}

The Bridge House is a small structure with a 48-ft x 24-ft footprint and an approximate weight of 41 tons. Table 1 below illustrates the mass take off of the different structural and nonstructural components of the building that contribute to the mass.

Table 1: Mass Take-Off

$\underline{\text { Roof }}$

Structural

\begin{tabular}{|c|c|c|}
\hline Metal Deck & 18-gauge steel & $3.0 \mathrm{psf}$ \\
\hline Framing & w8x31@8ft o.c. & $4.5 \mathrm{psf}$ \\
\hline Framing & $\mathrm{C} 12 \times 20.7$ & $5.2 \mathrm{psf}$ \\
\hline Columns & HSS3x3x.25 & $1.1 \mathrm{psf}$ \\
\hline Braces & HSS3x3x.25 & $1.0 \mathrm{psf}$ \\
\hline
\end{tabular}

Nonstructural

\begin{tabular}{|l|l|l|}
\hline Roofing & Rigid Insulation and Gravel & $15.0 \mathrm{psf}$ \\
\hline
\end{tabular}

$\underline{\text { Floor }}$

Total $29.8 \mathrm{psf}$

\begin{tabular}{|c|c|c|}
\hline \multicolumn{3}{|l|}{ Structural } \\
\hline Concrete & 4" thick lightweight conc & $22.5 \mathrm{psf}$ \\
\hline Metal Deck & 18-gauge steel & $3.0 \mathrm{psf}$ \\
\hline Framing & W8x35@8ft o.c. & $5.1 \mathrm{psf}$ \\
\hline Framing & $\mathrm{C} 12 \times 20.7$ & $5.2 \mathrm{psf}$ \\
\hline Columns & HSS3x3x.25 & $1.1 \mathrm{psf}$ \\
\hline Braces & HSS3x $3 \times .25$ & $1.0 \mathrm{psf}$ \\
\hline
\end{tabular}

Nonstructural

\begin{tabular}{|c|c|c|}
\hline \multirow{2}{*}{ Window/Door Frames } & $\mathrm{L} 3 \times 2 \times 1 / 4$ & $1.2 \mathrm{psf}$ \\
\hline & $\mathrm{L} 3 \times 2 \times 1 / 5$ & $1.0 \mathrm{psf}$ \\
\hline \multirow[t]{2}{*}{ Facades } & Plywood $^{1}$ & $0.4 \mathrm{psf}$ \\
\hline & Glass $^{1}$ & $0.8 \mathrm{psf}$ \\
\hline Other & Misc & $0.2 \mathrm{psf}$ \\
\hline
\end{tabular}

${ }^{1}$ The façade of The Bridge House is composed of plywood and glass. These values represent the total weight of the material divided by the square footage of the floor. 
Nonstructural components such as utility equipment and furnishings usually contribute a substantial amount of additional mass to a structure; however, due to the current vacant occupancy of the structure, the nonstructural components only make up about $20 \%$ of the total mass.

Current roofing manufacturers list gravel and rigid foam insulation at a material weight of approximately 7 psf and 1.5 psf, respectively. However, due to the relatively small size of the structure, small change in mass can result in considerable change in the modal parameters. Therefore, the weight of the roof had to be verified.

To verify the weight of the roof, a 1-ft x 1-ft square of gravel and rigid foam insulation was cut out, placed into a bag, and weighed as in Figure $\mathrm{J}$ below.

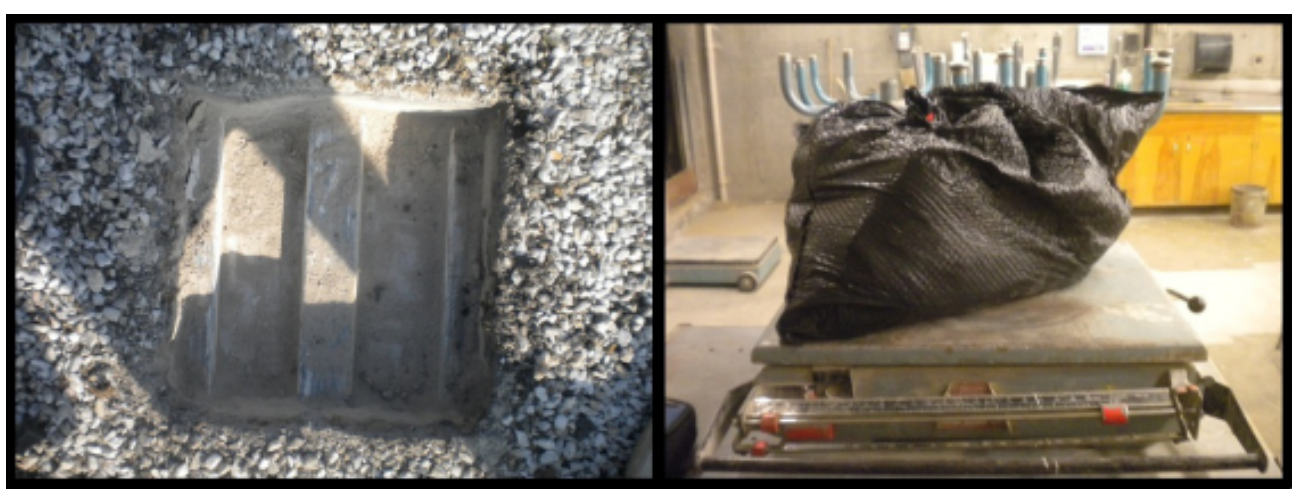

Figure J: Weight Verification of a 1-ft $x$ 1-ft Square Hole on the Roof

The 1-ft x 1-ft square of gravel and rigid insulation weighed $15 \mathrm{lbs}$, equivalent to 15 psf, exceeding the maximum listed weight by 214 percent.

The façade of the structure rests on the on top of the floor slab and is connected with seldom welds to the columns without any evident connections to the roof; hence any weight associated with the façade is resisted by the floor. This assumption is essential 
when creating the mass matrix since it contributes additional weight to the perimeter of the floor diaphragm.

The mass is evenly distributed throughout the structure; however, for computational purposes, it is simplified as lumped masses at the nodes of the discretized structure as seen in Figure K below.

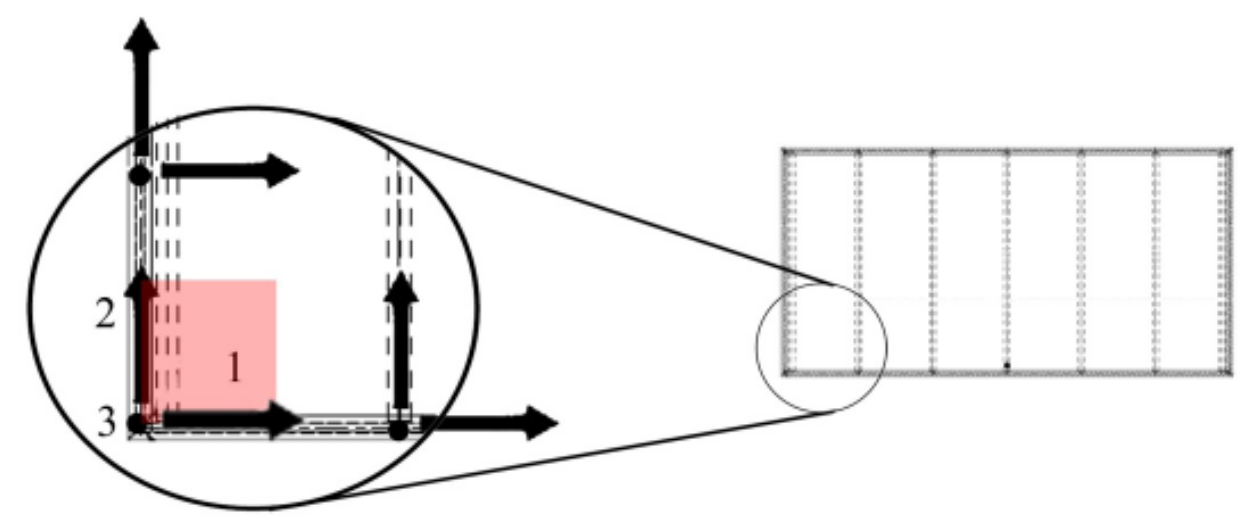

Figure K: Tributary Area per Degree of Freedom for Construction of Mass Matrix

The out-of-plane flexibility of the roof and floor diaphragm had a significant effect on the mode shapes of the structure; therefore, it was essential to capture all three N-S, E-W and the vertical (also known as degree of freedom (DOF) 1, 2, and 3 in Figure K) components of the building's motion. The discretized experimental structure was assembled with a total of 70 nodes, 35 nodes per floor, and 5 nodes per beam line. The tributary area to each node was used and a mass matrix similar to Figure L below was assembled. 


$$
\mathbf{M}=\left|\begin{array}{cccc}
\mathrm{M}_{11} & 0 & 0 & 0 \\
0 & \mathrm{M}_{22} & 0 & 0 \\
0 & 0 & \mathrm{M}_{33} & 0 \\
0 & 0 & 0 & \mathrm{M}_{\mathrm{ij} . .}
\end{array}\right|
$$

Figure L: Mass Matrix

The lumped mass at each node is the sum of the mass contributions of all the structural elements tributary to the node and corresponds to all translational DOF at that node (e.g., $\mathrm{M}_{11}=\mathrm{M}_{1}$ is corresponds to DOF 1 and $\mathrm{M}_{\mathrm{ij}}$ is corresponds to DOF $\mathrm{i}$ where $\mathrm{i}=\mathrm{j}$ ). In general, for a lumped mass model, the diagonal entries in the mass matrix such as $\mathrm{M}_{\mathrm{ij}}$ are equal to 0 when $i \neq j$.

\subsection{Stiffness Approximations of Lateral Resisting Elements}

In addition to the mass matrix, the lateral stiffness of the structure was approximated to hand calculate the theoretical natural frequencies and mode shapes. For purposes of calculating the stiffness of the LFRS, it was assumed that the structure has a rigid diaphragm in both directions; therefore, only the stiffness of the LFRS was necessary. The stiffness in the N-S direction is provided by all perimeter columns in which the corner columns are built up sections composed of (4) HSS3X3X1/4 and the intermediate columns are single HSS3X3X1/4. The stiffness in the N-S direction was approximated using equation 2 .

$$
k_{N-S}=\sum \frac{12 E I}{L^{3}}
$$

Equation 2 
Where $\mathrm{L}$ is the length of the column and EI is bending stiffness of the column.

The stiffness in the E-W direction is provided by the HSS3X3X1/4 diagonal braces. There are 6 diagonal braces on each north and south face of the structure; however, because compression braces provide minimal stiffness, only the tension braces were considered when calculating the stiffness in the E-W direction. The stiffness in the E-W direction was approximated using equation 3 below.

$$
k_{E-W}=\sum \frac{E A}{L} \operatorname{COS}^{2} \theta
$$

Where $L$ is the length of the diagonal brace,

$E A$ is the axial stiffness of the diagonal brace, and

$\theta$ is the angle between diagonal brace and horizontal plane.

The lateral stiffness of the concrete piers was not necessary for the hand calculations; however, it will be referenced at a later section in this thesis. Assuming similar behavior as a cantilevered beam, the lateral stiffness of the concrete piers was approximated using equation 4 below.

$$
k_{\text {Conc.Pier }}=\frac{3 E I_{\text {cracked }}}{L^{3}}
$$

Equation 4

Where $L$ is the average length of the concrete pier and $E I_{\text {cracked }}$ is the cracked bending stiffness of the concrete pier $I_{\text {cracked }}$ was chosen in lieu of $I_{\text {gross }}$ based a conservative assumption assuming the lateral stiffness provided by the soil is significantly less than the lateral stiffness of the 
concrete piers. The concrete piers are embedded into the soil and in order to preserve the existing conditions of the Bridge House, the concrete pier lengths could not be verified. As an alternative, as-built construction drawings generated by the 1966 senior project Bridge House team were used as reference (see Appendix on page 104).

In addition to the stiffness generated by the concrete piers, there is also lateral stiffness provided by the soil. A soils report is not available to determine the current site conditions; however, the soil contains some cohesion with granular material; therefore the soil is in the range of clayey sand. A range of typical values for the modulus of subgrade reaction for clayey, medium-dense sand is given in the textbook Foundation Analysis and Design (Bowles 1996). The soil's modulus of sub grade reaction is a function of soil compaction and soil moisture content and can range anywhere from 61 $\mathrm{k} / \mathrm{ft}^{3}$ to $573 \mathrm{k} / \mathrm{ft}^{3}$.

The stiffness generated by the soil is equivalent to the analytical models in Figure $\mathrm{M}$ below, $k_{1}$ and $k_{2}$ are the stiffness of the soil acting on the concrete pier and concrete pad, respectively. Note that $k_{1} \neq k_{2}$ since the soil bearing area differs in both conditions.

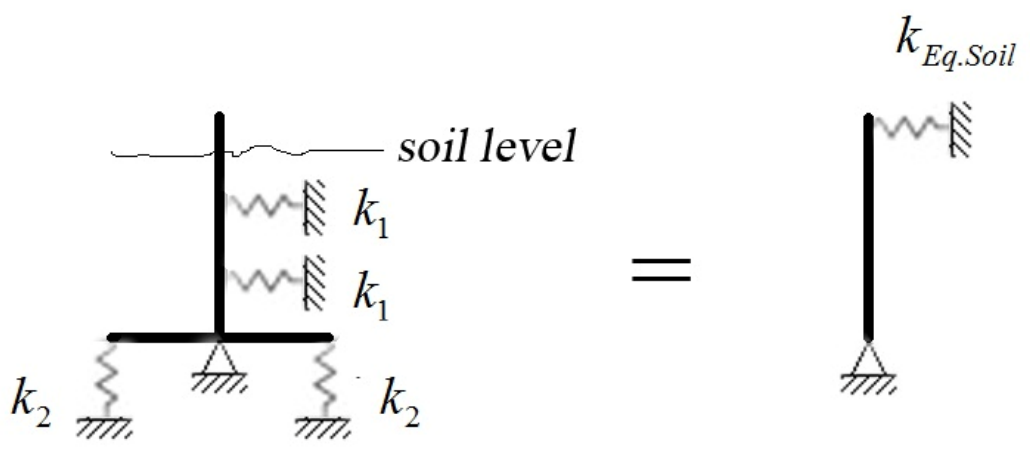

Figure M: Approximate Soil Spring Stiffness of Actual Conditions 
To simplify $k_{1}$ and $k_{2}$ an equivalent analytical model was used where $k_{E q . S o i l}$ was calculated using equation 5 below. Equation 5 was derived by applying a unit rotation at the base of the analytical model in Figure $\mathrm{M}$ and subsequently using the fundamental statics approach of $\sum F=0$.

$$
k_{E q . S o i l}=\frac{1}{6} \cdot \frac{h^{\prime 3} b^{\prime} k_{S}}{h^{2}}+\frac{1}{12} \cdot \frac{d^{3} b k_{S}}{h^{2}}
$$

Equation 5

Where $k_{E q \text {.Soil }}$ is the equivalent soil spring stiffness in the analytical model,

$h$ is the average height of the pier,

$b$ is the depth and width of the concrete pad,

$k_{S}$ is the modulus of subgrade reaction,

$h^{\prime}$ is the effective soil height,

$b^{\prime}$ is the depth and width of concrete pier.

Equation 5 determined that the minimum and maximum soil spring stiffness

based on the previously defined range for the modulus subgrade reaction, $7 \mathrm{k} / \mathrm{in}$ and 65

$\mathrm{k} / \mathrm{in}$, respectively. Thus the total soil stiffness in each direction varied from $28 \mathrm{k} /$ in to 260

$\mathrm{k} / \mathrm{in}$ (4 piers).

Table 2 below is a summary of all the previously calculated stiffness values.

Table 2: Stiffness Approximations of Lateral Resisting Elements

\begin{tabular}{|c|c|c|c|}
\hline$k_{N-S}$ & $k_{E-W}$ & $\Sigma k_{\text {Conc.Pier }}$ & $k_{\text {Eq.Soil }}$ \\
\hline $87 \mathrm{k} / \mathrm{in}$ & $1149 \mathrm{k} / \mathrm{in}$ & $576 \mathrm{k} / \mathrm{in}$ & $7 \mathrm{k} / \mathrm{in}-65 \mathrm{k} / \mathrm{in}$ \\
\hline
\end{tabular}




\subsection{EXPERIMENT BASIS}

One of the goals of this thesis was to determine the natural frequencies and mode shapes of the Bridge House. Obtaining the first 2 translational and the first rotational mode shapes was the primary objective, while all other vertical modes were secondary. To effectively excite the first N-S and E-W translational modes, the linear mass shaker was placed on the roof. The floor diaphragm supports slightly over half of the structure's mass in the vertical direction, thus the mass participation of the floor for each vertical mode is about half of the total sum in each vertical mode. Thus it was appropriate to excite the structure in the vertical direction by placing the shaker on the floor.

\subsection{Theoretical Validation of the Experimental Readings}

To validate the experimental results, a simplified theoretical forced vibration modal analysis using the principle of dynamic amplification was performed. Dynamic amplification utilizes amplification factors that are used to amplify the response of the structure's steady state accelerations under harmonic loading at its respective natural frequency. For this analysis, the roof diaphragm was assumed to be rigid in both translational directions, and the 30-1b harmonic force was applied to the roof's center of mass at a frequency of $4.45 \mathrm{~Hz}$ as shown in Figure $\mathrm{N}$ below. 


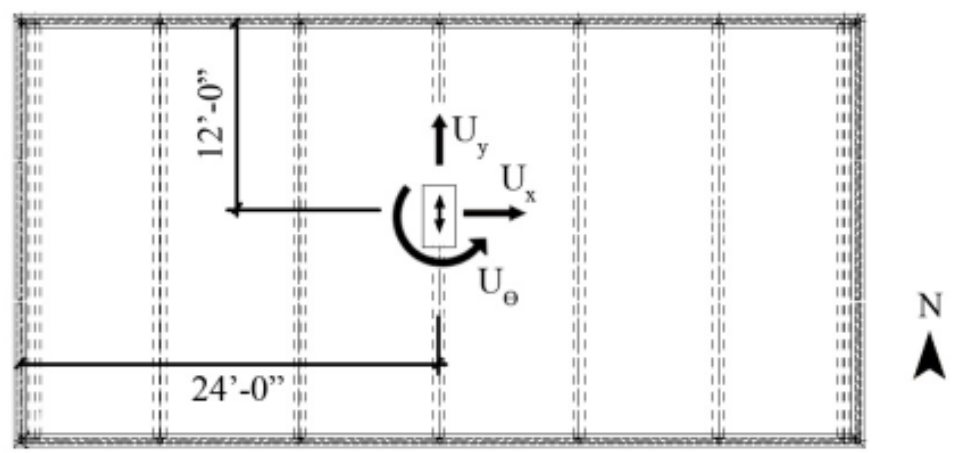

ROOF PLAN

\section{Figure N: Computational Set-up}

The equation of motion of a harmonic forced vibration response is given in equation 6 (Chopra 2007):

$$
m \ddot{u}+c \dot{u}+k u=p_{o} \sin \omega t
$$

Equation 6

Where $p_{o}$ is the amplitude of the force,

$\omega$ is the exciting frequency,

$m$ is the mass of the system,

$k$ is the stiffness of the system,

$c$ is the damping constant,

$u$ is the displacement of the system,

$\dot{u}$ is the velocity of the system, and

$\ddot{u}$ is the acceleration of the system.

The complementary solution to the differential equation in equation 6 is given in equation 7:

$$
u(t)=e^{-\xi \omega_{n} t}\left(A \cos \omega_{D} t+B \sin \omega_{D} t\right)+C \sin \omega t+D \cos \omega t
$$

Where $\xi$ is the damping ratio (experimentally determined),

$\omega_{n}$ is the natural frequency of the system,

$\omega_{D}$ is given by Equation 8, and 
$A, B, C, D$ are constants determined by standard procedures (Chopra 2007).

$$
\omega_{D}=\omega_{n} \sqrt{1-\xi^{2}}
$$

Equation 8

The first two terms in equation 7 represent the transient response, while the latter two represent the steady state response of the system. At steady state, the transient response essentially goes to zero, and thus can be neglected. Thus simplification of equation 7 results in equation 9:

$$
u(t)=C \sin \omega t+D \cos \omega t
$$

Where $C$ and $D$ are:

$$
\begin{aligned}
& C=\frac{p_{o}}{k} \frac{1-\left(\omega / \omega_{n}\right)^{2}}{\left[1-\left(\omega / \omega_{n}\right)^{2}\right]^{2}+\left[2 \xi\left(\omega / \omega_{n}\right)\right]^{2}} \\
& D=\frac{p_{o}}{k} \frac{-2 \xi \omega / \omega_{n}}{\left[1-\left(\omega / \omega_{n}\right)^{2}\right]^{2}+\left[2 \xi\left(\omega / \omega_{n}\right)\right]^{2}}
\end{aligned}
$$

Equation 9 can then be represented in a further simplified form of equation 7 as shown in equation 12 :

$$
u(t)=\frac{p_{o}}{k} R_{d} \sin (\omega t-\phi)
$$

Where $R_{d}$ is the dynamic amplification given by equation 13 , and $\phi$ is the phase shift given by equation 14 . 


$$
\begin{gathered}
R_{d}=\frac{1}{\sqrt{\left[1-\left(\omega / \omega_{n}\right)^{2}\right]^{2}+\left[2 \xi\left(\omega / \omega_{n}\right)\right]^{2}}} \\
\phi=\tan ^{-1} \frac{2 \xi\left(\omega / \omega_{n}\right)}{1-\left(\omega / \omega_{n}\right)^{2}}
\end{gathered}
$$

Equation 14

Equation 12 defines the displacement of a single degree of freedom with respect to time under a harmonic load, which is also equivalent to the modal displacement (equation 15) of a single degree of freedom (DOF) in a multi DOF system.

$$
q(t)=\frac{p_{o}}{k} R_{d} \sin (\omega t-\phi)
$$

Differentiating equation 15 twice yields equation 16, the modal accelerations:

$$
\ddot{q}_{n}(t)=\frac{-p_{n}}{k_{n}} R_{d} \omega^{2} \sin \left(\omega t-\phi_{n}\right)
$$

Where $\ddot{q}_{n}(t)$ is the acceleration of the $\mathrm{n}_{\text {th }}$ mode,

$k_{n}$ is equal to $\omega_{n}^{2}$ when mode shapes are mass orthonormalized, and $p_{n}$ is the effect of the loading on mode $\mathrm{n}$, given in equation 17 :

$$
p_{n}=\phi_{n}^{T} p
$$

The modal accelerations are then recoupled into the equation of motion by using equation 18 :

$$
\ddot{u}(t)=\Phi q
$$

Equation 18 
Where $\ddot{u}(t)$ are the global acceleration, and

$\Phi$ is the matrix of mode shapes.

Using the mass in Table 1 on page 13 and the lateral stiffness in the N-S and E-W direction, the results of Eq. 19 using are summarized in Table 3 below and compared to the experimental accelerations for $\omega=\omega_{n}$ and $\xi=0.044$ (experimentally determined). The mass and stiffness matrices along with the theoretical results are in the appendix.

\section{Table 3: Experimental vs. Computational Accelerations}

\begin{tabular}{|c|c|c|c|}
\hline & Computational Accelerations & Experimental Accelerations & Percent Difference \\
\hline Uy & $5.23 \mathrm{~m} \mathrm{~g}$ & $5.90 \mathrm{~m} \mathrm{~g}$ & $11.4 \%$ \\
\hline
\end{tabular}

The computational accelerations were $11.4 \%$ different from the experimental accelerations.

\subsection{Experimental Determination of Apparent N-S Mode Shape}

The N-S mode was experimentally determined using ambient vibration and forced vibration tests, the mode was anticipated to be a translational dominated mode in the N-S direction.

\subsubsection{Ambient Vibration Testing}

Ambient vibration testing (AVT) was first performed to try to determine the approximate frequency at which the first mode of vibration in the N-S direction occurred. AVT was performed without the linear mass shaker and due to the unoccupied state of 
the Bridge House; its main source for AVT was wind. To get a good representation of the natural frequencies, an average of 10 thirty-second AVT's were used to create a FFT response curve such as Figure O below. A peak in the FFT response curve represents a possible mode.

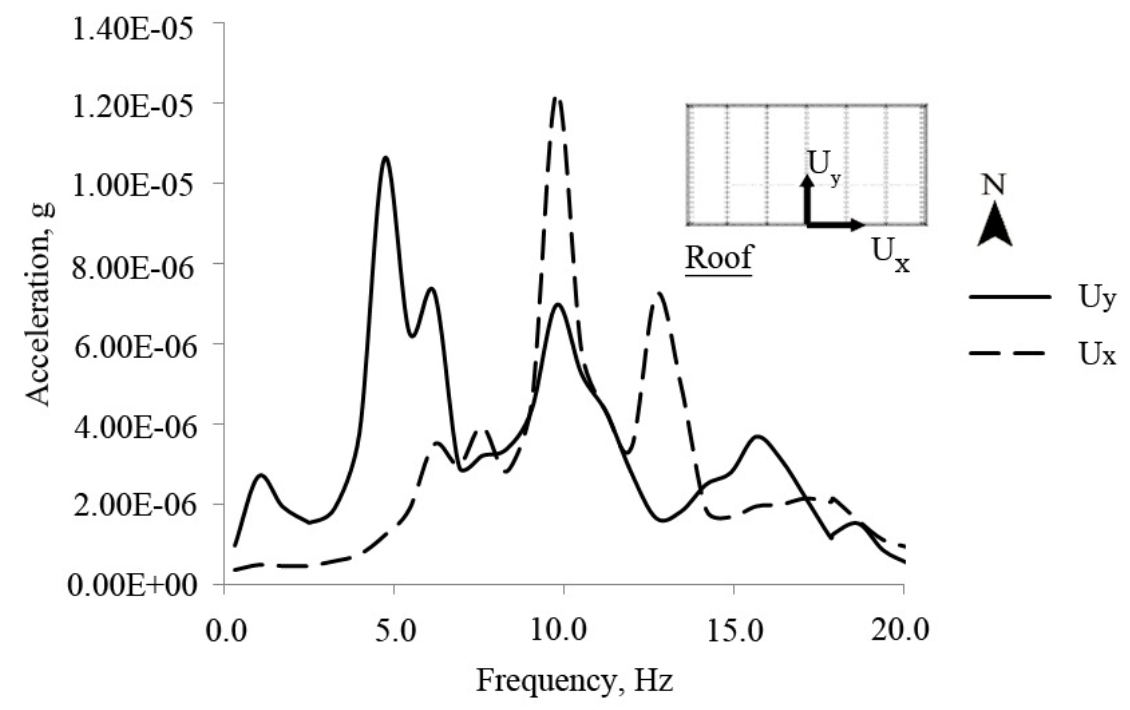

Figure O: First Ambient Vibration FFT Response

The accelerometers were placed in a strategic way in an attempt to locate the frequency at which the response of the mode is maximized. It was predicted that the first $\mathrm{N}-\mathrm{S}$ mode was primarily uniform N-S translational motion at the roof, thus the placement of the accelerometers at any location within the roof diaphragm was appropriate.

The first AVT was performed with two accelerometers at the south face of the structure on the roof (see Figure O). The FFT response curve in Figure O illustrates a distinct peak in the N-S direction at about $5 \mathrm{~Hz}$, where the response in the E-W direction was negligible. This was a good indication that the N-S mode was about $5 \mathrm{~Hz}$. An 
additional AVT at another distinct location on the roof was used to help verify that the peak at about $5 \mathrm{~Hz}$ was dominated by N-S motion, see Figure P below.

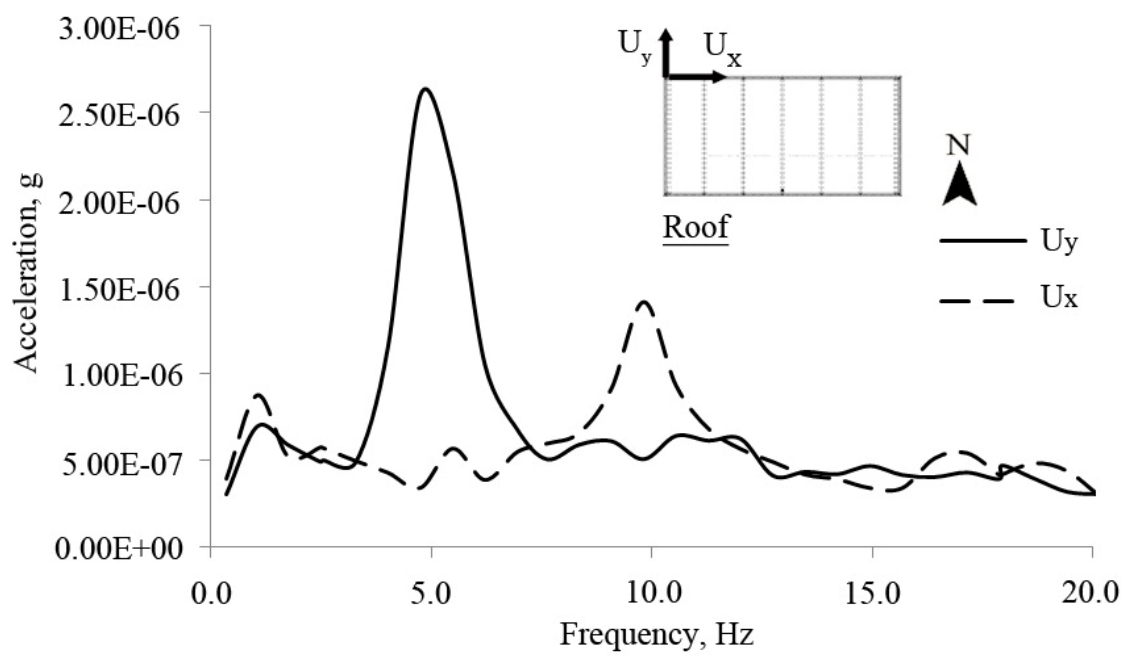

Figure P: Second Ambient Vibration FFT Response

The results of the second AVT also indicated a strong ambient response in the N$\mathrm{S}$ direction at about $5 \mathrm{~Hz}$. The E-W response was negligible at about $5 \mathrm{~Hz}$; however, there appeared to be an E-W peak at about $10 \mathrm{~Hz}$, possibly the first E-W mode. Subsequently, forced vibration testing (FVT) was performed to overcome the ambient response of the structure and more accurately determine the natural frequency of the N-S mode.

\subsubsection{Forced Vibration Testing}

Following AVT, FVT was performed in an attempt to amplify the response of the structure to isolate the N-S mode. The linear mass shaker was placed at the center of mass on the roof where the forced vibration sweep was executed for a range of 
frequencies of 3-6 Hz. The results of the forced vibration sweep can be seen in the FFT in Figure Q below.

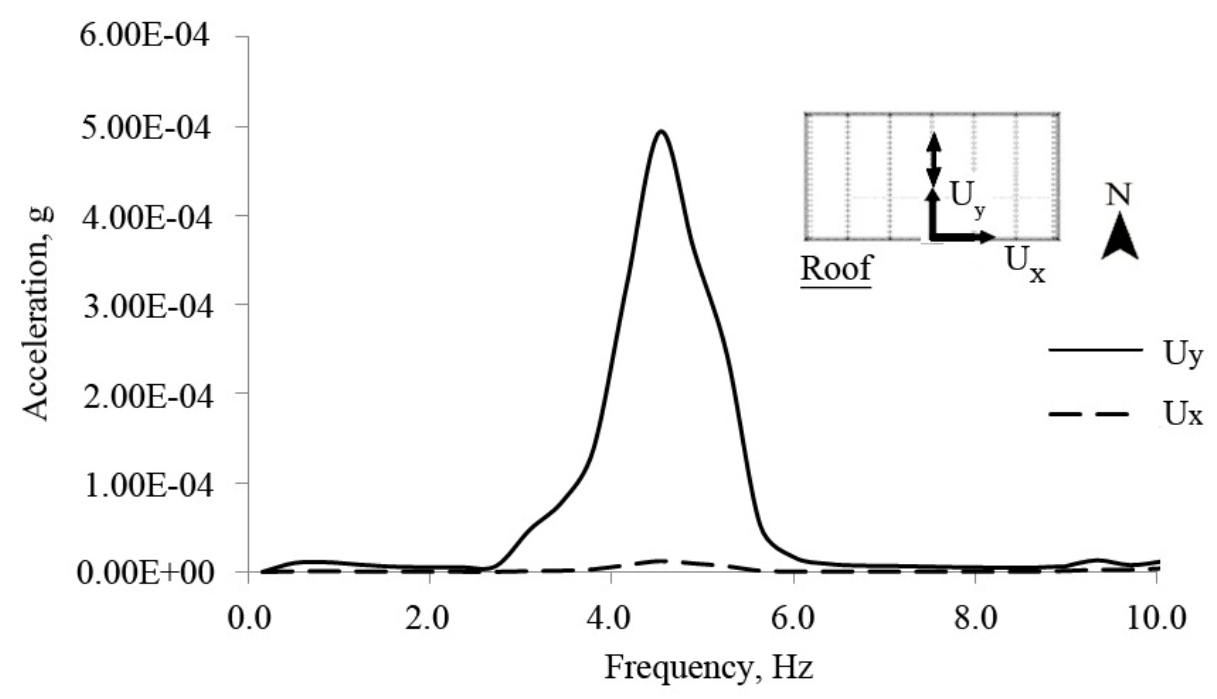

Figure Q: Forced Sweep FFT

At about $5 \mathrm{~Hz}$, it is clear that the response is dominated by N-S motion, thus reinforcing that the N-S mode is at approximately $5 \mathrm{~Hz}$. Note that the peak acceleration in the forced vibration sweep shown in Figure Q is 167 times greater than the peak acceleration in the AVT.

To better determine the frequency at which the N-S mode occurred, a micro sweep was subsequently performed. A micro sweep was done by exciting the structure through a small range of frequencies while simultaneously recording the steady state accelerations. The shaker was placed in the same location and orientated in the same direction as in Figure Q as it was evident that the N-S motion was maximized while the E-W minimized. Figure R below are results of the micro sweep for the N-S mode, also known as the N-S mode frequency response curve. 


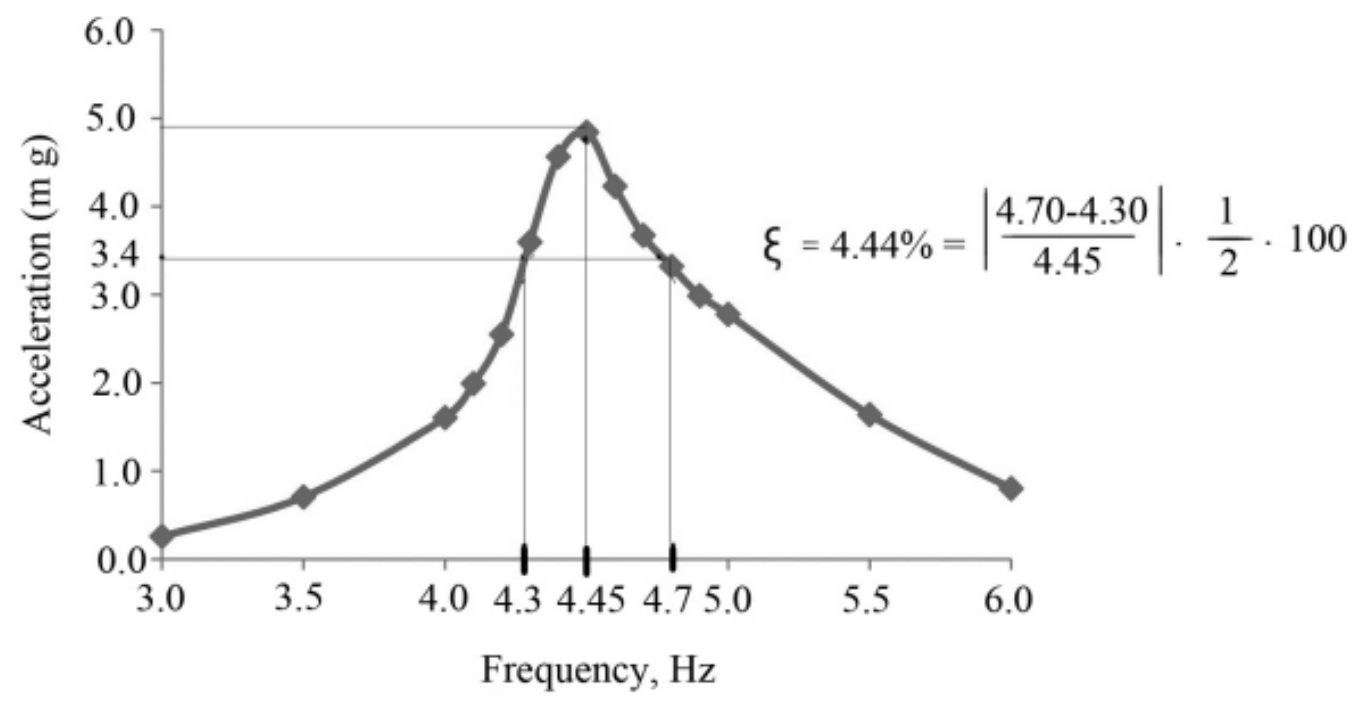

Figure R: Frequency Response Curve

The roof experienced a peak acceleration of about $5 \mathrm{~m} \mathrm{~g}$ at a frequency of 4.45

Hz. Note that the accelerations measured in the frequency response curve were steady state; thus, are 1667 times larger than the recorded ambient accelerations. The results of the AVT and FVT illustrate that as the accelerations demands increased (from AVT to FVT), the natural frequency slightly decreased. This occurs from the slippage in the connections as the acceleration demands increase, slightly reducing the stiffness. The effective damping shown in Figure $\mathrm{R}$ was calculated utilizing the half power band method as in Figure $\mathrm{S}$ below. 


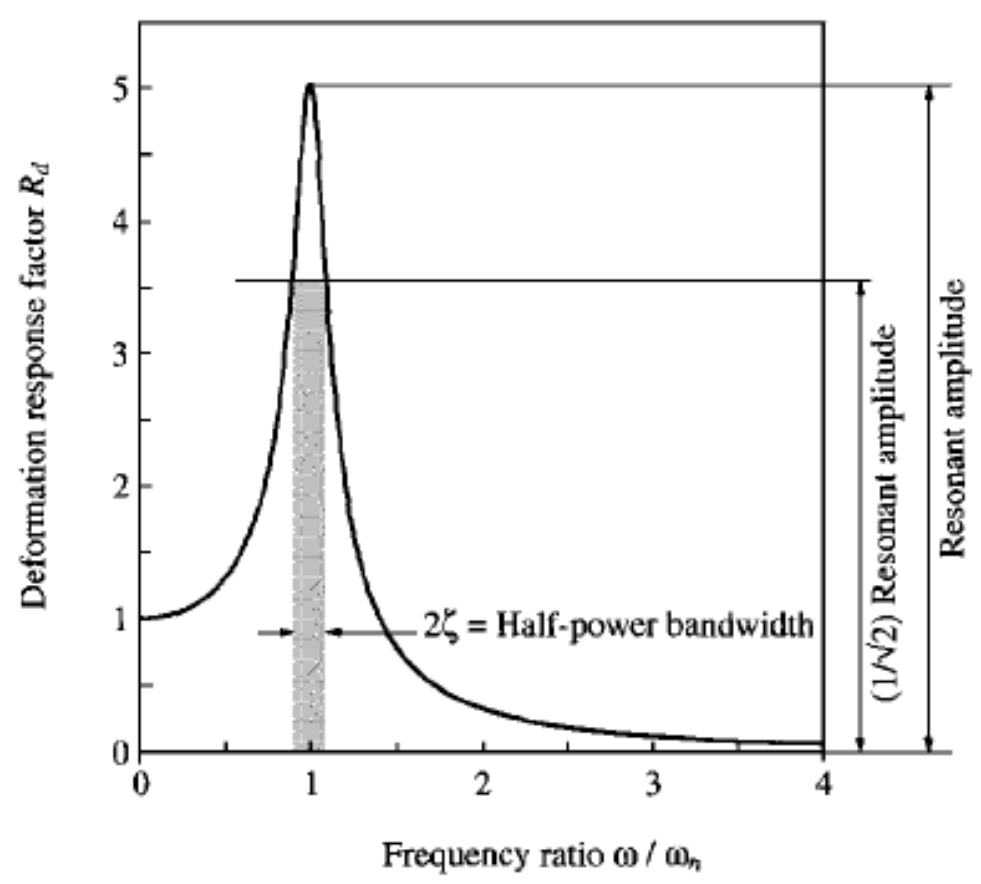

Figure S: Definition of Half Power Band Method

(Chopra 2007)

$\omega_{\mathrm{a}}$ and $\omega_{\mathrm{b}}$ are the forcing frequencies on either side of the resonant frequency at which the amplitude is $1 \div \sqrt{2}$ times the resonant amplitude (Chopra 2007). Using equation 19 the effective damping was calculated and illustrated on the frequency response curve on Figure R, Figure X, Figure CC, as well as Table 4 on page 43.

$$
\frac{\omega_{b}-\omega_{a}}{\omega_{n}}=2 \xi
$$

Once the natural frequency of the N-S mode was established, the shaker was set up to continuously oscillate at a frequency of $4.45 \mathrm{~Hz}$. Because the Bridge House is a bridge structure that spans $48 \mathrm{ft}$ over a seasonal creek, the out-of-plane motion were recorded at 70 locations throughout the roof and floor. Figure $\mathrm{T}$ below illustrates the plan view of the mapped out N-S mode. 


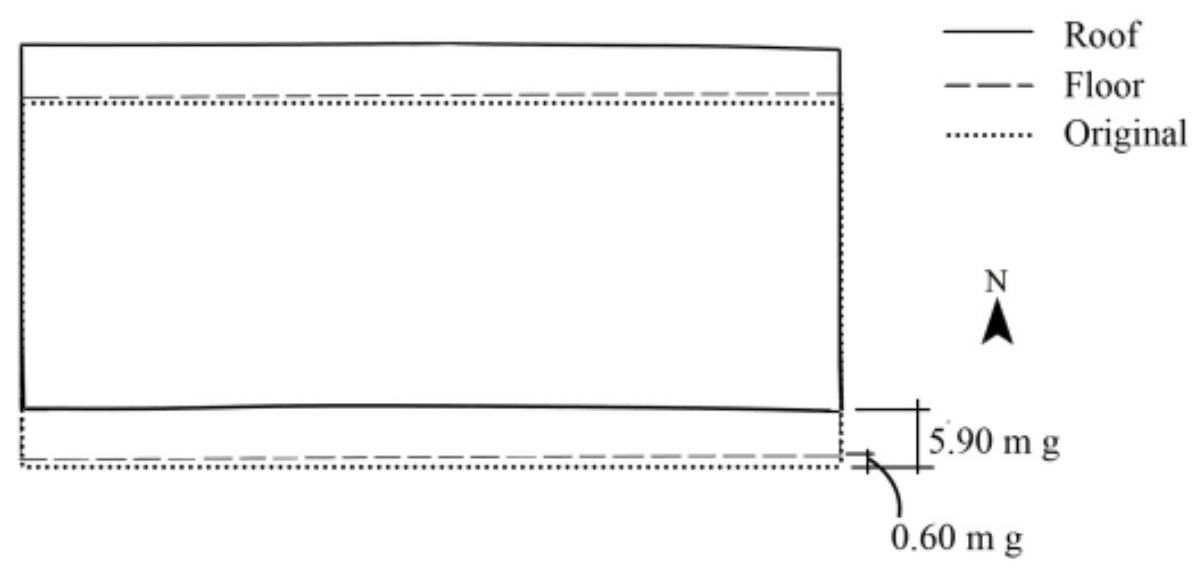

Figure T: First Experimental N-S Mode Shape

The N-S mode was dominated by translational motion where the roof diaphragm translated more than the floor. The moment frames in the N-S direction are 7 times more flexible than the foundations; hence the roof experienced about 10 times more deformation than the floor.

Results illustrate that the roof behaved similar to a rigid diaphragm. Per code, a diaphragm can be idealized as flexible where the maximum in-plane deflection of the diaphragm under lateral load is more than two times the average story drift of the adjoining vertical elements (ASCE-07-05). The in-plane stiffness of the diaphragm in the N-S direction is approximately $133 \mathrm{k} / \mathrm{in}$, whereas the lateral stiffness of the LFRS in the N-S direction is about $87 \mathrm{k} /$ in. The in-plane stiffness of the diaphragm is 1.53 times greater than the lateral stiffness of the LFRS in N-S direction. Thus, the diaphragm in the N-S direction behaved similar to a rigid diaphragm. 


\subsection{Experimental Determination of First E-W Mode Shape}

The E-W mode was experimentally determined using ambient vibration and forced vibration tests, the mode was anticipated to be a translational dominated mode in the E-W direction.

\subsubsection{Ambient Vibration Testing}

The subsequent target mode shape was the E-W mode. As previously mentioned in section 2.2.1, the accelerometers were placed in a strategic way to locate the frequency at which the primary response of the particular mode shape was maximized.

To begin to locate the E-W mode, the accelerometers were placed on the east end of the structure. Figure $U$ below illustrates the results of the AVT when the accelerometers were placed at that location.

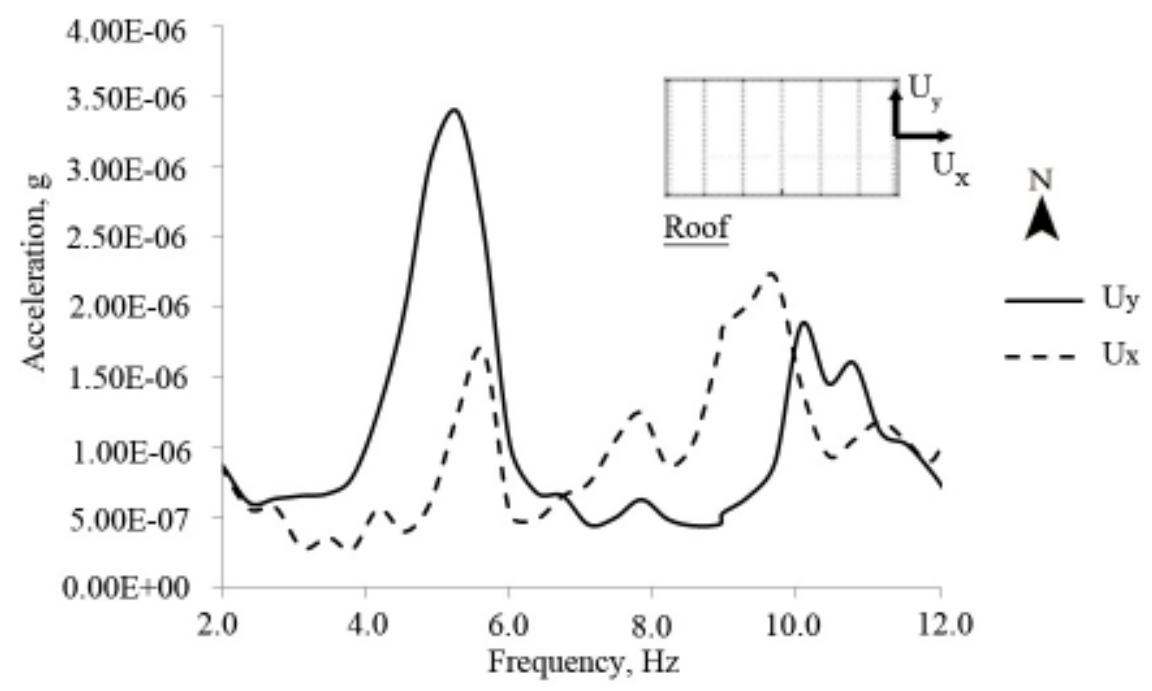

Figure U: Ambient FFT Response 
Multiple peaks occur in the ambient FFT response curves in Figure U. Similar to previous AVT's, the vertical ambient response was again greater than both the N-S and E-W by order of magnitudes, thus, to better examine the N-S and E-W response, the vertical response was omitted from Figure U. Figure U indicates that the ambient response in the E-W direction was strongest at $9 \mathrm{~Hz}$; however, other peaks in the E-W direction are also in existence and need to be considered. For a closer look at the overall ambient response of the structure, Figure $\mathrm{V}$ below was included to examine the vertical ambient response along with the N-S and E-W response.

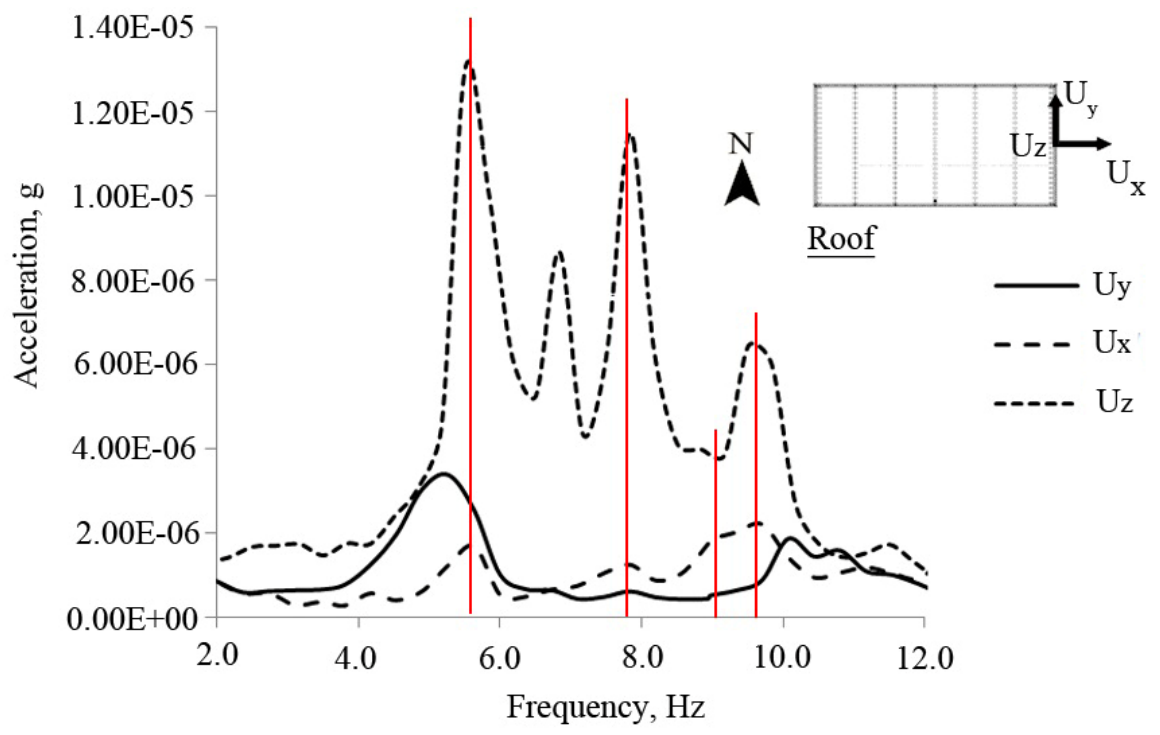

Figure V: Ambient FFT Response

It is clear in Figure V that the majority of the peaks that correspond to the E-W response are located below the vertical response peaks. The vertical response was significantly greater than the E-W response, indicating that these peaks are most likely a vertical mode. However if the E-W response is closely examined at slightly less than 10 $\mathrm{Hz}$, it is evident that there are 2 peaks that are closely spaced. The second peak occurs 
where the vertical response is greatest, whereas the first peak occurs where the vertical response is at its minimum. Additional AVT's were also performed at other locations to validate the frequency range of the E-W mode. Figure $\mathrm{V}$ indicates that there is a good possibility that the E-W mode occurs at about a frequency of $9 \mathrm{~Hz}$, thus a FVT sweep was subsequently conducted to reinforce that concept.

\subsubsection{Forced Vibration Testing}

The results of the ambient tests performed on the east end of the building generated satisfactory results; therefore the accelerometers were kept in the same location. The shaker was applied at the roof's center of mass to oscillate in the E-W direction at a frequency range of 7-11 Hz. The results were plotted in Figure W below.

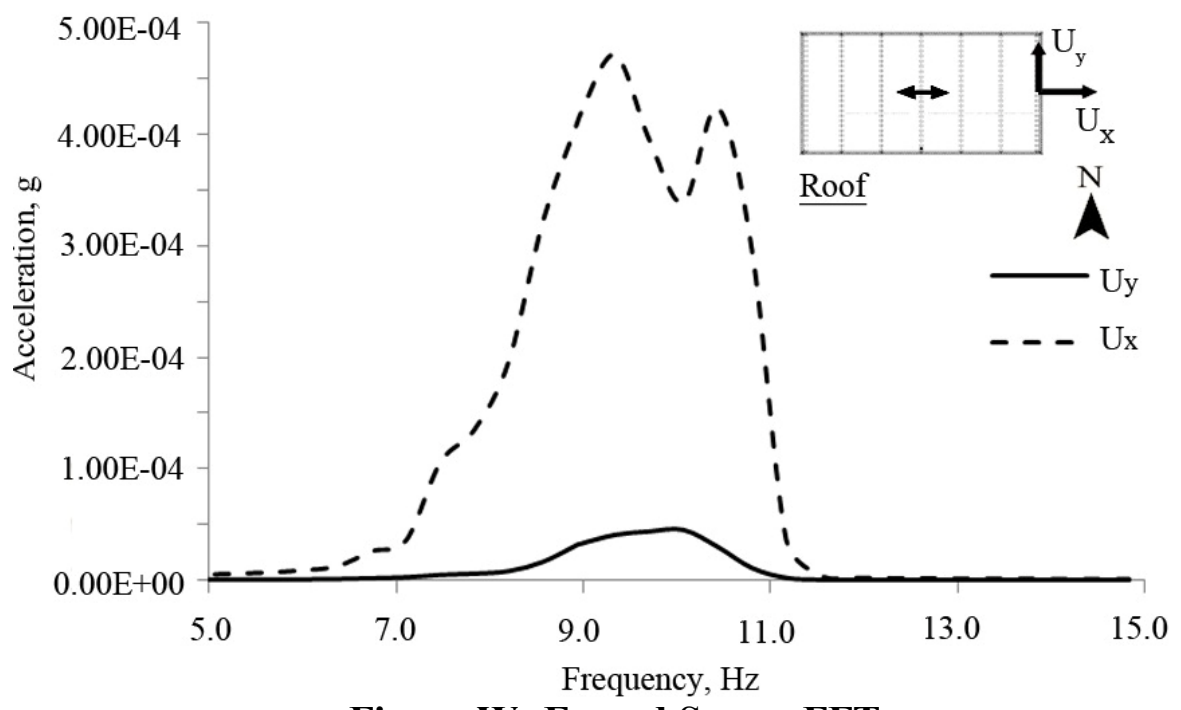

Figure W: Forced Sweep FFT

Figure $\mathrm{W}$ illustrates a strong response in the E-W direction, while the N-S response was relatively negligible. Note the accelerations in the forced vibration sweep were 225 times larger than the AVT accelerations. Figure $\mathrm{W}$ also shows that there are 
two closely spaced peaks in the E-W direction. One peak occurred at about $9 \mathrm{~Hz}$, while the other occurred at about $10.5 \mathrm{~Hz}$. The AVT in Figure V on page 32 illustrate similar peaks at similar frequencies. Thus, based on the results from Figure V, the E-W mode appears to occur at about $9 \mathrm{~Hz}$. To determine a more precise frequency that is in sync with the E-W mode, a micro sweep as described in section 2.2.2 was performed. See Figure $\mathrm{X}$ below.

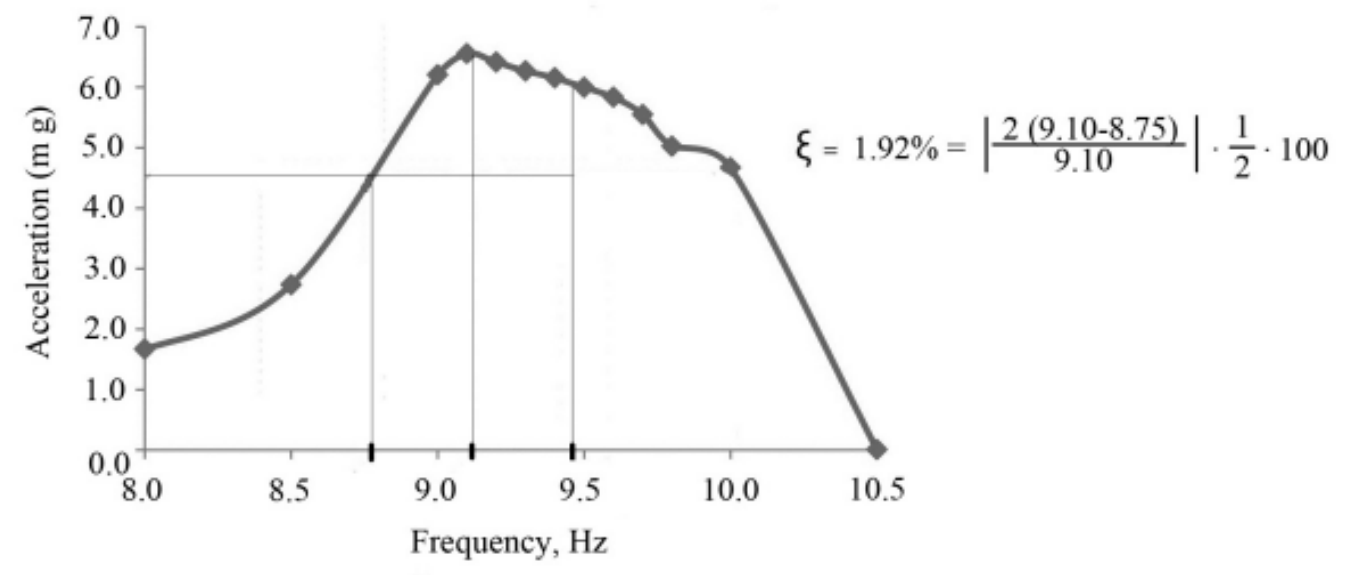

Figure X: Frequency Response Curve

The steady state accelerations were 3,250 times larger than the ambient accelerations and were at maximum at about $9.1 \mathrm{~Hz}$. The $1.92 \%$ damping ratio was calculated using the half power band method. The frequency response curve in Figure X does not have a distinctive peak; it is a wide-ranging curve resulting from 2 closely spaced modes. Ambient tests in Figure V suggested that the peak at about $10 \mathrm{~Hz}$ was a vertical mode thus it be inappropriate to use the full range of frequencies as in Figure $\mathrm{R}$ on page 28. Theoretically, both frequencies on either side of the peak should have occurred at similar distance apart; however, on Figure $\mathrm{X}$ it is clear there are no other 
modes present just prior to $9.10 \mathrm{~Hz}$. For this mode, it was suitable to assume that the frequency range for the half power band method was 2 times $(9.10-8.75) \mathrm{Hz}$.

To begin the mode shape mapping process, the shaker was set up to continuously oscillate at the natural frequency of $9.1 \mathrm{~Hz}$. Similar to the N-S mode, 70 locations were used to record the N-S, E-W and vertical accelerations throughout the building's floor and roof diaphragms. Figure $\mathrm{Y}$ below illustrates the plan view of the mapped out E-W mode.

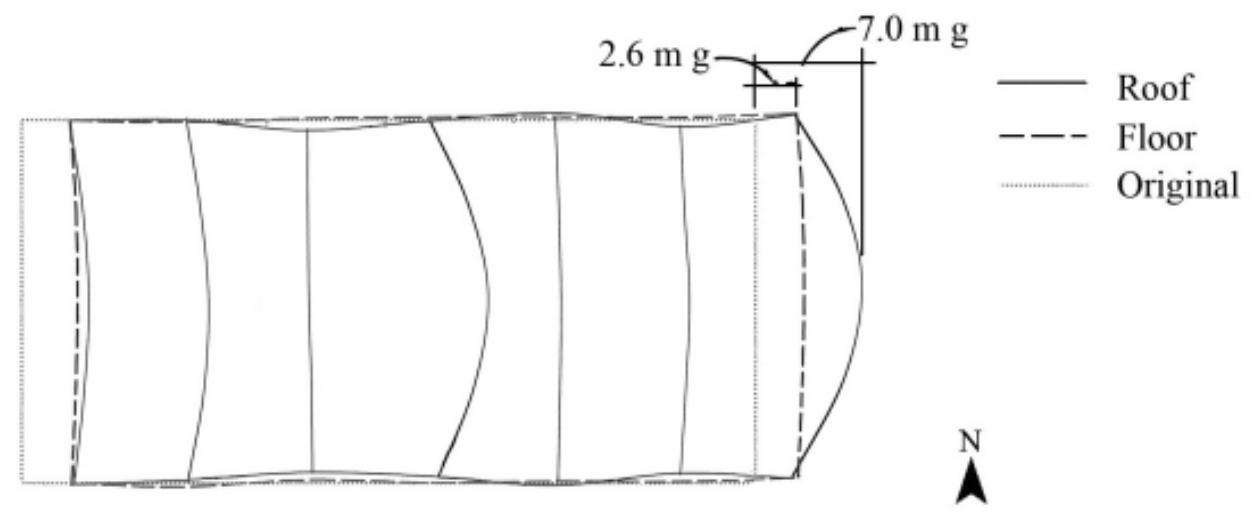

Figure Y: First Experimental E-W Mode Shape

The E-W mode evidently demonstrated some in-plane flexibility in the diaphragm. The LFRS engaged in this mode was the braced frames that are located along the long direction of the building. Note that in the previous N-S mode, the roof diaphragm behaved similar to a rigid diaphragm while the same diaphragm conversely behaved as a flexible diaphragm in the E-W direction. The LFRS in the E-W direction has an approximate stiffness of $1149 \mathrm{k} /$ in, about 13 times stiffer than the LFRS in N-S direction. The in-plane stiffness of the diaphragm in the E-W direction is approximately $544 \mathrm{k} /$ in. The diaphragm behaved differently in the orthogonal direction because the 
moment frames in the N-S direction is $53 \%$ more flexible than the N-S in-plane diaphragm, while the braced frames in E-W direction provides $211 \%$ more stiffness than the E-W in-plane diaphragm. As a result of the relatively large stiffness of the braced frames, the diaphragm had a larger participation in the E-W mode and thus behaved flexibly. Although the E-W mode appeared to be a translational mode, there were significant vertical accelerations in the roof and floor diaphragm. An isometric view of the vertical accelerations of the roof and floor diaphragms can be seen in Figure $\mathrm{Z}$ below.

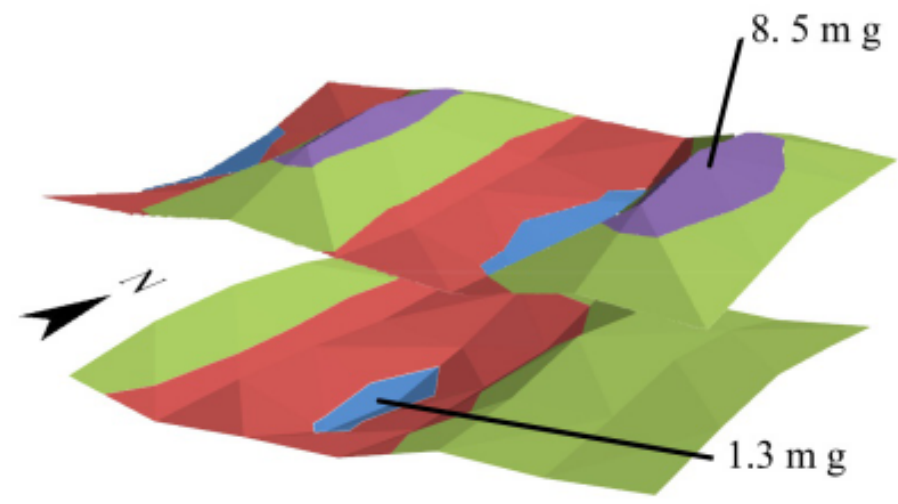

Figure Z: Vertical Accelerations of the Floor and Roof Diaphragm

The E-W mode is considered to be predominantly a translational mode; however, it also contained significant vertical accelerations. The roof vertical accelerations on the east end were larger than the any lateral roof acceleration.

The results from FVT also presented uncertainty about the connection between the roof diaphragm to the gravity wide flange beams (see Figure Y). Composite behavior between the two elements would have resulted from a series of evenly spaced spot welds. However, in Figure $\mathrm{Y}$ it is clearly not the case. By placing the accelerometer on the underside of the roof beams, it was determined that some beams were fully attached, 
some were partially attached, and some not attached at all. In general, Figure Y indicates that the steel deck was only welded at each ends of the 24-ft long sections.

In addition to the flexible diaphragm behavior, foundation flexibility was also noticeable in the E-W mode shape. The concrete piers are no different than a cantilevered beam and the stiffness is a function of its length, thus the different pier heights would have resulted in different lateral stiffness. Typically torsion arises when a variation of lateral stiffness occurs; however, the results of the E-W mode shape proved otherwise. Theoretically, the concrete piers have about $10 \%$ more lateral stiffness than the surrounding soil and the ratio of lateral frame stiffness to soil spring stiffness is about 2.2 in the E-W direction and about 0.15 in the N-S direction (see section 1.5). As a result, the concrete were susceptible to rocking in the apparent E-W mode.

\subsection{Experimental Determination of First Vertical Mode Shape}

The first vertical mode was experimentally determined using ambient vibration and forced vibration tests and was anticipated to be a first order vertical mode engaging the roof and the floor diaphragms.

\subsubsection{Ambient Vibration Testing}

The concrete-topped floor spans $48 \mathrm{ft}$, thus the vertical response of the building was quite significant. The roof supports less than half of the structure's mass in the vertical direction, thus the mass participation of the roof for each vertical mode would be about less than half of the total sum. The ideal location to place the accelerometers was 
at the center of the roof diaphragm. However, this location was obstructed by the permanent steel mounting brackets used to attach the linear mass shaker to the roof. Thus the accelerometers were placed in the roof in the middle front quarter of the diaphragm as seen in Figure AA below.

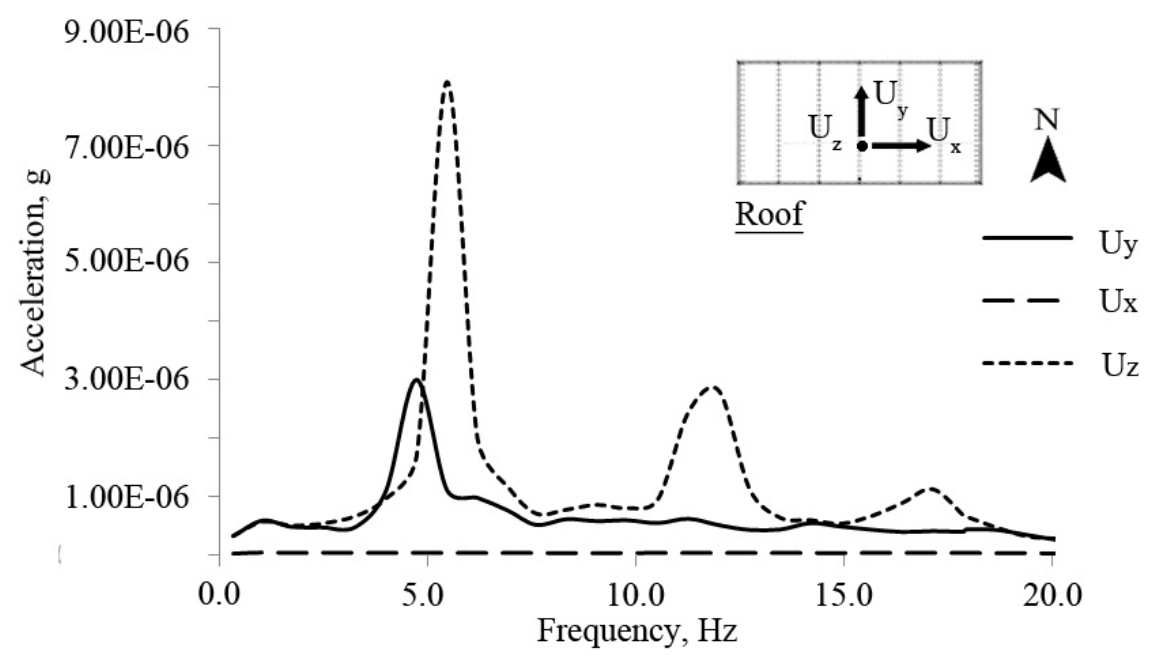

Figure AA: Ambient FFT Response

The ambient vertical response of the structure was up to 2.5 times stronger than the translational response. A large peak corresponding to the vertical direction was evident at about a frequency of $5 \mathrm{~Hz}$. There were additional peaks for the vertical response at frequencies of $11 \mathrm{~Hz}$ and $16 \mathrm{~Hz}$. However, to further investigate the vertical response at about $5 \mathrm{~Hz}$, a FVT was performed.

\subsubsection{Forced Vibration Testing}

The vertical shaker was placed at the center of mass of the floor, believed to be the location of the maximum response of the first vertical mode. Subsequently, the shaker 
was set to oscillate through a range of frequencies of $4.5 \mathrm{~Hz}$ to $6.5 \mathrm{~Hz}$. The results of the forced vibration sweep can be seen in Figure BB below.

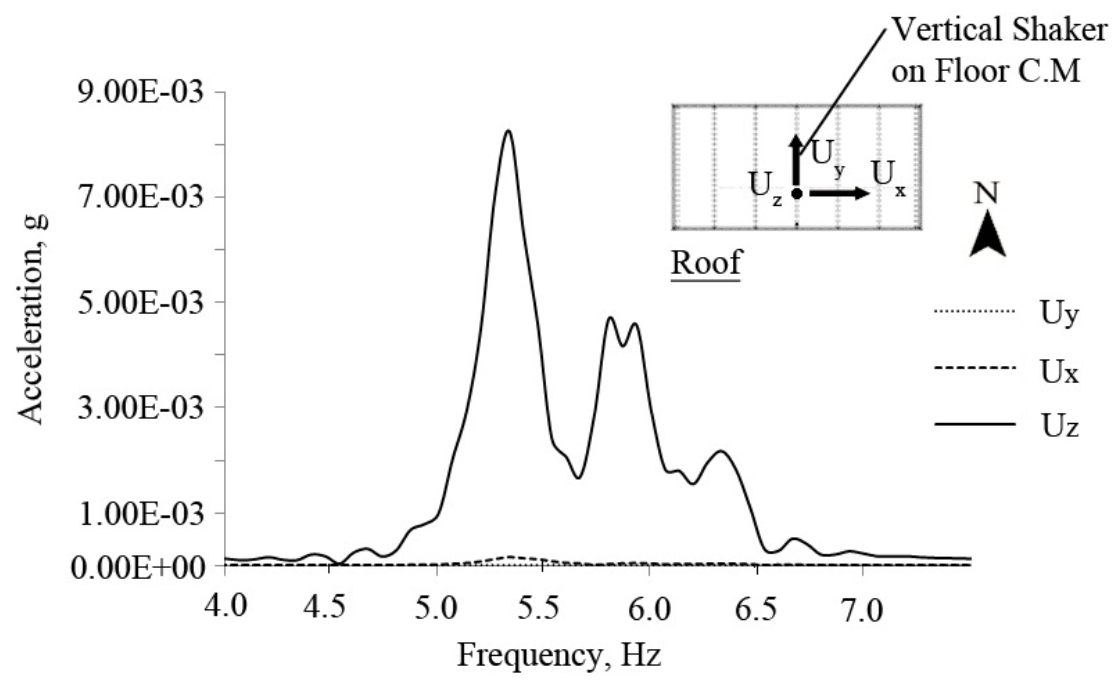

Figure BB: Forced Sweep FFT

There were three visible vertical peaks that result from the forced vibration sweep. The first one occurred at about $5.25 \mathrm{~Hz}$ followed by another set at about $6 \mathrm{~Hz}$ and lastly at about $6.25 \mathrm{~Hz}$. The largest peak, which was also the first peak, appeared to be the first vertical mode. The vertical accelerations seen in Figure AA were 1000 times larger than the ambient accelerations. It is interesting to note that the accelerations in the vertical direction were large enough for an observer to physically feel the structure oscillating. In order to distinguish the frequency of the first vertical mode, a micro sweep as described in section 2.2.2 was performed.

As in the forced vibration sweep, the accelerometers were placed in a similar location. The frequency range that was chosen to perform the micro sweep was $5 \mathrm{~Hz}$ through $6.5 \mathrm{~Hz}$. The frequency response curve can be seen on Figure CC below. 


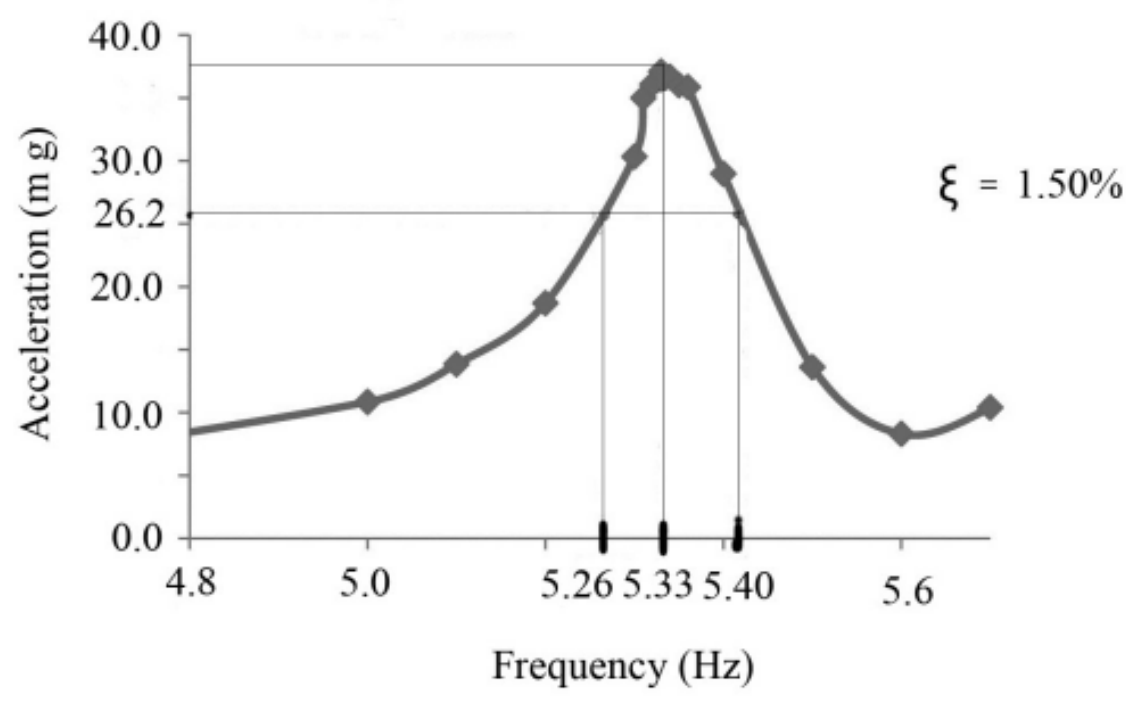

Figure CC: Frequency Response Curve

The maximum acceleration at the roof occurred at a frequency of $5.33 \mathrm{~Hz}$. The response for this particular mode was sensitive to the change in frequency; therefore the damping ratio for the first vertical mode was about $1.50 \%$. The vertical shaker was placed at the center of mass of the floor diaphragm and set up to continuously oscillate at the natural frequency $5.33 \mathrm{~Hz}$. Similar as in the translational modes, 70 locations were used to record the N-S, E-W, and vertical accelerations throughout the structure's floor and roof diaphragms. Figure DD below illustrates an isometric view of the first vertical mode. 


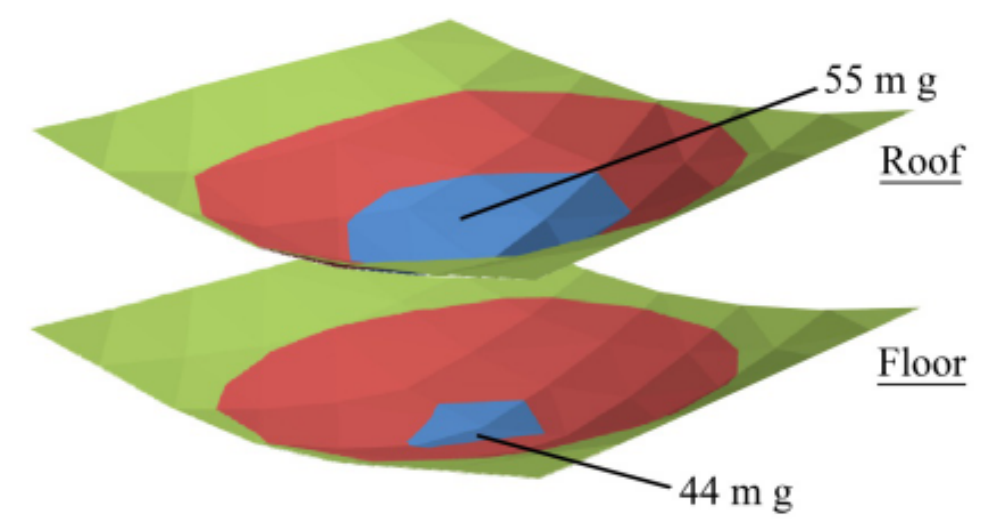

Figure DD: First Experimental Vertical Mode Shape

Figure DD is an isometric view of the vertical accelerations in the first mode shape. The primary motion of this mode was in the vertical direction, thus it was shown as an isometric rather than in plan.

As expected, the first mode of vibration in the vertical direction was the floor and roof diaphragm vibrating in phase with each other amid a deflected shape of a half sine wave. A maximum steady state acceleration of $55 \mathrm{mg}$ was experienced at the center of mass of the roof diaphragm, 6,875 times larger than the ambient vertical accelerations.

A total of 9 mode shapes were recorded. For simplicity, only the first two translational and first vertical modes (denoted modes 1, 2 and 7 in Table 4 on page 43) were explained in detail. Table 4 below is a summary of all 9 mode shapes. Please note that all subsequent discussions will refer to the experimental mode shapes as apparent mode shapes prior to performing the sweeping procedure. The sweeping procedure is a purification process of the experimental apparent mode shapes. A further explanation can be read in section 3.2 of this thesis. 
The first column on the left of Table 4 contains a brief description of the apparent mode. The middle column is a plan view of the translational accelerations, and the far right column is an isometric view of the vertical accelerations. 
2.0 Experiment Basis 43

Table 4: Summary of Experimental Mode Shapes

\begin{tabular}{|c|c|c|}
\hline Mode & $\begin{array}{c}\text { Plan View of Experimental Mode } \\
\text { Shapes }\end{array}$ & $\begin{array}{c}\text { Isometric View of Experimental } \\
\text { Mode Shape }\end{array}$ \\
\hline $\begin{array}{l}\text { Mode 1: } 1^{\text {st }} \mathrm{N}-\mathrm{S} \\
\text { Frequency: } 4.45 \mathrm{~Hz} \\
\text { Damping: } 4.44 \%\end{array}$ & 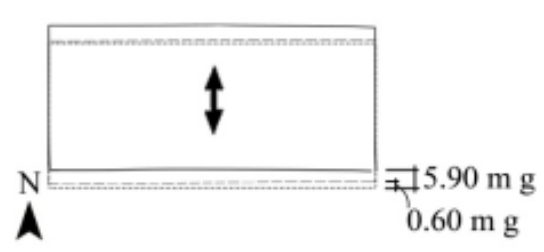 & $0 \mathrm{~m} \mathrm{~g}$ \\
\hline $\begin{array}{l}\text { Mode 2: } 1^{\text {st }} \text { Vertical } \\
\text { Frequency: } 5.33 \mathrm{~Hz} \\
\text { Damping: } 1.50 \%\end{array}$ & $\mathrm{~N}\left[\begin{array}{c}1.2 \mathrm{mg} \\
0.0 \mathrm{mg} \\
\end{array}\right.$ & $\mathrm{mg}$ \\
\hline $\begin{array}{l}\text { Mode 3: } 2^{\text {nd }} \text { Vertical } \\
\text { Frequency: } 5.91 \mathrm{~Hz} \\
\text { Damping: } 3.80 \%\end{array}$ & . & $\mathrm{mg}$ \\
\hline $\begin{array}{l}\text { Mode 4: } 3^{\text {rd }} \text { Vertical } \\
\text { Frequency: } 6.60 \mathrm{~Hz} \\
\text { Damping: } 1.70 \%\end{array}$ & $\stackrel{0.8 \mathrm{mg}}{\leftrightarrow}$ & $\mathrm{mg}$ \\
\hline $\begin{array}{l}\text { Mode 5: } 4^{\text {th }} \text { Vertical } \\
\text { Frequency: } 7.50 \mathrm{~Hz} \\
\text { Damping: } 1.72 \%\end{array}$ & $\mathrm{~N}$ & 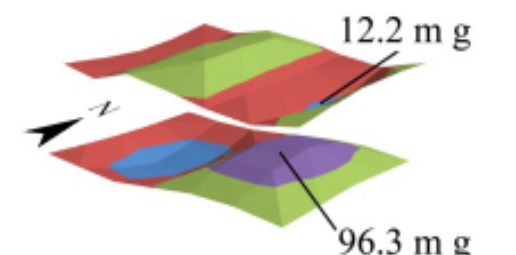 \\
\hline $\begin{array}{l}\text { Mode 6: } 5 \text { th Vertical } \\
\text { Frequency: } 8.50 \mathrm{~Hz} \\
\text { Damping: } 2.71 \%\end{array}$ & • & $7 \mathrm{~m} \mathrm{~g}$ \\
\hline
\end{tabular}


Table 5 Continued: Summary of Experimental Mode Shapes

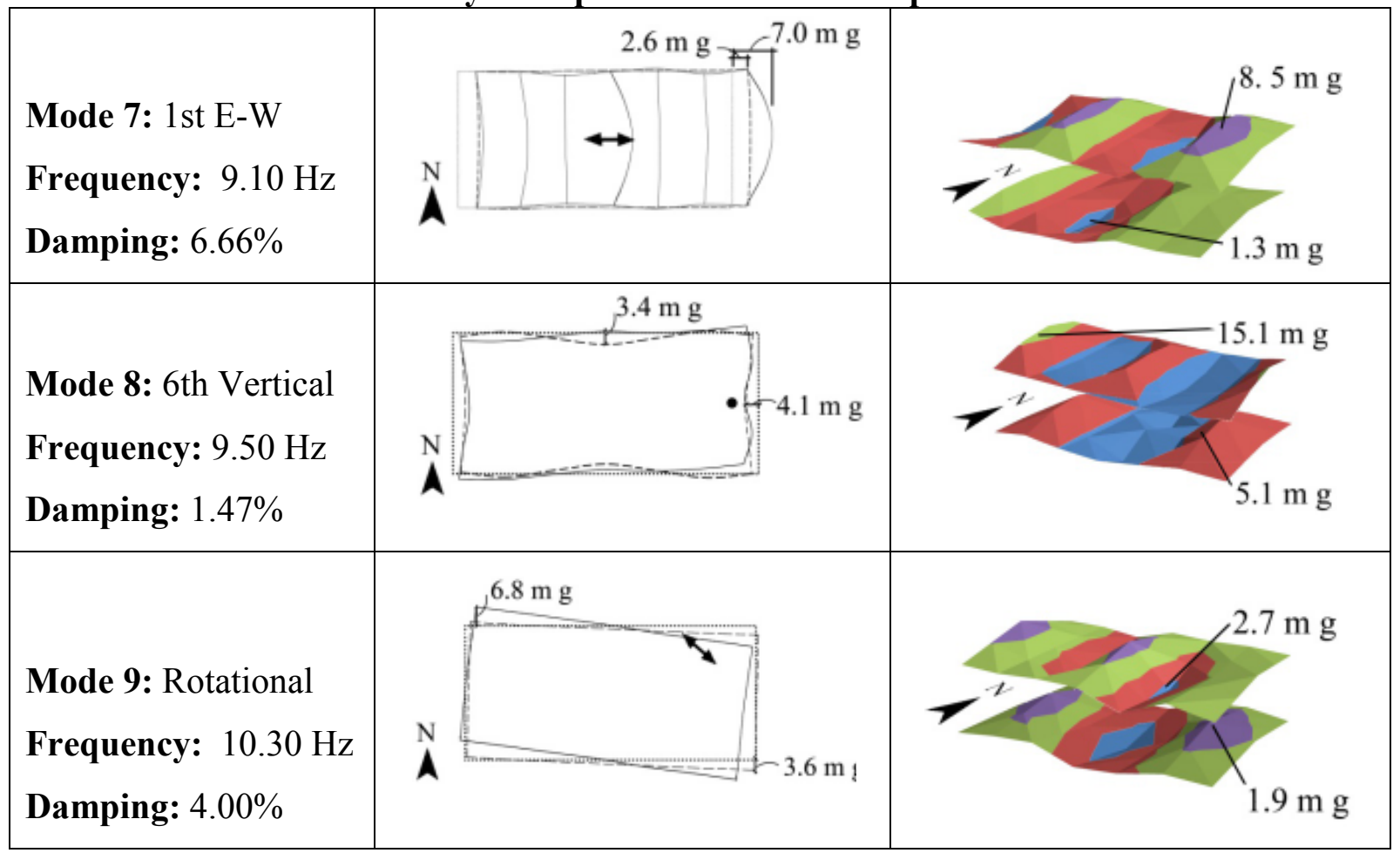

Apparent mode 3 was the second vertical mode at a frequency of $5.91 \mathrm{~Hz}$. It was similar to apparent mode 2 with the exception that the roof and floor diaphragms vibrated out of phase. The damping ratio was $3.80 \%, 2.5$ times more than apparent mode 2 . Damping can decrease the acceleration demands which as seen in apparent mode 3, the maximum acceleration was about 2.25 times less than the maximum floor acceleration in apparent mode 2. Coupling of apparent modes 2 and 3 occurred due to the fact that the frequencies of the two apparent modes were less than $0.75 \mathrm{~Hz}$ apart and also due to the fact that the two apparent modes were excited in the same location.

The natural frequency for apparent mode 4 was experimentally determined to be at $6.60 \mathrm{~Hz}$. Apparent mode 4 was unique in the sense that it was a vertical mode found by 
applying the horizontal shaker in the E-W direction. The shaker was mounted to the underside of the middle wide-flange roof beam; because it was applied to the underside of the beam, it initiated torsion into the beam, which caused out-of-plane deformation of the roof diaphragm. It is interesting to note that although apparent mode 4 was excited using the horizontal shaker, the vertical accelerations were almost 9 times more than the translational accelerations. The apparent mode shape was defined by the out-of-plane deformations of the roof and floor diaphragms. The roof created a deflected shape that appeared as two sine waves, whereas the floor only deformed into one sine wave.

Apparent mode 5 was the $4^{\text {th }}$ vertical mode with a frequency of $7.50 \mathrm{~Hz}$. It was excited using the vertical shaker at the east quarter point of the floor diaphragm. Although apparent mode 4 and 5 were similar, the differences were in the acceleration demands on the floor diaphragm and the roof's deflected shape. The largest acceleration in apparent mode 5 was $96.3 \mathrm{~m} \mathrm{~g}$, about 8 times more than the accelerations in apparent mode 4. In general the roof diaphragm in apparent mode 5 experienced maximum accelerations where they were essentially zero in apparent mode 4.

Apparent mode 6 was excited with the vertical shaker on the east end of the floor where the natural frequency was determined to be $8.50 \mathrm{~Hz}$. Apparent mode 6 was a vertical mode where the roof diaphragm resembles that of apparent modes 5,7 and 8 . The floor's deflected shape appeared that of a $1 \frac{1}{4}$ sine wave. The accelerations throughout the building were considerably less than any other apparent vertical mode. The damping ratio was calculated to be $2.71 \%$ and aside from apparent mode 3 , the damping ratio was larger than all other apparent vertical mode. The low accelerations in apparent mode 6 
could have resulted from the placement of the vertical shaker. The shaker was placed approximately $4 \mathrm{ft}$ from the east end support where the oscillating $30-\mathrm{lb}$ force was absorbed by the stiff support, ineffectively exciting the structure.

Apparent mode 8 was a third order vertical mode. Its response was also dominated by the out-of-plane deformation in the diaphragms; however, the response was not nearly as strong as the previously mentioned vertical modes. The damping ratio was also relatively low at $1.47 \%$. The out-of-plane deformation of the floor was defined by 1 $1 / 2$ sine waves, whereas the roof was defined by 2 sine waves.

Apparent mode 9 was a rotational mode that was excited by placing the shaker on the roof at a 45 degree angle on the $\mathrm{N}-\mathrm{E}$ end of the building. The damping ratio was calculated to be $4.0 \%$. Apparent mode 9, rotation about the vertical axis, experienced considerable vertical accelerations on both the floor and roof diaphragms that seemed to be similar to the vertical accelerations in apparent mode 8 .

\subsection{Modal Orthogonality of Experimental Mode Shapes}

One of the fundamental principles in structural dynamics is the orthogonality of the eigenvalue solutions (Chopra 2007). When $\omega_{\mathrm{j}} \neq \omega_{\mathrm{i}}$

$$
\phi_{j} M \phi_{i}=0
$$

Two modes with distinct frequencies are 90 degrees out of phase with each other if the result of equation 20 is equal to zero. When $\omega_{j}=\omega_{i}$ 


$$
\phi_{j} M \phi_{i}=1
$$

Equation 21

Equation 21 is equal to 1 if the $i$ th and $j$ th modes are in phase with each other. Both equation 20 and equation 21 are theoretical solutions when two modes are either out of phase or in phase with each other, respectively. When conducting experimental FVT, the results between two different modes will never yield a solution of 1 .

Similar to equation 20 and equation 21 , another frequently used correlation tool is the modal assurance criterion (MAC). A MAC number is a statistical indicator used (Allemang 2003) to define the consistency (degree of linearity) between two sets of mode shapes. The MAC also takes on a value from zero to unity where zero represents inconsistent correspondence and unity represents a consistent correspondence. The MAC number can be calculated using equation 22 :

$$
\mathrm{MAC}=\frac{\left(\phi_{i}^{T} \mathrm{M} \phi_{j}\right)^{2}}{\left(\phi_{i}^{T} \mathrm{M} \phi_{i}\right)\left(\phi_{j}^{T} \mathrm{M} \phi_{j}\right)}
$$

Where $\phi_{i}$ and $\phi_{j}$ represent the two mode shapes being compared, and $\mathrm{M}$ is the mass matrix of the structure.

Apparent modes acquired through FVT will always have some interaction with other modes. The severity of interaction depends if the mode of interest is excited in an ideal location. For example, placing the vertical shaker at a quarter point (a non-ideal location for apparent modes 2 or 3 ) of the floor diaphragm will possibly excite apparent modes $2,3,4,5$ and 6 . Apparent modes 7, 8 and 9 will not be excited because apparent mode 7 and 9 are considered non vertical modes and the quarter point in apparent mode 8 
occurs at a node of the deflected shape. The ideal location for shaker placement would be where the peak response of the apparent mode occurs, see Table 4 on page 43 . A further explanation of ideal shaker locations will be given later in this section.

Applying equation 22 will yield a range of solutions of $0<\mathrm{x}<1$, where $\mathrm{x}$ is the correlation between the $i$ th and $j$ th mode. Table 6 below is a matrix of MAC numbers comparing experimental results.

Table 6: Mass Weighted Correlation Numbers Comparing Experimental Mode Shapes

\begin{tabular}{|c|c|c|c|c|c|c|c|c|c|}
\hline & 1 & 2 & 3 & 4 & 5 & 6 & 7 & 8 & 9 \\
\hline 1 & 1.00 & 0.00 & 0.00 & 0.00 & 0.00 & 0.00 & 0.01 & 0.00 & 0.09 \\
\hline 2 & 0.00 & 1.00 & 0.04 & 0.00 & 0.00 & 0.01 & 0.00 & 0.01 & 0.00 \\
\hline 3 & 0.00 & 0.04 & 1.00 & 0.00 & 0.00 & 0.01 & 0.00 & 0.00 & 0.00 \\
\hline 4 & 0.00 & 0.00 & 0.00 & 1.00 & 0.01 & 0.01 & 0.01 & 0.00 & 0.00 \\
\hline 5 & 0.00 & 0.00 & 0.00 & 0.01 & 1.00 & 0.41 & 0.02 & 0.00 & 0.00 \\
\hline 6 & 0.00 & 0.01 & 0.01 & 0.01 & 0.41 & 1.00 & 0.12 & 0.19 & 0.00 \\
\hline 7 & 0.01 & 0.00 & 0.00 & 0.01 & 0.02 & 0.12 & 1.00 & 0.00 & 0.00 \\
\hline 8 & 0.00 & 0.01 & 0.00 & 0.00 & 0.00 & 0.19 & 0.00 & 1.00 & 0.00 \\
\hline 9 & 0.09 & 0.00 & 0.00 & 0.00 & 0.00 & 0.00 & 0.00 & 0.00 & 1.00 \\
\hline
\end{tabular}

Note that the diagonal values in Table 6 correspond to the condition in Eq. 21, thus the values are equal to 1 .

Apparent modes 1 and 9 had a correlation of 0.09. Apparent mode 9 was the apparent rotational mode, and apparent mode 1 was the N-S mode. Although both were excited at two different shaker locations, the apparent rotational mode did not contain some N-S translational motion. Thus apparent modes 1 and 9 yield a correlation of 0.09 . 
Apparent mode 6 had correlations of $0.41,0.12$ and 0.19 with apparent modes 5, 7 and 8, respectively. Apparent modes 5, 6, and 8 were excited on the east end of the floor using the vertical shaker and showed in similar out-of-plane motion of the roof diaphragm. Apparent mode 7 was considered a translational mode but because the relative stiffness of the lateral system to the diaphragm is substantially large, the roof diaphragm underwent significant out-of-plane deformation.

The interaction of apparent mode 6 with apparent modes 5, 7, and 8 indicated that there was a possibility that apparent mode 6 was not a real mode. Interaction of apparent modes naturally occurs in forced vibration testing; however, the degree of interaction can be minimized when the shaker is placed at the most optimal location. Apparent mode 6 was excited with the vertical shaker placed on the floor on the east end of the structure. If apparent modes 5, 7, and 8 are examined in Table 4, one can conclude vertical accelerations at the location where the vertical shaker was placed are in existence. Thus what appeared to be apparent mode 6 was simply the response of the structure composed of apparent modes 5,7 , and 8 .

For future research, because the real mode 6 was not found, it is suggested that the vertical shaker be placed in a location that will maximize the response of mode 6 while minimizing the response of all other modes. Figure EE shows elevation views of apparent modes $2,3,4,5$, and 6 with a proposed location for placement of the vertical shaker in an attempt to capture the real mode 6. 


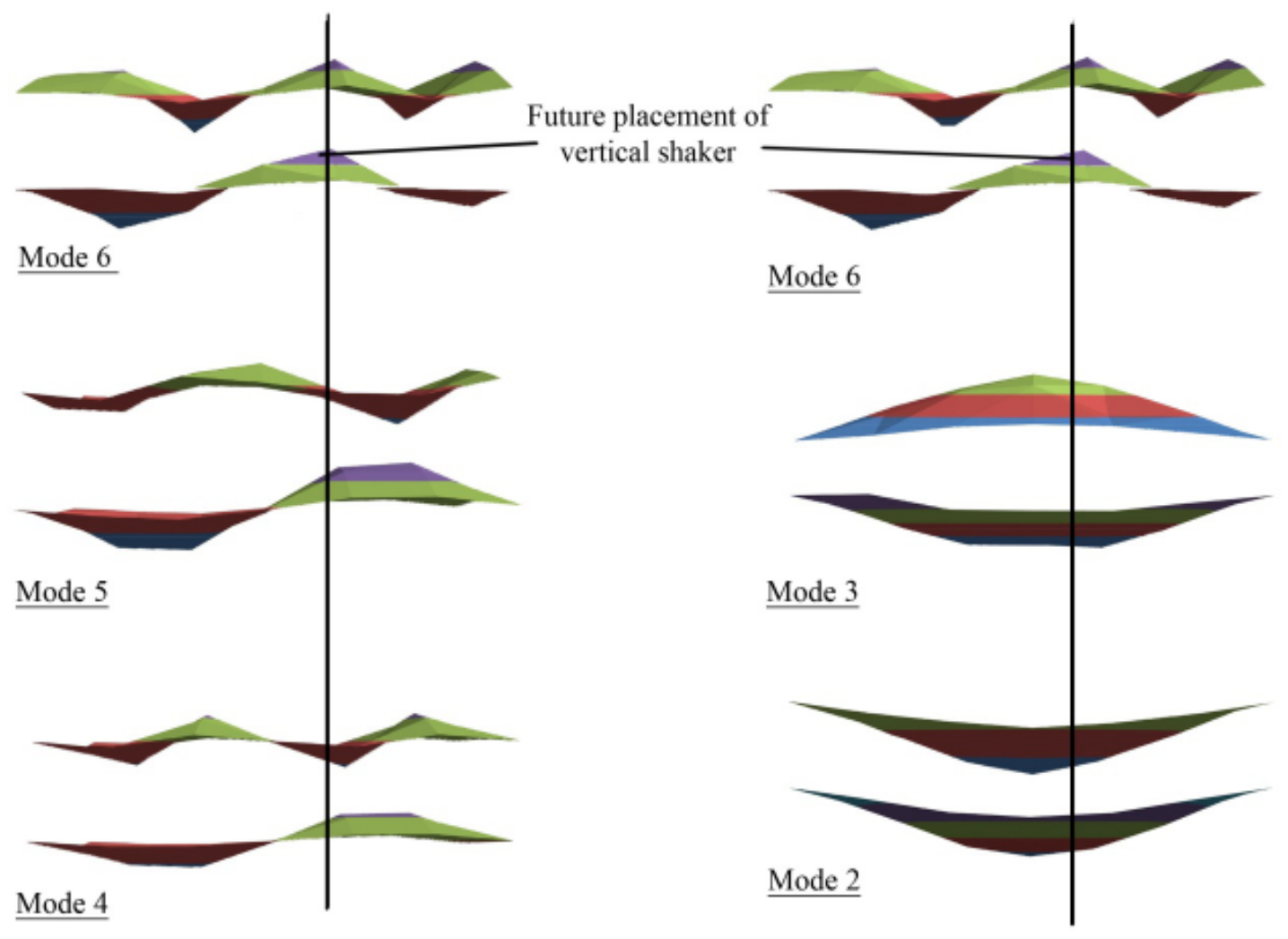

Figure EE: Future Placement of Vertical Shaker to Optimize Apparent Mode 6

To capture the real mode 6 , it is proposed to place the vertical shaker on the floor $12 \mathrm{ft}$ from the south face at a frequency that shall be determined by the same procedures explained earlier in sections 2.2 through 2.4. The proposed new location for the vertical shaker would be within the vicinity of the maximum accelerations for apparent modes 2 and 3 occur, and although this location will minimize the response of apparent modes 4 and 5, some interaction between apparent mode 6 with apparent modes 2 and 3 may occur. However there is a possibility that the frequencies between the apparent modes may be distant enough that apparent modes 2 and 3 will not be excited. 


\subsection{Experimental Findings}

Interesting findings through FVT were diaphragm flexibility, frequency shift due to temperature effects, a vertical anomaly on the floor diaphragm in the apparent N-S mode, and foundation flexibility.

\subsubsection{Roof Diaphragm Flexibility}

As previously discussed in section 2.2, the roof diaphragm in the apparent N-S mode behaved as a nearly rigid diaphragm. See Figure FF below.

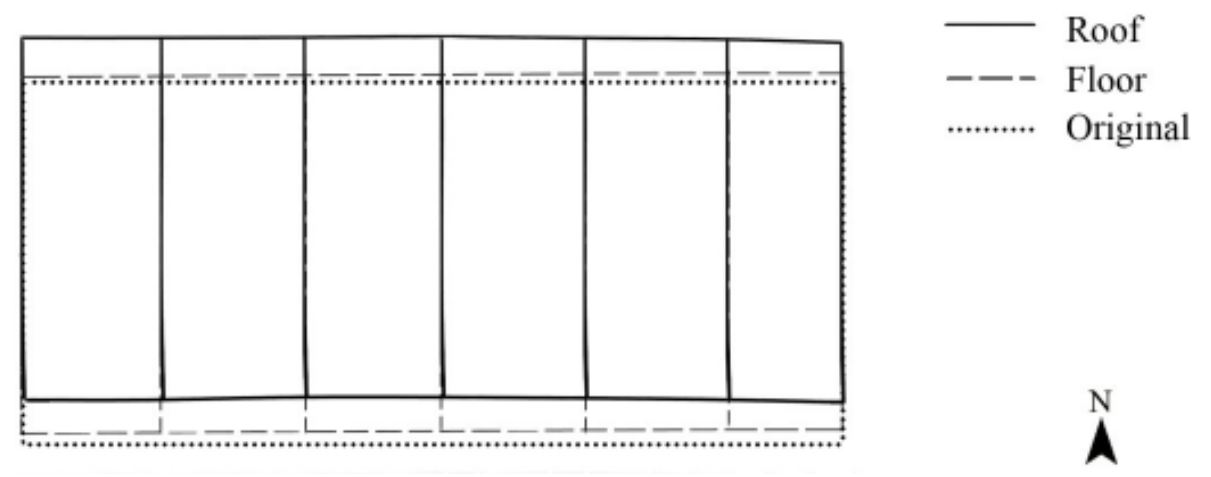

Figure FF: N-S Experimental Mode Shape

In the apparent E-W mode, different responses among the roof beams become an overall part of the apparent E-W mode. Thus, for clarification they were also included in Figure FF. Figure GG below illustrates the flexibility in the roof diaphragm for the apparent E-W mode. 


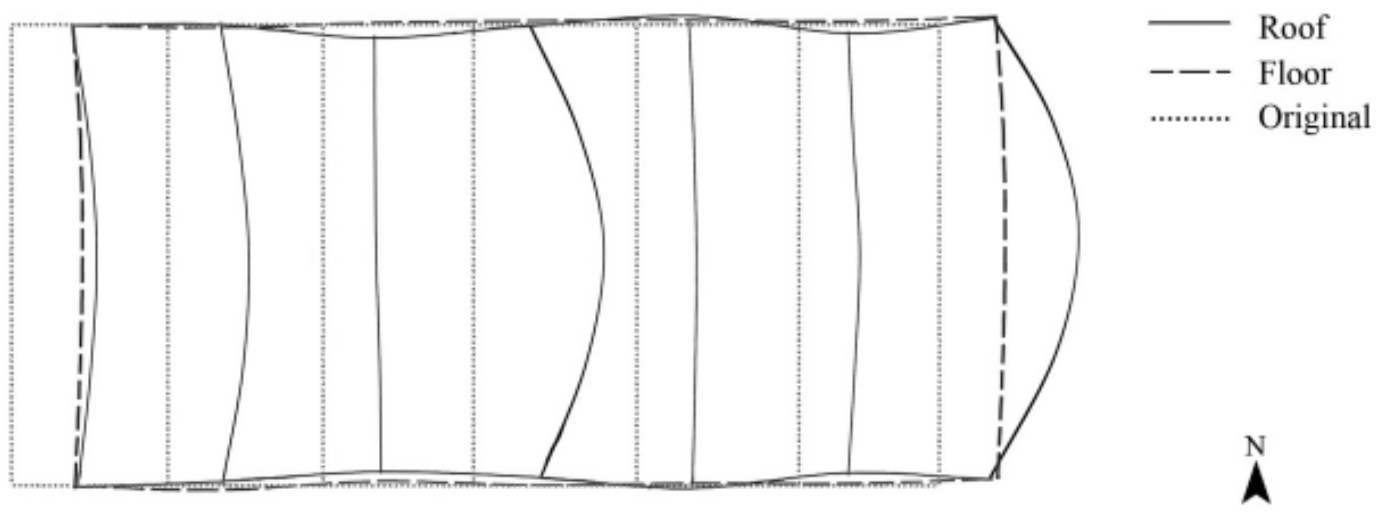

Figure GG: E-W Apparent Mode Shape

Research has been shown that for buildings with diagonal braces as the LFRS, the in-plane flexibility of the floor and roof diaphragms may significantly influence the dynamic behavior of building structures. Specifically for single story steel buildings, the in-plane stiffness of the roof diaphragm are magnitudes smaller than the stiffness of the LFRS (Trembley and Stiemer 1996).

Some major factors that contribute to the flexibility of the diaphragm are warping of the panel, slip of the connections, and the geometry of the steel deck panel (Luttrell 1995). In addition to the diaphragm not being properly attached to the roof gravity beams; on-site inspections lead to speculate that there was no interlocking connection between the 2-ft wide steel deck panels. The roof diaphragm is composed of rigid insulation topped with gravel that is supported by wide flange gravity beams at 8 - $\mathrm{ft}$ on center. To preserve the state of the Bridge House, a non-destructive analytical parametric study was performed in an attempt to estimate the diaphragm stiffness. 
The side lap connection (connector slip parameter) between the panels can significantly influence the diaphragm stiffness. Thus, three types of connections that were investigated. See Figure HH below.

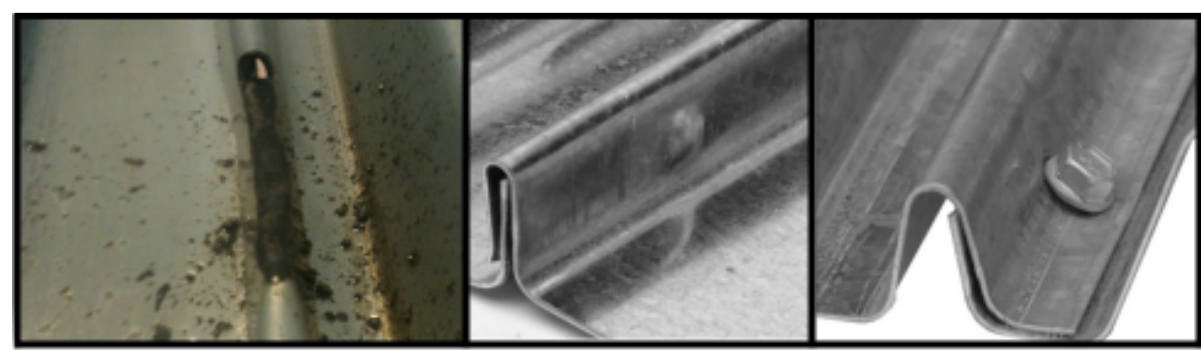

Figure HH: Steel Deck Panel Connections A) Seam Weld B) Button Punch C) Screw

The three different connections evaluated in this parametric study are used in current practice, whereas only the seam weld and button punch was used at the time the Bridge House was built. Equation 23 is provided by the Steel Deck Institute's (SDI) Diaphragm Design Manual to estimate the shear modulus of a steel deck diaphragm:

$$
G^{\prime}=\frac{E t}{2(1+v) \frac{s}{d}+D_{n}+C}
$$

Where $\mathrm{G}^{\prime}$ is the shear modulus defined by Eq.1,

$\mathrm{E}$ is the modulus of elasticity, $\mathrm{t}$ is the base metal thickness, $\mathrm{D}_{\mathrm{n}}$ is the warping constant, $\mathrm{C}$ is the connector slip parameter, $\mathrm{s}$ is the girth of corrugation per rib, $\mathrm{d}$ is the corrugated pitch, and $v$ is Poisson's ratio, 0.3. 
Medhekar and Kennedy (1997) investigated the response of a low rise steel building under seismic ground motion and adapted equation 24 to determine the natural period of a low rise steel building.

$$
\mathrm{T}=2 \pi \sqrt{\frac{\mathrm{K}_{\mathrm{B}}+\mathrm{K}_{\mathrm{D}} \mathrm{W}}{\mathrm{K}_{\mathrm{B}} \mathrm{K}_{\mathrm{D}} \mathrm{g}}}
$$

Where $K_{D}$ is the diaphragm stiffness defined by equation 25 ,

$\mathrm{K}_{\mathrm{B}}$ is the lateral stiffness of the vertical bracing,

$\mathrm{W}$ is the seismic weight, $\mathrm{g}$ is gravity.

With,

$$
\mathrm{K}_{\mathrm{D}}=\frac{\pi^{2}}{\frac{\mathrm{L}^{3}}{\pi^{2} \mathrm{EI}}+\frac{\mathrm{L}}{\mathrm{G}^{\prime} \mathrm{b}}}
$$

Where $\mathrm{L}$ is the length of the diaphragm,

EI is bending stiffness of the diaphragm, $\mathrm{G}^{\prime}$ is the shear modulus of the diaphragm defined by equation 23 , $\mathrm{b}$ is the width of the diaphragm.

Equation 24 accounts for all significant characteristics of low rise steel buildings with flexible roof diaphragms and yields excellent results when compared to more elaborate numerical methods.

Each 2-ft wide deck panel in the Bridge House are 24-ft long and are supported by wide flange beams at $8 \mathrm{ft}$ on center as seen in Figure II below. 


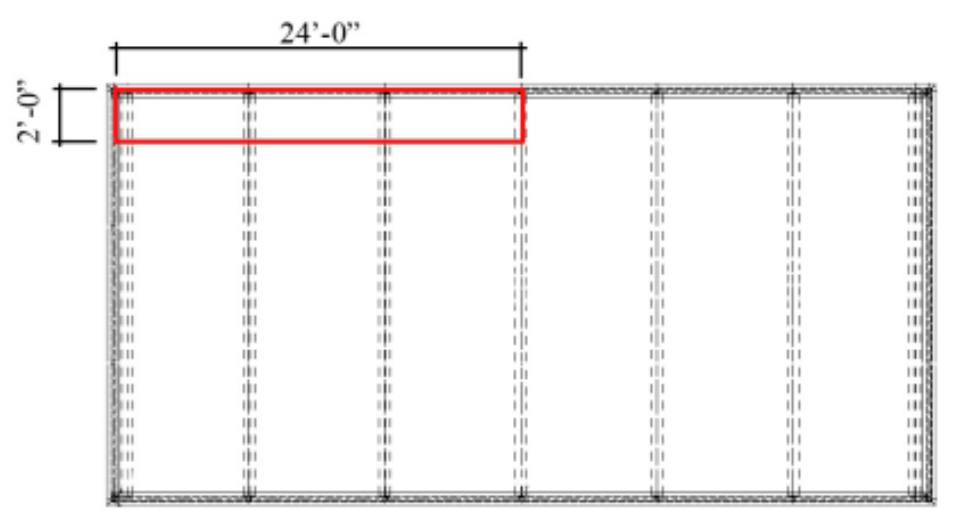

Figure II: Roof Steel Deck Panel Configuration

The shear stiffness of the diaphragm was calculated using equations provided by the Steel Deck Institute (SDI) (Luttrell 1995). Table 7 below is a summary of results using equation 23,24 , and 25 for the three different connection types. Where $\mathrm{G}$ ' is the diaphragm shear modulus, $\mathrm{K}_{\mathrm{D}}$ is the diaphragm stiffness and $\mathrm{f}$ is the natural frequency calculated by taking the inverse of equation 24 .

Table 7: Diaphragm Stiffness and Natural Frequency of the Analytical E-W Mode for Different Connections Types

\begin{tabular}{|c|c|c|c|c|c|c|c|c|c|}
\hline & \multicolumn{3}{|c|}{$\begin{array}{c}\text { Button } \\
\text { Punch }\end{array}$} & \multicolumn{3}{c|}{ Screws } & \multicolumn{3}{c|}{ Welds } \\
\hline $\mathrm{n}_{\mathrm{s}}$ & $\mathrm{G}^{\prime}$ & $\mathrm{K}_{\mathrm{D}}$ & $\mathrm{f}$ & $\mathrm{G}^{\prime}$ & $\mathrm{K}_{\mathrm{D}}$ & $\mathrm{f}$ & $\mathrm{G}^{\prime}$ & $\mathrm{K}_{\mathrm{D}}$ & $\mathrm{f}$ \\
\hline 0 & 27.6 & 543.9 & 11.1 & 27.6 & 543.9 & 11.1 & 27.6 & 543.9 & 11.1 \\
\hline 3 & 28.3 & 557.5 & 11.2 & 34.4 & 676.3 & 11.9 & 43.1 & 847.0 & 12.7 \\
\hline 6 & 29.0 & 571.1 & 11.3 & 40.7 & 799.9 & 12.5 & 56.4 & 1105.7 & 13.6 \\
\hline 9 & 29.7 & 584.6 & 11.3 & 46.6 & 915.5 & 13.0 & 67.8 & 1328.8 & 14.2 \\
\hline 12 & 30.4 & 598.0 & 11.4 & 52.2 & 1023.8 & 13.4 & 77.8 & 1523.4 & 14.6 \\
\hline 16 & 31.3 & 615.7 & 11.5 & 59.0 & 1158.0 & 13.8 & 89.4 & 1747.1 & 15.0 \\
\hline
\end{tabular}

As previously stated, the steel deck sheets are $24 \mathrm{ft}$ long and are supported by gravity beams. The number of side lap connections for this parametric study is located in the far left column of Table 6 , denoted as $n_{s}$. For example, when ns $=3,3$ evenly spaced 
connections per 24-ft panel are considered. In past and current practice it is common to spot weld the steel deck to the steel beams, thus for calculation purposes, spot welds were assumed to be used where the diaphragm was connected to the gravity beams.

As a baseline the experimental natural frequency of the apparent E-W mode was used as reference. From examination of Table 7, as the density of all connections increased, the diaphragm stiffness and the natural frequency of the analytical E-W mode also increased. It was also observed that welded side lap connections provided the most stiffness while button punch connections offered the least. Although all of the results overestimated the experimental natural frequency $(9.10 \mathrm{~Hz})$, a $22 \%$ error arose as a result of assuming there are no connections between the side laps. Note that the parametric study did not account for the additional flexibility from the missing restraints between the steel deck panels and their supporting beams. As previously explained, it was experimentally determined that a portion of the gravity roof beams were fully attached to the metal deck while some were partially attached. In general, test results lead to believe that the steel deck was only welded at each ends of the 24-ft long sections. If the calculations performed per SDI were to account for the current conditions, the stiffness of the diaphragm would have decreased and would have yielded better analytical results.

Three steel deck interlocking connections were evaluated; each connection generated different results for the analytical frequency of the E-W mode. In comparison to the experimentally determined natural frequency of the apparent E-W mode, the analytical results were best when it was assumed that no interlocking connection between the steel deck panels existed. Thus the results of the parametric study lead to believe that 
there is no connection other than friction between the steel deck panels. As a result, the diaphragm provides minimal bending resistance in the E-W direction, and thus behaved flexibly in the apparent E-W mode.

\subsubsection{Temperature Effects}

It was determined through FVT that the Bridge House, a steel structure, is sensitive to increasing surrounding temperatures. During hot weather it was believed that some of the steel elements in the LFRS of the structure elongated and went into compression as a result of deformation compatibility, decreasing the structure's geometric stiffness which in turn affected the dynamic response of the structure. The thermal phenomenon was observed and investigated only in the apparent N-S mode as seen in Figure JJ below.

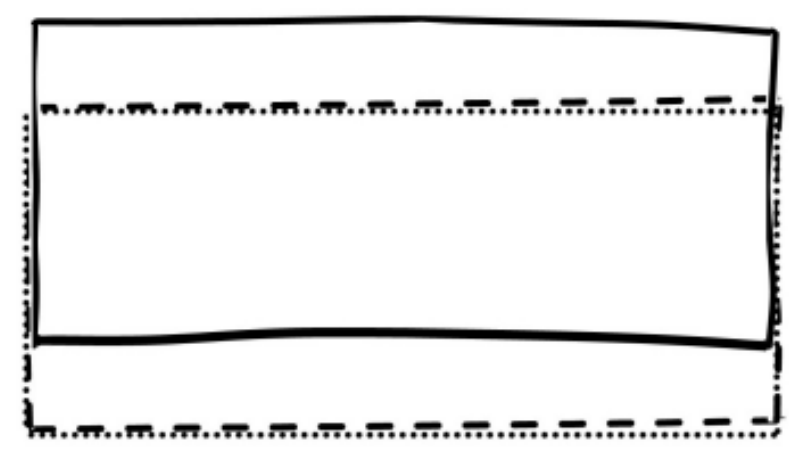

(..... ORIGINAL

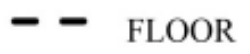

$\longrightarrow$ ROOF

Figure JJ: N-S Experimental Mode Shape

The thermal phenomenon was first observed when the steady state accelerations from the FVT in the apparent N-S mode significantly varied throughout the day. At the time of testing, the sun consistently shined on the S-W end of the structure where as the north face was sheltered by a flock of trees. See Figure KK below. 


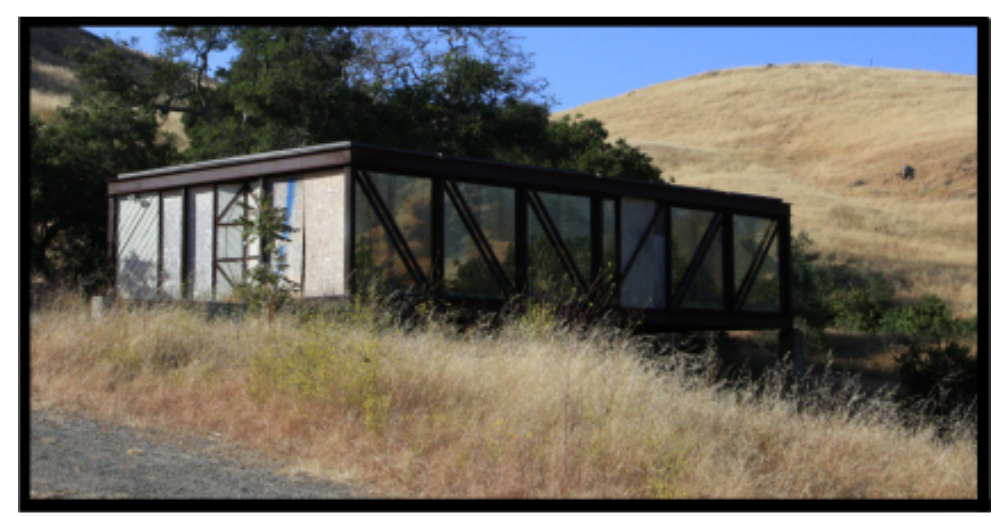

Figure KK: Isometric on Site View of the Bridge House

In the morning, the south face of the Bridge House experienced rapid increase in temperature and as the day progressed, the west end heated up and the south face cooled down. The change in temperature experienced in the west and south faces throughout the day were recorded to be $65^{\circ} \mathrm{F}$. The north and east end of the building were not exposed to the sun, thus the temperature of the steel elements on those faces did not significantly vary. To see the magnitude of this phenomenon, the surface temperature of the structure's west end was monitored and a frequency response curves for two different surface temperatures were created (see Figure LL below). Various steel elements were exposed throughout the day, thus the increase in temperature throughout the Bridge House was non uniform. However, for an explanation of this phenomenon, only the west end of the structure was investigated. 


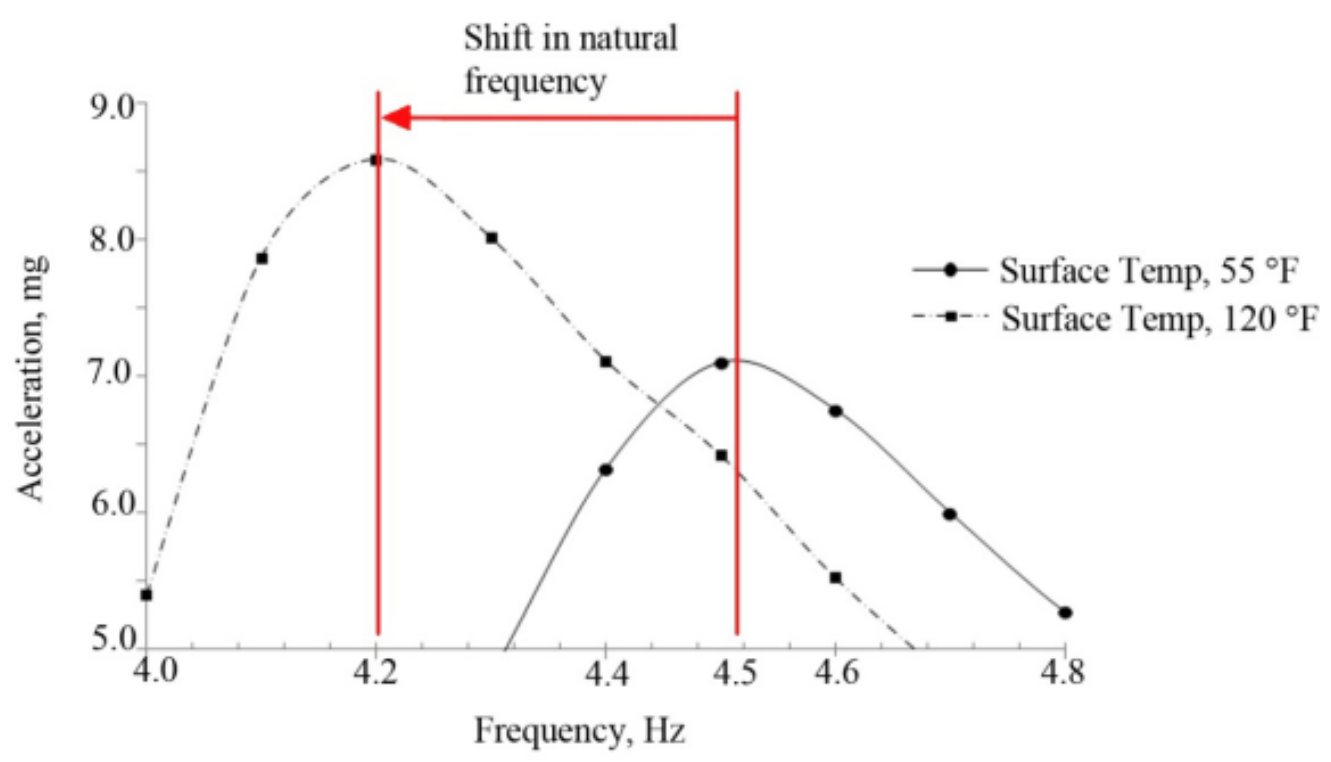

Figure LL: Frequency Response Shift Due to Thermal Phenomena

When the surface temperature of the west end was at about $55^{\circ} \mathrm{F}$ the natural frequency of the apparent N-S mode was at about 4.5 Hz and when the temperature increased to a temperature of $120^{\circ} \mathrm{F}$, the natural frequency dropped to about $4.2 \mathrm{~Hz}$, a 7 $\%$ decrease.

Figure MM below contains a multitude of frequency response curves that were created throughout the day, summarizing the results of the steel surface temperature vs. the natural frequency of the apparent N-S mode. 


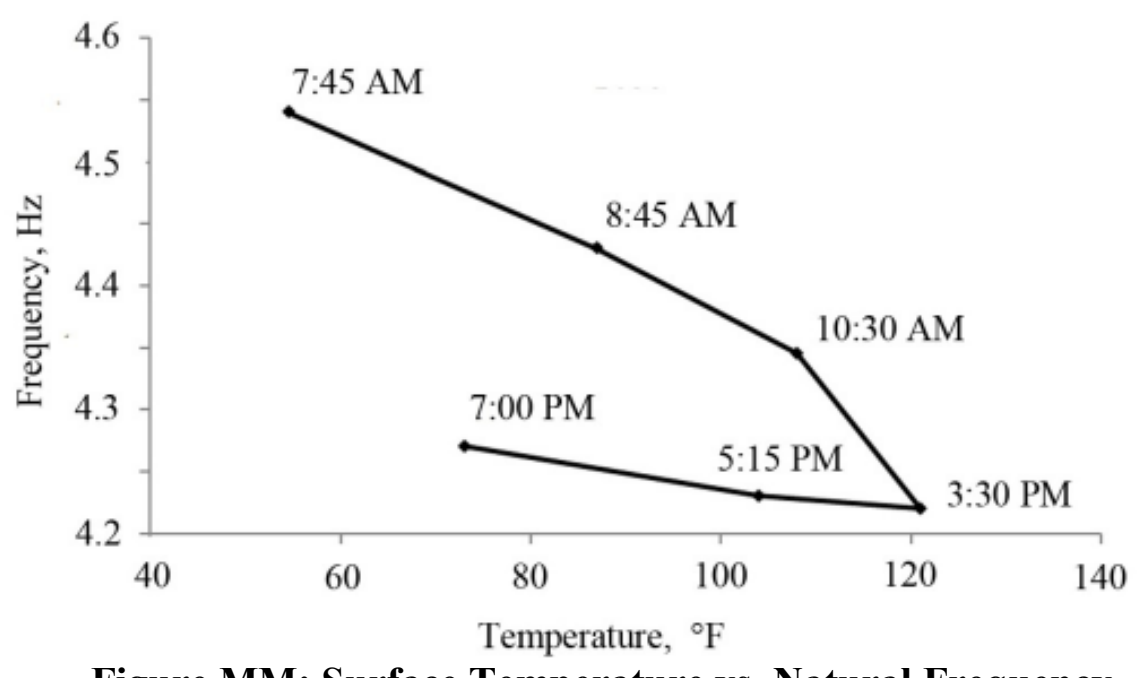

Figure MM: Surface Temperature vs. Natural Frequency

At a surface temperature of about $55^{\circ} \mathrm{F}$, the natural frequency of the apparent $\mathrm{N}-\mathrm{S}$ mode was about $4.5 \mathrm{~Hz}$ and from there on, the frequency decreased as the surface temperature increased. The frequency reached a minimum of $4.2 \mathrm{~Hz}$ when the surface temperature reached a maximum of $120^{\circ} \mathrm{F}$. After a peak temperature of $120^{\circ} \mathrm{F}$, the natural frequency began to gradually climb back up. Although Figure MM contains an 11-hour range of data, the natural frequency did not return to $4.5 \mathrm{~Hz}$. However, FTVs performed the following morning confirmed that the frequency was back to $4.5 \mathrm{~Hz}$.

To further investigate this phenomenon, an analytical model was created where a similar temperature change as in Figure MM was applied to the west end of the structure. The deflected shape of the structure as a result of the temperature loading along with the temperature induced compression stresses was illustrated on Figure NN below. 


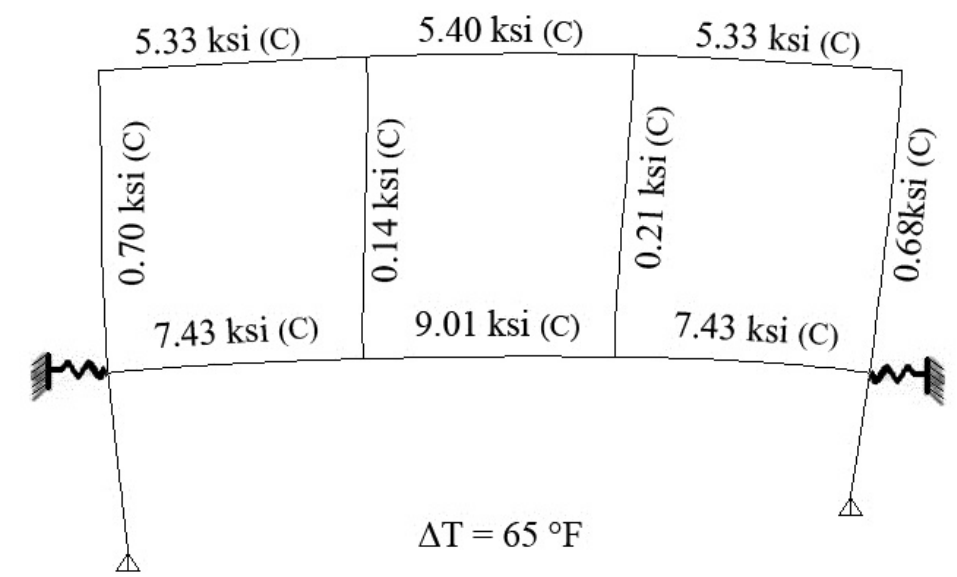

Figure NN: Compression Stresses Due to Thermal Expansion

To simulate the experimental results, a thermal load of a $65^{\circ} \mathrm{F}$ temperature change was applied to the columns and girders on the structures west end. As the structure heats up, the steel elements in Figure NN want to naturally expand against the structure and its supports, inducing compression stresses in the floor and roof beams up to $20 \%$ of the yield stress. Similar to a P-delta effect, the flexural stiffness of the members in Figure NN decreased, causing the natural frequency to also decrease. To observe the participation of the thermally affected steel elements in the N-S mode, an elevation view of the analytical N-S mode was provided in Figure OO below.

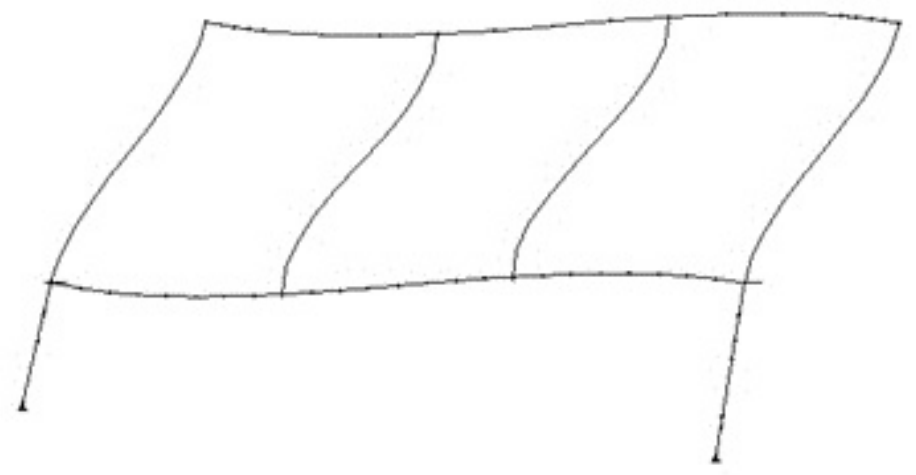

Figure OO: East Elevation of First N-S Analytical Mode Shape 
Since the mass of the structure was unchanged the stiffness of the structure must have decreased. Globally, as the temperature increased, the steel in the Bridge House wanted to naturally expand; however, boundary conditions restrained the elements from expanding thus resulting in compression. In the case of the apparent N-S mode, the Pdelta effect caused the flexural stiffness in the N-S direction to decrease, thus also decreasing the natural frequency. This phenomenon was determined to only affect the frequency of the apparent N-S mode. However, in order to globally understand the thermal phenomenon, other modes should be evaluated to determine if other modes are more, equally, or less affected. To better understand why the natural frequency is sensitive as the temperature of the structure increases and insensitive as the temperature decreases, additional research is recommended.

\subsubsection{Vertical Anomaly on the Floor Diaphragm in First N-S Mode}

The building was excited in the N-S direction; however, a vertical anomaly on the floor diaphragm was consistently detected in the apparent N-S mode. Although the primary motion of the building was N-S, significant vertical accelerations were evident on the east end of the floor diaphragm. An isometric view of the vertical mass normalized floor accelerations can be seen in Figure PP below. 


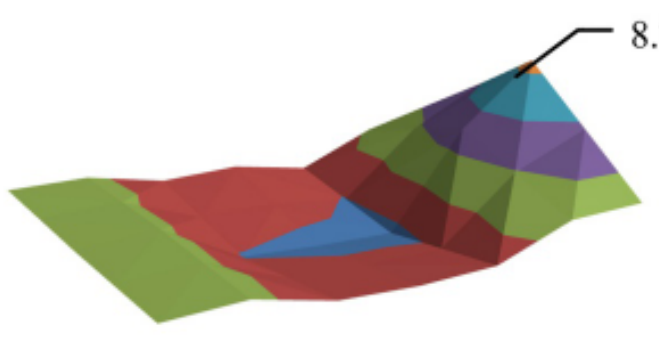

3 Lbs Force
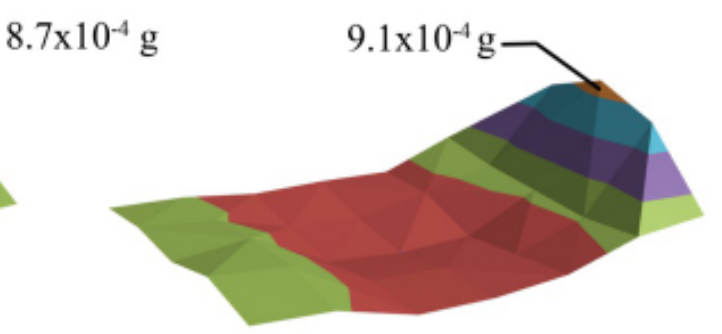

$\underline{30 \text { Lbs Force }}$

Figure PP: Mass Normalized Vertical Floor Accelerations of the N-S Mode

One test utilized a 30-1b force whereas the second test used a 3-lb force. The 3-1b force test was established to examine if the 3-lb force was small enough to effectively excite the structure without overcoming friction of the possible detached floor. The steady state accelerations of the $3-1 b$ test were $90 \%$ smaller than the results of the $30-1 b$ test; however, the global results of both tests were similar due to mass normalization.

The flexibility of the east end of the floor experienced a mass normalized acceleration of $9.1 \times 10^{-4} \mathrm{~g}, 1.6$ times more than the normalized translational accelerations of the floor as seen in Figure QQ below.

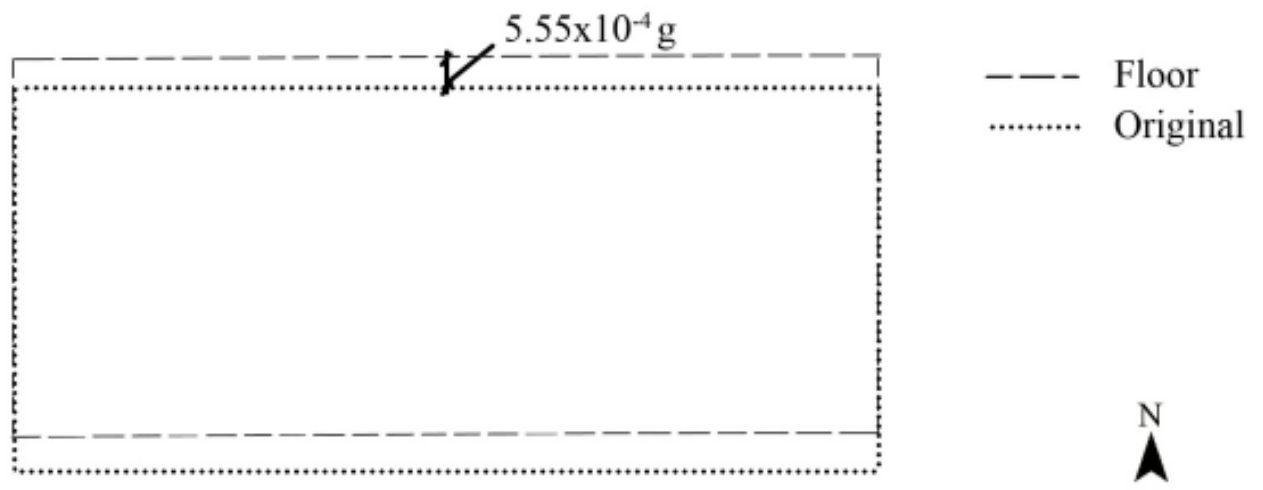

Figure QQ: Mass Normalized Translational Floor Accelerations of the N-S Mode 
The vertical accelerations observed are clearly from the contribution of another mode. It is unknown as to why such a large vertical response is generated from excitement of the structure in the N-S direction; however, it is reasonable to conclude that from the FVT results, there is a lack of connection between the floor diaphragm and the girder on the east end, causing the floor girder to thrust the floor diaphragm upward.

\subsubsection{Foundation Flexibility}

Experimental results suggest that foundation flexibility was an important component of most of the apparent mode shapes. The foundations are 18- in x 18-in concrete piers bearing on $4.5-\mathrm{ft}$ x 4.5 -ft concrete pads. All four foundation piers are different in length as seen in Figure RR on below.
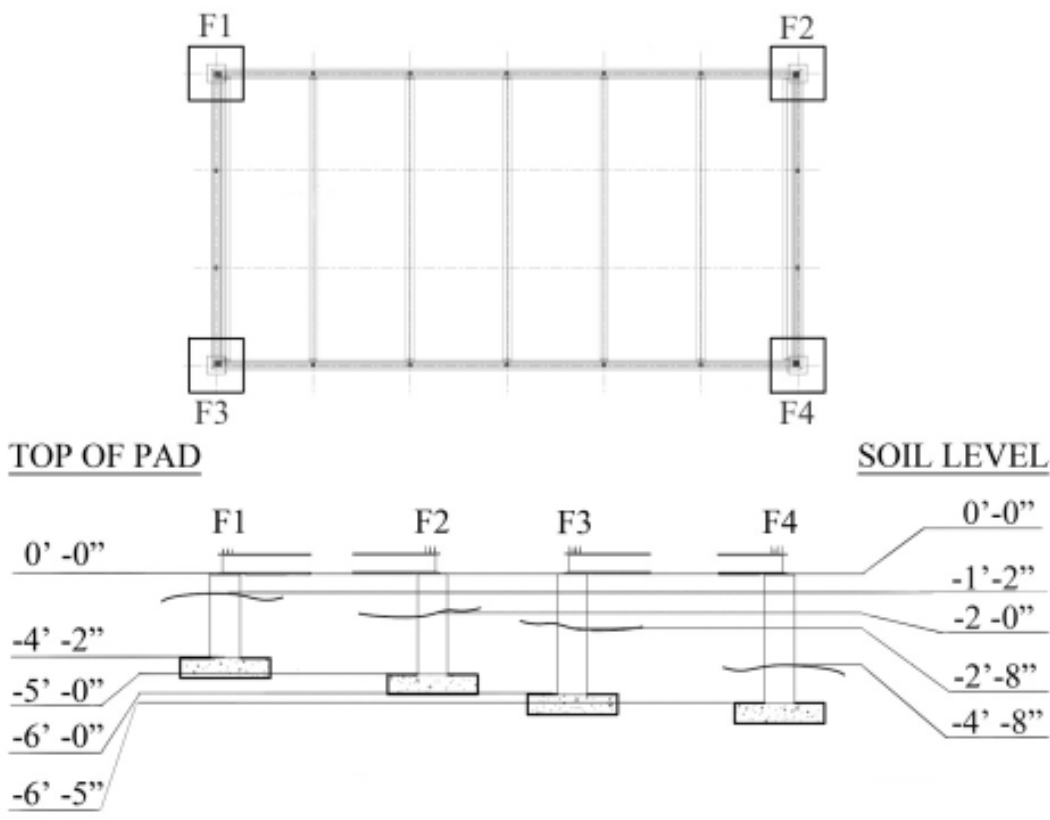

Figure RR: Configuration of Concrete Foundation Piers 
The pier denoted as F1 in Figure RR is almost completely embedded in the soil, whereas F4 is almost completely exposed. The concrete piers are believed to be similar to a cantilever beam where the stiffness of a pier is a function of its length. As a result, the different pier heights would generate different lateral stiffness. Typically torsion arises when a variation of stiffness occurs; however, the FVT results proved otherwise. By examining the apparent mode shapes, it was reasonable to conclude that the soil bearing against and on the concrete piers was not sufficient to engage the piers in bending, causing concrete piers to rock in the apparent N-S and E-W mode. To illustrate the motion of the foundations in the apparent N-S mode, Figure SS below provides the mass normalized floor accelerations.

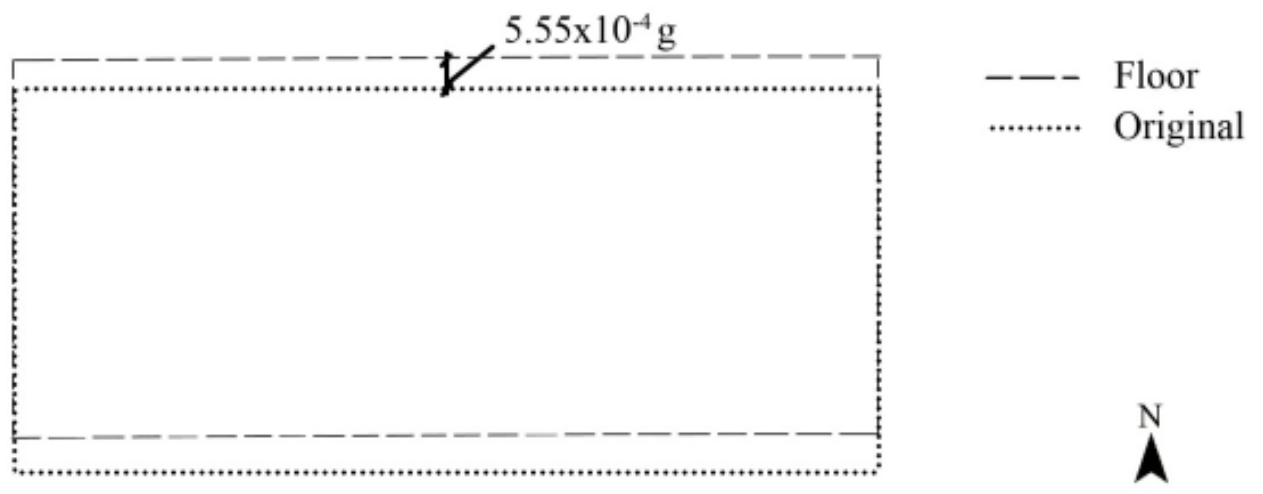

\section{Figure SS: Mass Normalized Translational Floor} Accelerations of the N-S Mode Shape

The Bridge House was experimentally determined to be pin connected to the foundations. Thus, due to deformation compatibility, if the floor was moving, so were the foundations. To illustrate the motion of the foundations in the apparent E-W mode, Figure TT below provides the mass normalized floor accelerations. 


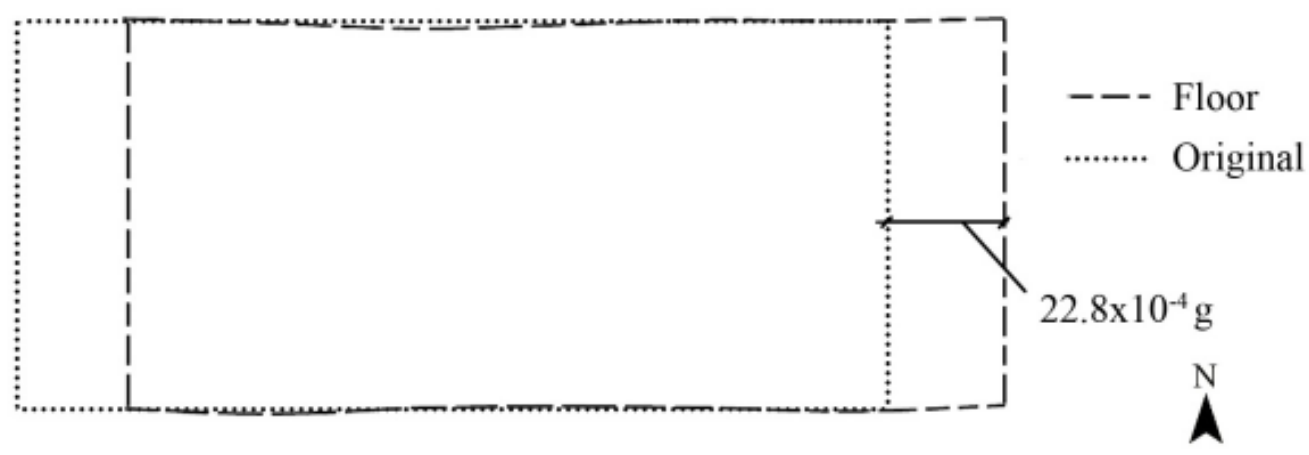

Figure TT: Mass Normalized Translational Floor Accelerations of the E-W Mode Shape

The apparent E-W mode was composed of translational E-W motion in combination with significant roof vertical accelerations. The lateral stiffness of the LFRS in the N-S direction is considerably less than the lateral stiffness of the foundations/soil whereas on the other hand, the LFRS in the E-W direction is considerably larger. Thus as a result, the floor in the apparent E-W mode laterally accelerated about 4 times more than in the apparent N-S mode. To complete the illustration of the motion of the foundations in three orthogonal directions, Figure UU below exhibits the mass normalized translational floor accelerations of the $1^{\text {st }}$ apparent vertical mode.

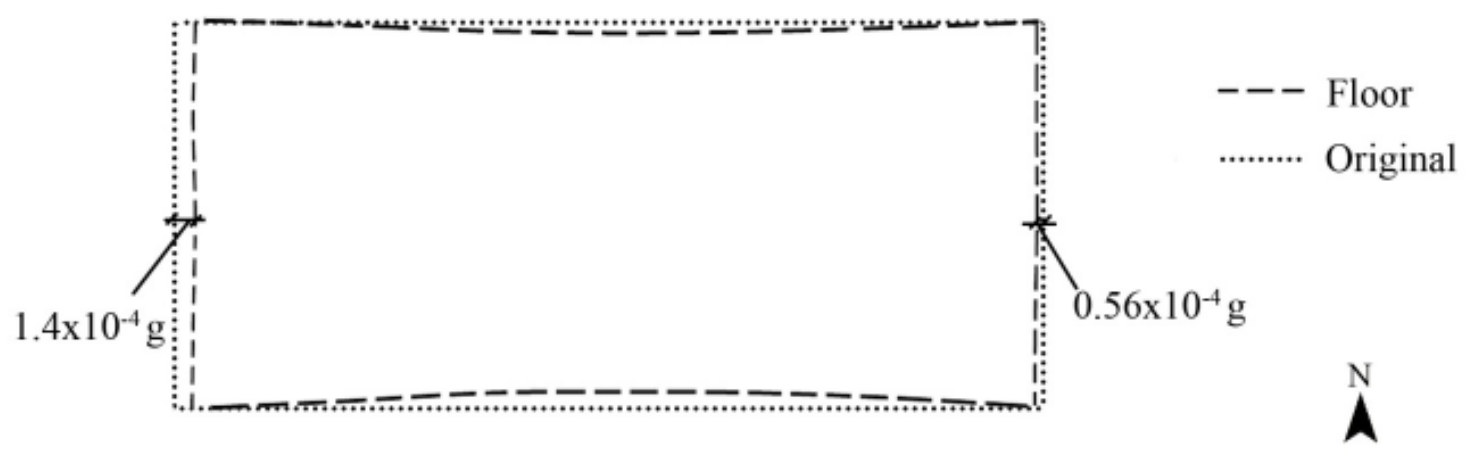

Figure UU: Mass Normalized Translational Floor Accelerations for the First Vertical Mode Shape 
The $1^{\text {st }}$ apparent vertical mode was dominated by in-phase out-of-plane motion of the floor and roof diaphragm. Although predominantly was a vertical mode, the piers slightly experienced lateral accelerations; however, they were not as significant as in the apparent E-W and N-S mode.

The three mode shapes in Figure SS, TT and UU were illustrated to highlight the lateral response of the concrete piers in three orthogonal apparent mode shapes.

Foundation flexibility can be observed in all three figures, thus it is reasonable to conclude that foundation flexibility played an important role in the dynamic behavior of the Bridge House. 


\subsection{ANALYTICAL BASIS}

The second part of this project was to develop an analytical model that accurately captured the dynamic behavior of the Bridge House utilizing a methodology known as system identification. System identification is an effective tool used to develop analytical models from experimental data. Test-validated analytical models can stimulate the understanding of real dynamic behavior, thereby creating an improved understanding of the assumptions used in the analysis and design of a structure.

The original construction documents were not readily available. However the structure is in an exposed condition, thus most of the modeling decisions were based on what was physically seen in the structure. An essential component in the development of the computational model was estimating the mass of the structure. Not having a good estimation of the mass can result in significant inaccuracy of the modal parameters in the computational model.

The intention of the analytical modeling process is to begin with a simple hand analysis and end with a complex computational model, focusing on the refinement of the computational model based on comparisons with experimental results.

\subsection{Progression of Analytical Modeling}

Translational modes and vertical modes are two distinct dynamic responses, thus the progression of the analytical modeling was divided into 2 sections. The first section elaborated on the translational modes, while the $2^{\text {nd }}$ elaborated on the vertical modes. 
Note that for the computational model, the mass of the roof and floor was evenly distributed throughout both diaphragms. However, the existing window assemblies create concentrated line masses along the perimeter of the floor. As a result, the rotational inertia of the floor was underestimated, resulting in a smaller natural frequency. Capturing the rotational mode was far beyond simply being within the range of the experimentally determined natural frequency; discrepancies in the mode shapes indicate that the structure's rotational stiffness is too low and that there are significant vertical accelerations in the experimental results not being captured by the computational model. Due to the limited scope of this thesis, the rotational mode was excluded from this portion of the thesis. The rotational mode is considered relatively insignificant in comparison to the rest of the modes; however, for completeness the results were still reported.

\subsubsection{Translational Modes}

The first attempt in trying to analytically model the Bridge House was done by performing a simple hand analysis assuming a rigid roof diaphragm with a fixed base as seen in Figure VV below.

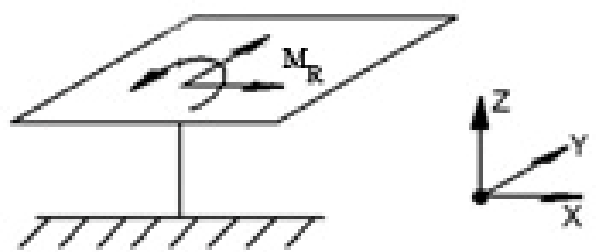

Figure VV: Lumped Mass Rigid Diaphragm Mode

(Rendon) 
The frequency results for the hand analysis assuming a rigid diaphragm were 4.97 $\mathrm{Hz}$ for the $\mathrm{N}-\mathrm{S}$ mode and $18.09 \mathrm{~Hz}$ for the E-W mode. Comparison to the experimental results, shows a percent error of $11.68 \%$ and $98.80 \%$, respectively. Experimental results in Table 4 on page 43 for the N-S and E-W apparent modes indicate that the roof diaphragm behaves nearly rigid in the apparent N-S mode and flexible in the apparent EW mode. Thus, use of the rigid diaphragm assumption can lead to an overestimation of the natural frequency. Because diaphragm flexibility in low rise steel structures can significantly decrease the natural frequency of a structure, a flexible diaphragm was incorporated into the following computational model shown in Figure WW below.

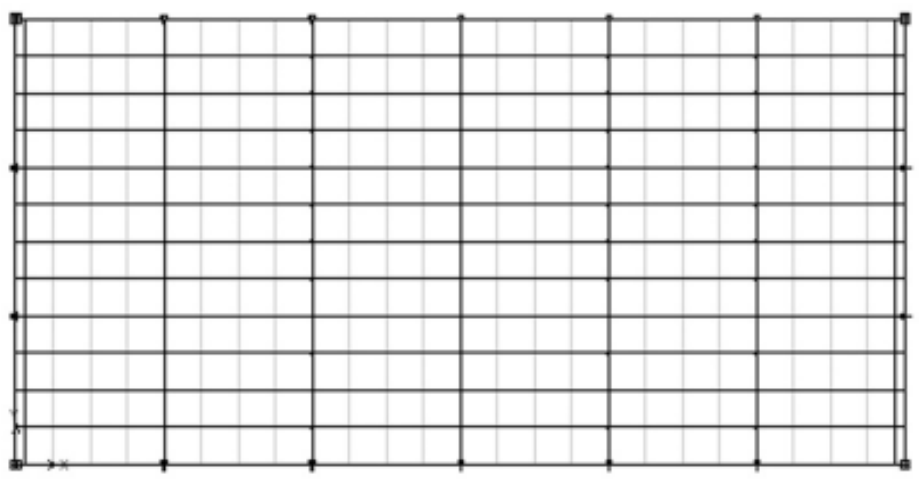

Figure WW: Flexible Roof Diaphragm

The intent of the flexible diaphragm was to replicate the experimental results in the apparent E-W mode. A fine mesh of out-of-plane elements in combination with the roof gravity beams was used to generate the roof diaphragm as seen in Figure WW. The thickness of the out-of-plane elements were calibrated to match the calculated mid span deflection of a simply supported corrugated steel deck. Table 8 below is a summary of the analytical results for a computational model with a flexible diaphragm. 
Table 8: Flexible Roof Diaphragm vs. Experimental Results

\begin{tabular}{|l|c|c|c|}
\hline & N-S Mode & E-W Mode & Rotational Mode \\
\hline Analytical Frequency & $3.58 \mathrm{~Hz}$ & $6.13 \mathrm{~Hz}$ & $5.27 \mathrm{~Hz}$ \\
\hline Experimental Frequency & $4.45 \mathrm{~Hz}$ & $9.10 \mathrm{~Hz}$ & $10.70 \mathrm{~Hz}$ \\
\hline Percent Difference & $-19.60 \%$ & $-32.60 \%$ & $-50.75 \%$ \\
\hline
\end{tabular}

As previously mentioned, the in-plane flexibility of a diaphragm can significantly decrease the natural frequency of the structure. A simple change of the diaphragm from rigid to flexible caused the frequency in the N-S direction to drop to $3.58 \mathrm{~Hz}$ and $6.13 \mathrm{~Hz}$ in the E-W direction, a $28 \%$ and $66 \%$ decrease from the previous model, respectively. The analytical and experimental mode shape can be seen in Figure XX below.
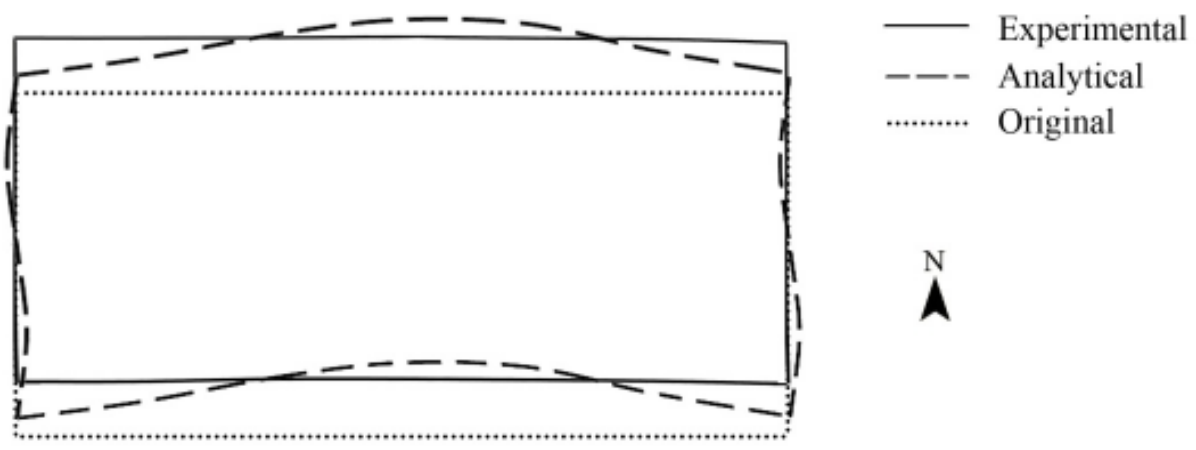

Figure XX: Experimental vs. Analytical N-S Roof Mode Shape

Experimental results illustrated that the roof diaphragm was nearly rigid in the apparent N-S mode. However, the analytical model resulted in an overly flexible diaphragm. To increase the N-S in-plane stiffness, in-plane stiffness elements were integrated to create a hybrid diaphragm as seen Figure YY below. 


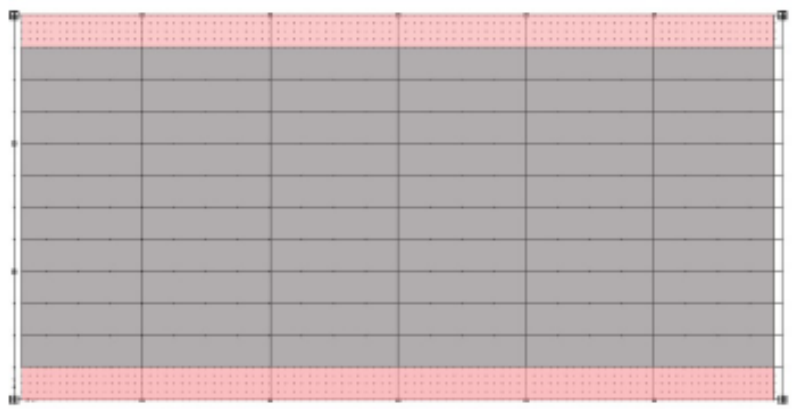

In-plane stiffness element

Out of plane stiffness element

Figure YY: Hybrid Roof Diaphragm

It was experimentally determined that the diaphragm was not entirely fastened to the gravity beams, and a parametric study concluded that the steel deck panels were simply overlapped with no physical connection; however, some stiffness in the N-S direction is provided by the individual panels that are connected to the beams. To incorporate the in-plane stiffness of the N-S direction while preserving the flexibility in the E-W, in-plane stiffness elements were incorporated into the longitudinal perimeter of the diaphragm as seen in Figure YY. The results of the hybrid diaphragm are summarized below in Table 9 below.

Table 9: Hybrid Roof Diaphragm vs. Experimental Results

\begin{tabular}{|l|c|c|c|}
\hline & N-S Mode & E-W Mode & Rotational Mode \\
\hline Analytical Frequency & $4.41 \mathrm{~Hz}$ & $10.56 \mathrm{~Hz}$ & $7.65 \mathrm{~Hz}$ \\
\hline Experimental Frequency & $4.45 \mathrm{~Hz}$ & $9.10 \mathrm{~Hz}$ & $10.70 \mathrm{~Hz}$ \\
\hline Percent Difference & $0.90 \%$ & $16.04 \%$ & $28.50 \%$ \\
\hline
\end{tabular}

Applying in-plane stiffness elements to the longitudinal perimeter of the structure increases the diaphragm's in-plane stiffness in both directions, resulting in a frequency of 4.41 Hz in the N-S direction and $10.56 \mathrm{~Hz}$ in the E-W direction, a $23 \%$ and $72 \%$ increase from the previous model, respectively. When compared to the experimentally determined 
frequencies, the analytical model yields a percent error of $0.90 \%$ for the N-S mode and $16.04 \%$ for the E-W mode. The analytical and experimental N-S mode shape can be seen in Figure ZZ below.

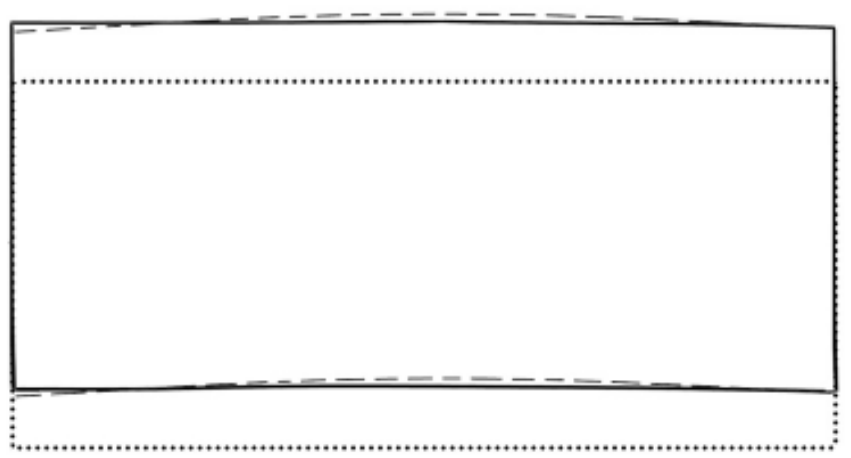

- Experimental

- - - Analytical

Original

Figure ZZ: Experimental vs. Analytical N-S Roof Mode Shape

The increase of the diaphragm's in-plane stiffness is evident in Figure ZZ resulting in a much improved correlation between the analytical and experimental results. Creating a hybrid diaphragm allows for flexibility in the E-W direction while maintaining the in-plane stiffness in the N-S direction. The analytical and experimental E-W mode shape can be seen in Figure AAA below.

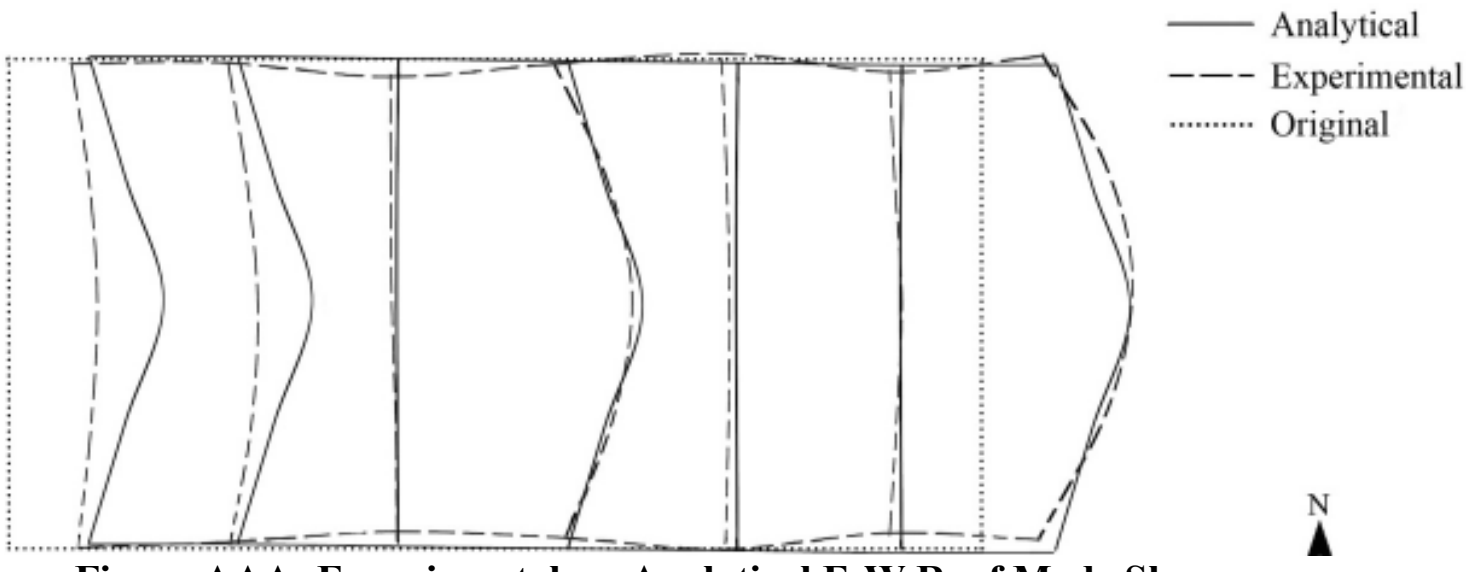

Figure AAA: Experimental vs. Analytical E-W Roof Mode Shape 
In Figure AAA the roof diaphragm in the E-W mode can be seen to behave as a flexible diaphragm; and therefore, also demonstrates a good correlation with the experimental results. Note that the beams were included in Figure AAA since the beams that were experimentally determined to be unattached were also released from the diaphragm. Although the roof diaphragm shows a good correlation with experimental results in both N-S and E-W directions, the foundation flexibility visibly seen in the experimental results is not included in this model.

Experimental results indicated that foundation flexibility was present in every apparent mode, particularly in the apparent E-W mode. In an attempt to analytically model the flexibility in the foundations the fixed restraints were replaced with soil springs as seen in Figure BBB below.

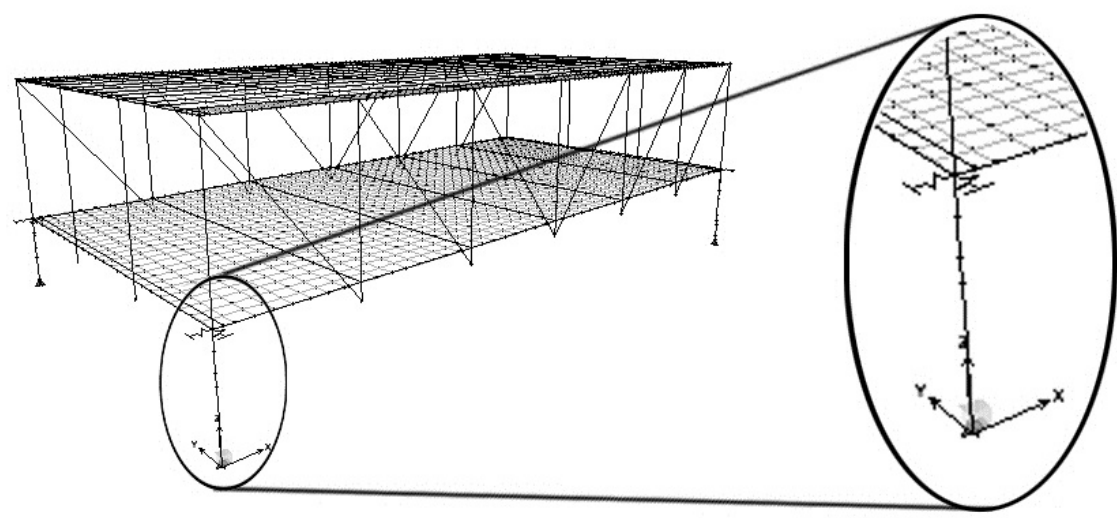

Figure BBB: Analytical Model with Foundation Flexibility

The soil springs were calibrated to have stiffness of $130 \mathrm{k} / \mathrm{in}, 2$ times more than the theoretically calculated stiffness in section 1.5. Although the maximum soil spring stiffness is larger than what was theoretically calculated, unknown soil and foundation 
conditions can significantly alter the soil spring stiffness defined in equation 5 on page 19.

The average height of the piers was referenced from the original construction drawings that were created in the early 1960's. In 2011, the Bridge House senior project team (Rehabilitation 2011) confirmed that portions of the structure were not constructed in accordance with the original construction drawings. For example, braces on the short ends of the building were shown in the plan but were never installed. Thus it is possible that there is discrepancy between the foundation piers shown in the drawings and the onsite conditions.

Three variables that can alter the soil spring stiffness are the modulus of subgrade, average pier height, and the width of the concrete pads that support the concrete piers. In order to obtain an accurate value for the soil's modulus of subgrade, an in depth soil investigation would have to be performed. However, based on good computational results, an analytical soil spring stiffness of $130 \mathrm{k} / \mathrm{in}$ is considered ideal. In order to generate a stiffness of $130 \mathrm{k} / \mathrm{in}$, the modulus of subgrade reaction would have to be two times more than the maximum textbook value of $65 \mathrm{k} / \mathrm{ft}^{3}$ (see section 1.5 ), a scenario that is quite unlikely. Another unknown variable that can alter the soil spring stiffness is the average pier heights. While preserving a modulus of subgrade reaction of $65 \mathrm{k} / \mathrm{ft}^{3}$, the average pier height would have to decrease from 5-ft-9-in to about 4-ft- 0 -in to obtain the ideal soil spring stiffness, a scenario that is more likely. Lastly, dimensions of the existing concrete pads also have an effect on the soil spring stiffness. The original construction plans specify that the concrete pads are 4-ft-6-in wide; however, while also 
preserving a modulus of subgrade reaction of $65 \mathrm{k} / \mathrm{ft}^{3}$, a soil spring stiffness of $130 \mathrm{k} /$ in can also be achieved if the pads are 1 foot wider than specified per plan.

Considering the uncertainty of both the onsite conditions and what is specified on the construction plans, a stiffness of $130 \mathrm{k} /$ in for an analytical soil spring is feasible. Table 8 is a summary of the results from the dynamic analysis that incorporate the soil springs in the analytical model. The results of the hybrid diaphragm with foundation flexibility are summarized below in Table 10.

Table 10: Hybrid Diaphragm Model with Foundation Flexibility vs. Experimental Results

\begin{tabular}{|l|c|c|c|}
\hline & $\mathrm{N}-\mathrm{S}$ & E-W & Rotational \\
\hline Analytical & $3.76 \mathrm{~Hz}$ & $8.08 \mathrm{~Hz}$ & $6.49 \mathrm{~Hz}$ \\
\hline Experimental & $4.45 \mathrm{~Hz}$ & $9.10 \mathrm{~Hz}$ & $10.70 \mathrm{~Hz}$ \\
\hline Percent Difference & $15.52 \%$ & $11.16 \%$ & $39.31 \%$ \\
\hline
\end{tabular}

Applying the soil springs increased the overall lateral flexibility of the structure. The natural frequency in the N-S mode decreased to $3.76 \mathrm{~Hz}$, while the E-W mode decreased to $8.08 \mathrm{~Hz}$, a $15.52 \%$ error and an $11.16 \%$ error, respectively. Although the frequency dropped unfavorably, some additional stiffness that has been unaccounted for can be included to attempt to increase the frequency in both directions.

It was concluded that the 2-ft wide corrugated steel deck panels did not have any interlocking connection. However, some frictional restraint does exist, resulting from the weight the steel deck supports in combination with the settlement of the rigid insulation between the panels through time. To model the friction, beam elements with an exceptionally small cross sectional area were used to serve as diagonal bracing within the 
diaphragm. The intention of the diagonal bracing was to slightly increase the in-plane stiffness of the diaphragm and improve the correlation between the analytical and experimental results. Figure $\mathrm{CCC}$ below is a plan view of the analytical model that incorporates diagonal bracing in the roof diaphragm.

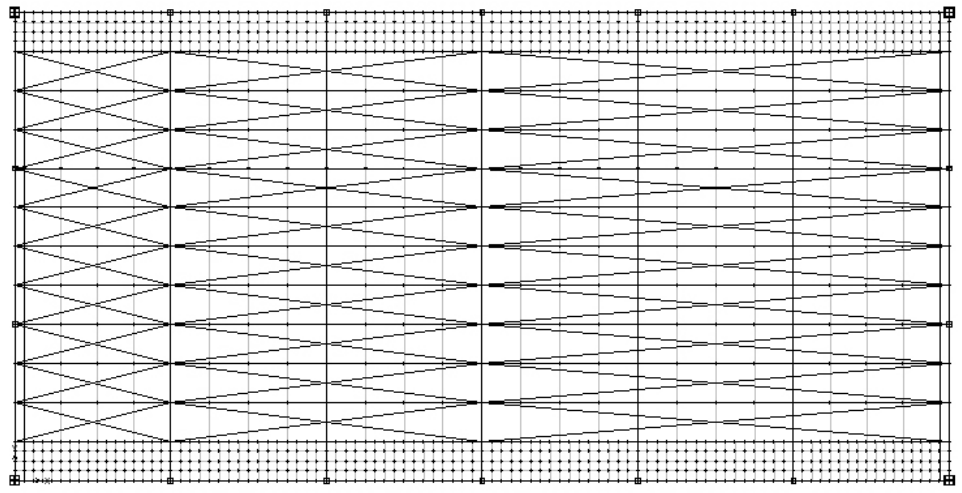

Figure CCC: Flexible Roof Diaphragm Model with Diagonal Bracing

The cross bracing spanned through the beams that were experimentally determined to be un-attached to the steel deck. For example, beams 5 and 6 numbered from left to right in Figure AAA on page 73 were experimentally determined to be free of any connection to the diaphragm. Thus, just like the steel deck, the diagonal bracing also spanned over beams 5 and 6 . Table 11 below summarizes the results of the hybrid diaphragm model with diagonal braces and foundation flexibility.

Table 11: Flexible Roof Diaphragm Model with Diagonal Bracing vs. Experimental Results

\begin{tabular}{|l|c|c|c|}
\hline & $\mathrm{N}-\mathrm{S}$ & $\mathrm{E}-\mathrm{W}$ & Rotational \\
\hline Analytical & $4.10 \mathrm{~Hz}$ & $8.20 \mathrm{~Hz}$ & $7.38 \mathrm{~Hz}$ \\
\hline Experimental & $4.45 \mathrm{~Hz}$ & $9.10 \mathrm{~Hz}$ & $10.70 \mathrm{~Hz}$ \\
\hline Percent Difference & $7.86 \%$ & $9.89 \%$ & $31.02 \%$ \\
\hline
\end{tabular}


Applying the diagonal bracing in the roof diaphragm enhanced the overall lateral in-plane stiffness of the diaphragm. The results can be seen in Table 11 above. Both the natural frequencies of the N-S and E-W mode increased, resulting in an improved correlation between the experimental and analytical results. The natural frequency of the analytical N-S mode was $7.86 \%$ different, while the E-W mode was $9.89 \%$ different.

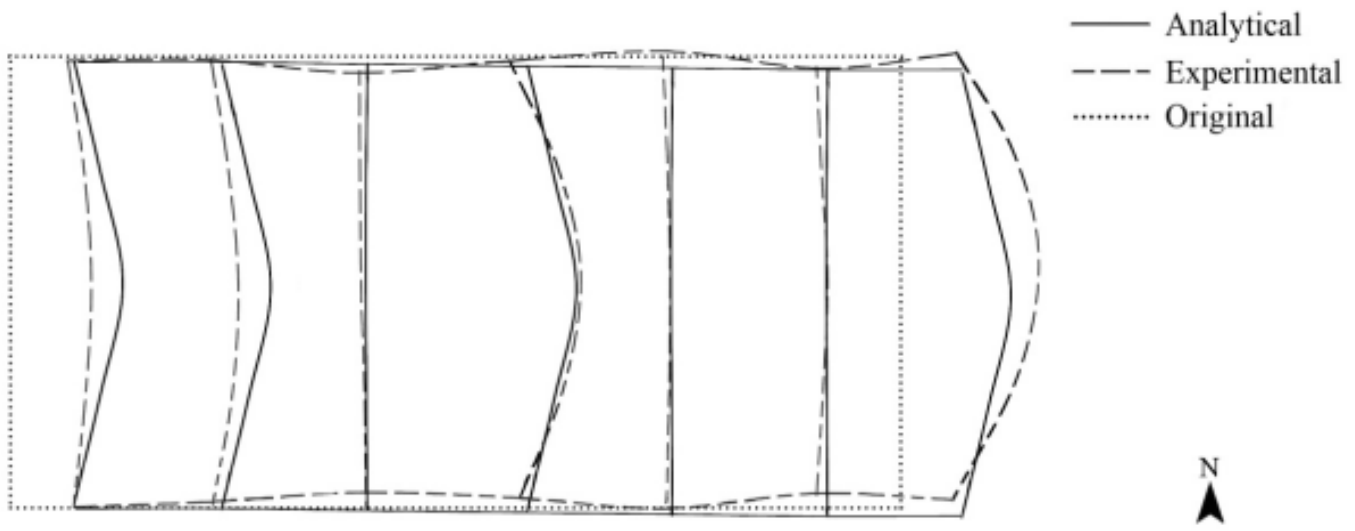

Figure DDD: Experimental vs. Analytical Flexible Roof Diaphragm Model with Diagonal Bracing

Although the discrepancies are quite obvious in Figure DDD, the correlation between the experimental and analytical results has improved. When compared to the previous analytical model, the flexibility on the east end of the building has been reduced. Stiffening the diaphragm also improved natural frequency for both the N-S and E-W mode shapes.

Although the rotational mode was not discussed in detail in this thesis, Figure EEE below illustrates the analytical and experimental mode shapes. 


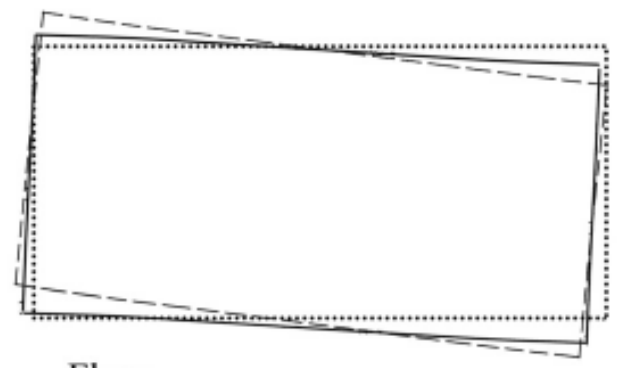

Floor

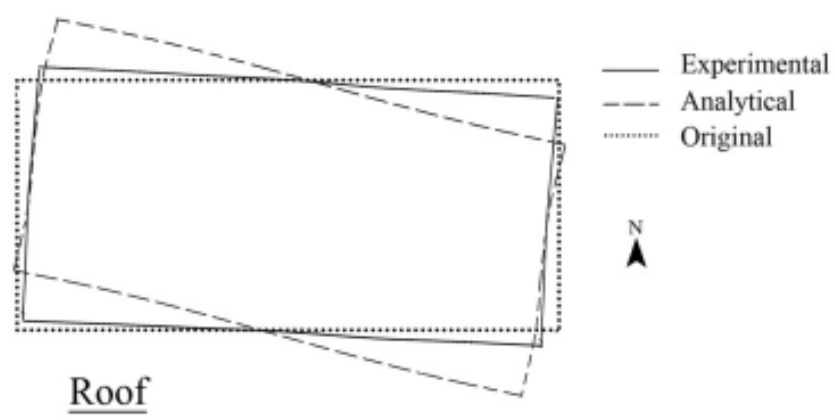

Figure EEE: Analytical vs. Experimental Rotational Mode

As previously mentioned, capturing the rotational mode was far beyond simply being within the range of the experimentally determined natural frequency; discrepancies in the mode shapes indicate that the structure's rotational stiffness is too low and that there are significant vertical accelerations in the experimental results not being captured by the computational model. As a result the correlation between the analytical and experimental results is approximately zero.

There are many abnormalities in this structure. However, when compared to the experimental results, the analytical model that incorporated the diagonal braces in the roof diaphragm yielded the best results.

\subsubsection{Vertical Modes}

The Bridge House is a bridge structure, thus there were vertical modes that were experimentally captured. As previously mentioned, there were a total of 6 vertical modes. Utilizing the same analytical model that included the diagonal braces, a summary of analytical results are compared to the experimental results in Table 12 below. 
Table 12: Analytical Vertical Modes vs. Experimental Vertical Modes

\begin{tabular}{|c|c|c|c|c|c|c|}
\hline & $\begin{array}{c}1 \mathrm{st} \\
\text { Vertical }\end{array}$ & $\begin{array}{c}2 \mathrm{nd} \\
\text { Vertical }\end{array}$ & $\begin{array}{c}3 \mathrm{rd} \\
\text { Vertical }\end{array}$ & $\begin{array}{c}4 \text { th } \\
\text { Vertical }\end{array}$ & $\begin{array}{c}5 \text { th } \\
\text { Vertical }\end{array}$ & $\begin{array}{c}6 \text { th } \\
\text { Vertical }\end{array}$ \\
\hline $\begin{array}{c}\text { Model } \\
\text { Frequency }\end{array}$ & $5.09 \mathrm{~Hz}$ & $5.50 \mathrm{~Hz}$ & $\mathrm{~N} / \mathrm{A}$ & $6.74 \mathrm{~Hz}$ & N/A & $9.30 \mathrm{~Hz}$ \\
\hline $\begin{array}{c}\text { Experimental } \\
\text { Frequency }\end{array}$ & $5.33 \mathrm{~Hz}$ & $5.91 \mathrm{~Hz}$ & $6.60 \mathrm{~Hz}$ & $7.50 \mathrm{~Hz}$ & $8.50 \mathrm{~Hz}$ & $9.50 \mathrm{~Hz}$ \\
\hline $\begin{array}{c}\text { Percent } \\
\text { Difference }\end{array}$ & $4.5 \%$ & $6.9 \%$ & $\mathrm{~N} / \mathrm{A}$ & $10.1 \%$ & N/A & $2.1 \%$ \\
\hline
\end{tabular}

As shown in Table 12, the largest percent error calculated was $10.1 \%$ while the lowest was $2.1 \%$. The apparent $3^{\text {rd }}$ and $5^{\text {th }}$ experimental modes were not identifiable through visual observation of the analytical deflected shapes; therefore, the percent errors were not calculated for those two particular modes. It is a possibility that those two particular modes were not captured in the computational model; however, that conclusion cannot be drawn until a sweeping procedure is performed and correlation values between the computational mode shapes and experimental modes are computed. A further explanation on the sweeping procedure and correlation values also known as modal assurance criterion (MAC) numbers will be in the subsequent section.

\subsection{Comparison of Analytical to Experimental Mode Shapes}

When a structure is excited by means of forced vibration at a natural frequency, the mode of interest does not respond solely; the response of the structure naturally includes the participation of other modes as well. Thus, every apparent mode captured is considered to be diluted by other dynamic modes. The degree of dilution depends on the placement of the shaker as previously discussed in section 2.5. In order to optimize the 
response of the structure, the shaker should be placed in a location where the response of the mode of interest is most dominant.

To directly compare "pure" apparent mode shapes to analytical mode shapes, the apparent mode shapes have to be purified as suggested by Gram-Schmidt (Golub 1989). The purpose of purifying each apparent mode is to eliminate the participation of other dynamic modes; however, in order to effectively purify each apparent mode, every dynamic mode needs to be captured.

There were a total of 9 apparent modes that were experimentally captured in this thesis. As indicated by Gram-Schmidt, the apparent modes should be organized from the purest to the most diluted. Considering a mode "pure" assumes that the mode does not contain any participation of other dynamic modes. Thus a judgment has to be made as to which apparent mode is rationally considered most "pure". In a conventional building the most common dynamic modes in an "ultra low" force vibration test are the first two translational and the rotational mode. With only three modes to choose from, the sweeping procedure is clear-cut. However, having two translational, five vertical, and one rotational mode to rearrange makes the procedure much more complex. Any change in the arrangement of the modes will cause a significant change in the results, thus it is important to organize the modes in a precise order.

In the first attempt to organize the apparent modes from purest to most diluted, it was assumed that mode 1 was the "purest" followed by modes 5, 2, 3, 8, 6, 4, 9 and 7. Mode 1 was chosen as the "purest" as its response was primarily translational motion in 
the N-S direction with very minimal out-of-plane motion in the roof and floor diaphragms. Mode 5, a second order vertical mode, was chosen as the second purest as its response was the strongest out of all 9 modes. Its peak acceleration was an out-of-plane acceleration of $0.1 \mathrm{~g}$ at the floor.

Modes 2 and 3 are coupled first order vertical modes. In mode 2 the out-of-plane motion of the roof and floor diaphragms are in-phase, while in mode 3 the roof and floor diaphragms are out-of-phase. The peak response of mode 2 is greater than mode 3 but almost 2.5 times less than mode 5. Apparent mode 8 is a third order vertical mode and its response is also dominated by well defined roof and floor out-of-plane deformations; however, the vertical accelerations in apparent mode 8 are about 4 times less than apparent mode 2 .

Apparent modes 6, 4, 9, and 7 are considered to be the most diluted. AVTs and FVTs for apparent mode 6 indicated that the vertical shaker should placed at mid span 4$\mathrm{ft}$ from the east end of the floor. However, this peculiar location (close a stiff support) produced a well defined vertical mode with out-of-plane deformations in the roof and floor. Apparent mode 4 is unique in the sense that it is a vertical mode found by applying the horizontal shaker in the E-W direction. The shaker was mounted to the underside of the middle wide-flange roof beam; because it was applied to the underside of the beam, it initiated torsion into the beam, which caused out-of-plane deformation of the roof diaphragm. Considering that both modes 6 and 4 are vertical modes, mode 6 was chosen in front of mode 4 because mode 6 was found by utilizing the vertical shaker. Modes 9 and 7 are rotational and translational modes, respectively. Mode 7 was chosen as the most 
diluted due to the significant out-of-plane accelerations in the roof diaphragm. As previously mentioned, it was concluded that the steel deck panels were not interlocked with one another, and not all beams were properly attached to the steel deck. As a result of these abnormalities, the response of apparent mode 7 was significantly affected. Apparent modes 6 and 4 have similar roof out-of-plane deformations. In theory, by placing apparent modes 6 and 4 in front of apparent mode 7, the out-of-plane deformations of the roof diaphragm in mode 7 should get "swept out" by apparent modes 6 and 4.

In order to demonstrate the effect of the sweeping procedure, Table 13 below was created. Table 13 is a matrix of MAC numbers in which the columns represent the analytical mode shapes and the rows represent the apparent mode shapes.

Table 13: MAC Numbers Comparing Un-Swept-Apparent Results to Analytical Results

\begin{tabular}{|c|c|c|c|c|c|c|c|c|}
\hline \multicolumn{2}{|c|}{ Analytical } & 1 & 2 & 3 & 8 & 6 & 9 & 10 \\
\cline { 2 - 9 } & $4.10 \mathrm{~Hz}$ & $5.03 \mathrm{~Hz}$ & $5.54 \mathrm{~Hz}$ & $7.98 \mathrm{~Hz}$ & $7.04 \mathrm{~Hz}$ & $8.76 \mathrm{~Hz}$ & $9.82 \mathrm{~Hz}$ \\
\hline 1 & $4.45 \mathrm{~Hz}$ & 0.98 & 0.01 & 0.00 & 0.00 & 0.00 & 0.00 & 0.00 \\
\hline 2 & $5.33 \mathrm{~Hz}$ & 0.00 & 0.94 & 0.02 & 0.00 & 0.00 & 0.00 & 0.00 \\
\hline 3 & $5.91 \mathrm{~Hz}$ & 0.00 & 0.00 & 0.91 & 0.00 & 0.00 & 0.00 & 0.00 \\
\hline 4 & $6.60 \mathrm{~Hz}$ & 0.00 & 0.00 & 0.00 & 0.42 & 0.49 & 0.00 & 0.00 \\
\hline 5 & $7.50 \mathrm{~Hz}$ & 0.00 & 0.00 & 0.00 & 0.00 & 0.94 & 0.00 & 0.01 \\
\hline 6 & $8.50 \mathrm{~Hz}$ & 0.00 & 0.01 & 0.01 & 0.07 & 0.50 & 0.01 & 0.21 \\
\hline 7 & $9.10 \mathrm{~Hz}$ & 0.00 & 0.00 & 0.00 & 0.40 & 0.02 & 0.24 & 0.00 \\
\hline 8 & $9.50 \mathrm{~Hz}$ & 0.00 & 0.01 & 0.01 & 0.00 & 0.00 & 0.00 & 0.84 \\
\hline 9 & $10.30 \mathrm{~Hz}$ & 0.08 & 0.00 & 0.00 & 0.00 & 0.00 & 0.01 & 0.00 \\
\hline
\end{tabular}

In Table 13, the MAC numbers for apparent modes 1, 2, 3, and 5 were all above 0.90 , which represents an excellent correlation. With a MAC number of 0.84 , the un- 
swept apparent mode 8 correlates well with analytical mode 10 . The un-swept apparent mode 4 has MAC numbers of 0.49 and 0.42 with analytical modes 6 and 8 , respectively. As observed in Table 4 on page 43 the out-of-plane deformations of the floor diaphragm in the apparent mode 4 resembled analytical mode 6 , while the out-of-plane deformation of the roof diaphragm in apparent mode 4 resembled analytical mode 8 .

Un-swept apparent mode 6 has a MAC number of 0.50 with analytical mode 6 . Apparent mode 6 shows similar out-of-plane deformations in the floor diaphragm to apparent mode 4. Lastly, un-swept apparent mode 7 have similar out-of-plane deformation in the roof as in analytical mode 8 and similar translational displacement as in analytical mode 9 , which generates MAC numbers of 0.40 and 0.24 , respectively. To summarize the effect of the sweeping procedure, Table 14 below contains the MAC numbers comparing the swept experimental results to the analytical results. 
3.0 Analytical Basis 85

Table 14: MAC Numbers Comparing Swept-Experimental Results (Modes 1, 5, 2, 3, 8, 6, 4, 9, 7) to Analytical Results

\begin{tabular}{|c|c|c|c|c|c|c|c|c|}
\hline \multicolumn{2}{|c|}{ Analytical } & 1 & 2 & 3 & 8 & 6 & 9 & 10 \\
\cline { 3 - 9 } \multicolumn{2}{|c|}{ Swept Exp. } & $4.10 \mathrm{~Hz}$ & $5.03 \mathrm{~Hz}$ & $5.54 \mathrm{~Hz}$ & $7.98 \mathrm{~Hz}$ & $7.04 \mathrm{~Hz}$ & $8.76 \mathrm{~Hz}$ & $9.82 \mathrm{~Hz}$ \\
\hline 1 & $4.45 \mathrm{~Hz}$ & 0.98 & 0.01 & 0.00 & 0.00 & 0.00 & 0.00 & 0.00 \\
\hline 2 & $5.33 \mathrm{~Hz}$ & 0.01 & 0.93 & 0.02 & 0.00 & 0.00 & 0.00 & 0.00 \\
\hline 3 & $5.91 \mathrm{~Hz}$ & 0.00 & 0.02 & 0.89 & 0.00 & 0.00 & 0.00 & 0.00 \\
\hline 4 & $6.60 \mathrm{~Hz}$ & 0.00 & 0.00 & 0.00 & 0.65 & 0.00 & 0.00 & 0.01 \\
\hline 5 & $7.50 \mathrm{~Hz}$ & 0.00 & 0.00 & 0.00 & 0.00 & 0.94 & 0.00 & 0.01 \\
\hline 6 & $8.50 \mathrm{~Hz}$ & 0.00 & 0.00 & 0.00 & 0.18 & 0.01 & 0.05 & 0.03 \\
\hline 7 & $9.10 \mathrm{~Hz}$ & 0.00 & 0.00 & 0.00 & 0.02 & 0.01 & 0.46 & 0.01 \\
\hline 8 & $9.50 \mathrm{~Hz}$ & 0.00 & 0.00 & 0.00 & 0.00 & 0.00 & 0.00 & 0.85 \\
\hline
\end{tabular}

After performing the sweeping procedure and purifying the experimental mode shapes, most of the MAC numbers remained almost the same. Only 2 moderately increased. The MAC numbers for the experimental modes 1, 2, 3, 5, 8, and 9 were virtually unchanged, while the MAC numbers for experimental modes 4 and 7 reasonably increased by 0.23 and 0.22 , respectively. Prior to performing the sweeping procedure, experimental mode 4 and analytical mode 6 had similar out-of-plane floor diaphragm deformations. In Table 14 the correlation between the two modes was swept out by mode 5 , which simultaneously increased the correlation with analytical mode 8 . The out-ofplane deformations in experimental mode 7 were swept out by experimental modes 4,5 , and 6 , reducing the correlation with analytical mode 8 and an increasing the correlation with analytical mode 9.

Although some of the MAC numbers slightly increased, results lead to believe that there were some dynamic modes were missing. As previously mentioned, in order to effectively perform the sweeping procedure, all of the structure's dynamic modes have to 
be captured. Essentially, 9 modes may have not been enough. One of the essential modes not recorded is a mode that is primarily composed of out-of-plane deformation of the roof diaphragm. To effectively sweep out the out-of-plane deformations of the roof in apparent mode 7, the missing mode needs to be captured. However, for computational reasons, the apparent E-W mode was theoretically purified (artificially setting the vertical roof accelerations in apparent mode 7 to zero) from the out-of-plane roof deformations just as they would have been if the missing mode was recorded.

As a result of that assumption, the un-swept MAC number in Table 13 on page 83 for apparent mode 7 and analytical mode 9 significantly increased from 0.24 to 0.78 . To re-perform the sweeping procedure, the experimental modes were reorganized to reflect the artificial purification of apparent mode 7. As previously explained, apparent modes 1 , $5,2,3$, and 8 are believed to be the "purest", and thus were left in the same order. The last four experimental modes were reorganized in the following order: 7, 4, 6, and 9. Apparent mode 7 was moved to the front of the group as a result of its artificial purification and aside from apparent mode 9, apparent mode 4 and 6 were extremely diluted and are similar in shape. However, apparent mode 4 was chosen as more pure due to a mass weighted correlation number of 0.41 (see Table 6 on page 48) between apparent mode 6 and apparent mode 5 . A value of 0.41 indicates a moderate correlation between the two apparent modes and being that apparent mode 5 is considered the $2^{\text {nd }}$ most pure, by default it is assumed that apparent mode 4 is as more pure between the two modes. (see Table 4 on page 43). To summarize the effect of the second attempt at the sweeping 
procedure, Table 15 below contains the MAC numbers that compare the revised swept experimental results to the analytical results.

Table 15: MAC Numbers Comparing Swept-Experimental Results (Modes 1, 5, 2, 3, 8, 7, 4, 6, 9) to Analytical Results

\begin{tabular}{|c|c|c|c|c|c|c|c|c|}
\hline \multicolumn{2}{|c|}{ Analytical } & 1 & 2 & 3 & 8 & 6 & 9 & 10 \\
\cline { 2 - 9 } \multicolumn{2}{|c|}{ Swept Exp. } & $4.10 \mathrm{~Hz}$ & $5.03 \mathrm{~Hz}$ & $5.54 \mathrm{~Hz}$ & $7.98 \mathrm{~Hz}$ & $7.04 \mathrm{~Hz}$ & $8.76 \mathrm{~Hz}$ & $9.82 \mathrm{~Hz}$ \\
\hline 1 & $4.45 \mathrm{~Hz}$ & 0.98 & 0.01 & 0.00 & 0.00 & 0.00 & 0.00 & 0.00 \\
\hline 2 & $5.33 \mathrm{~Hz}$ & 0.01 & 0.93 & 0.02 & 0.00 & 0.00 & 0.00 & 0.00 \\
\hline 3 & $5.91 \mathrm{~Hz}$ & 0.00 & 0.02 & 0.89 & 0.00 & 0.00 & 0.00 & 0.00 \\
\hline 4 & $6.60 \mathrm{~Hz}$ & 0.00 & 0.00 & 0.00 & 0.76 & 0.00 & 0.06 & 0.00 \\
\hline 5 & $7.50 \mathrm{~Hz}$ & 0.00 & 0.00 & 0.00 & 0.00 & 0.94 & 0.00 & 0.01 \\
\hline 6 & $8.50 \mathrm{~Hz}$ & 0.00 & 0.00 & 0.00 & 0.00 & 0.00 & 0.00 & 0.05 \\
\hline 7 & $9.10 \mathrm{~Hz}$ & 0.00 & 0.00 & 0.00 & 0.10 & 0.01 & 0.86 & 0.00 \\
\hline 8 & $9.50 \mathrm{~Hz}$ & 0.00 & 0.00 & 0.00 & 0.00 & 0.00 & 0.00 & 0.85 \\
\hline 9 & $10.30 \mathrm{~Hz}$ & 0.00 & 0.00 & 0.00 & 0.00 & 0.00 & 0.00 & 0.00 \\
\hline
\end{tabular}

Overall the MAC numbers summarized in Table 15 are much improved over the MAC numbers in Table 14. The MAC numbers for swept experimental modes 1, 2, 3, 5, and 8 are unchanged and were previously discussed; therefore, this section will only emphasize the MAC numbers for experimental modes 4, 6, 7, and 9.

As previously discussed, experimental mode 4 was found by exciting the structure at the roof level in the E-W direction. Although it was primarily a vertical mode, some translation deformation in the E-W direction can be seen as a result of the shaker position. By virtue of the sweeping procedure, the translational deformations in experimental mode 4 are swept out by experimental mode 7 , resulting in a MAC number of 0.76 . 
Prior to performing the sweeping procedure, the out-of-plane deformations in the roof diaphragm in experimental mode 7 were artificially swept out and resulted in a MAC number of 0.78 . After performing the sweeping procedure, the out-of-plane deformations in the floor diaphragm were swept out by experimental mode 5, resulting in a much improved MAC number of 0.86 .

\subsection{Analytical Model of Vertical Anomaly}

An interesting anomaly that was found by virtue of forced vibration testing was a vertical irregularity in the floor diaphragm in the N-S translational mode. As seen in Table 4 on page 43, experimental mode 1 is dominated by the $\mathrm{N}-\mathrm{S}$ translational motion of the roof diaphragm; however, a vertical anomaly can be observed in the east end of the floor and can also be seen in Figure FFF below.

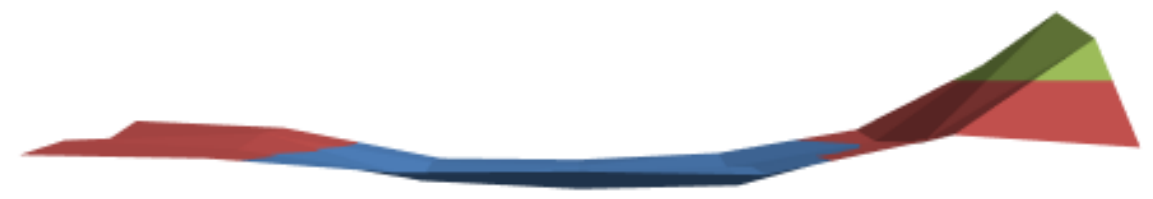

Figure FFF: Experimental Vertical Floor Response of First N-S Mode

The vertical irregularity can be seen in Figure FFF on the east end of the floor diaphragm. The vertical accelerations at this particular location were about 4 times greater than the vertical accelerations at mid span. For clarification of the location of the vertical anomaly, the floor plan of the Bridge House is shown in Figure GGG below. 


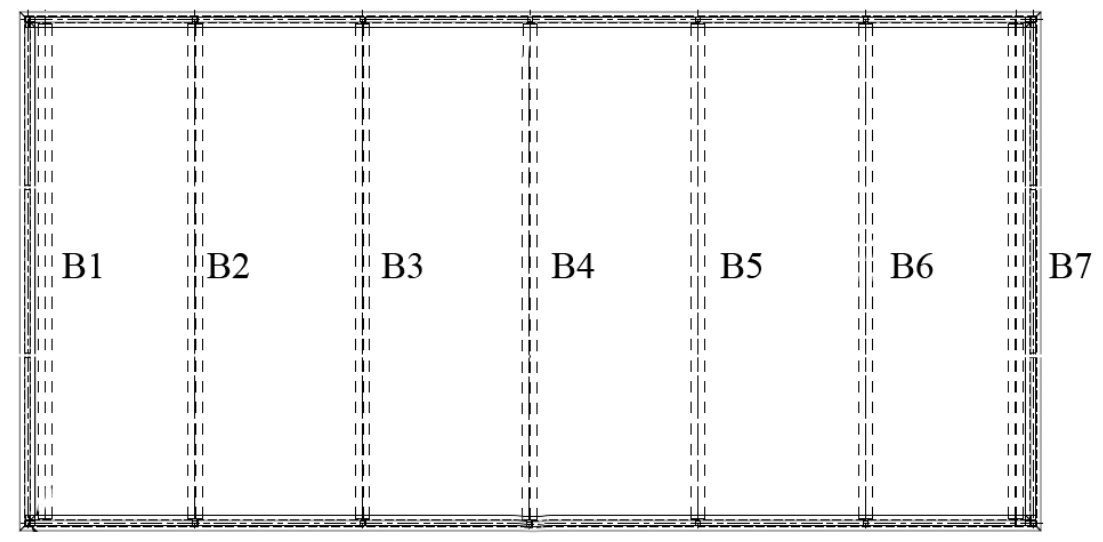

Figure GGG: Floor Plan

The vertical anomaly occurs at beam B7 as shown in Figure GGG. The assembly of the floor diaphragm is composed of lightweight concrete over metal deck, which is then supported by the wide flange beams as shown in Figure GGG. As previously stated, the acceleration readings were taken from the top of the concrete slab, thus the vertical anomaly results from the lack of connection between the metal deck and the wide flange beam B7. In an attempt to capture similar behavior of the floor diaphragm, the analytical model was modified so that the restraint between beam B7 and the floor diaphragm was released. Figure HHH below is the analytical mode shape of the floor that best resembles the vertical anomaly.

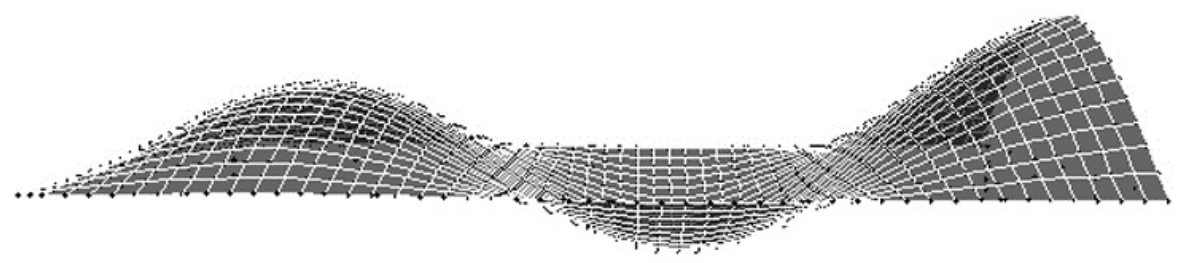

Figure HHH: Analytical of Model with Unconnected Beam (B7) 
The experimental and analytical results are not identical; however, there is a resemblance between the two. The computed MAC number comparing both Figure FFF and Figure HHH is 0.80 . Although the results are promising, a more in-depth investigation is needed to firmly conclude the as-built conditions of the Bridge House. It should be noted that the modifications done to the analytical model, in order to capture the dynamic mode seen in Figure HHH, were not included in the analytical model prior to this section and were done only to confirm a possible explanation of the vertical anomaly. 


\subsection{CONCLUSIONS}

The Bridge House is a one story steel structure supported on 4 concrete piers that spans $48 \mathrm{ft}$ over a seasonal creek. The lateral force resisting system (LFRS) is composed of ordinary moment frames in the N-S direction and braced frames in the E-W direction. It is vertically supported by a pair of trusses.

An experimental investigation was performed by means of system identification through ambient and forced vibration testing. Ambient vibration tests (AVT) were first performed to determine the dominant response of the Bridge House in either the N-S, E$\mathrm{W}$ and vertical directions through a selected range of frequencies, an indication that a possible mode was present. To better determine the natural frequency, AVT were followed by forced vibration tests (FVT). FVT amplified the response of the structure through the use of a linear mass shaker with an output force equivalent to $30 \mathrm{lbs}$.

An analytical model was developed to capture the dynamic behavior of the Bridge House. The process of generating an accurate computational model required a series of subsequent refined computational models based on comparisons with experimental results.

\subsection{AVT and FVT}

Ambient Vibration Tests (AVT) was used to find the approximate range of all nine natural frequencies. Forced Vibration Tests (FVT) was then performed to more accurately determine the natural frequency of each mode. Once the natural frequency and optimum shaker location was established, the shaker was positioned to continuously 
oscillate at each mode shape's respective natural frequency. Mode shape mapping was then used to determine the deformed shape of the structure at it respective resonant frequency. Experimental mode shapes in this thesis are referred to as apparent mode shapes prior to performing the sweeping procedure. To directly compare "pure" experimental mode shapes to analytical mode shapes, the influence of other dynamic modes on an apparent mode shape was minimized through the sweeping procedure.

The apparent N-S mode at $4.45 \mathrm{~Hz}$ was dominated by N-S translational motion. The roof diaphragm behaved similar to that of a rigid diaphragm because the theoretical $\mathrm{N}-\mathrm{S}$ in plane stiffness of the diaphragm is 1.53 times greater than the lateral stiffness of the moment frames. On the other hand, the apparent E-W mode was dominated by a combination of translational and vertical accelerations where the diaphragm demonstrated flexible behavior resulting from the theoretical E-W in plane diaphragm stiffness being 2 times less than the lateral stiffness of the braced frames. The apparent EW mode also highlights that some roof beams were experimentally determined to be fully attached, some partially attached and some not attached at all. The Bridge House spans $48 \mathrm{ft}$, thus vertical modes were also present in addition to the translational modes. A total of 5 vertical modes were captured and vertical accelerations were recorded up to $0.1 \mathrm{~g}$.

During the experimental investigation interesting findings such as diaphragm flexibility, foundation flexibility and frequency shifts due to thermal effects were found throughout the mode shape mapping process. 


\subsubsection{Diaphragms}

The roof diaphragm is made up of rigid insulation topped with gravel supported by 2-ft x 24-ft metal deck. In the dynamic response of the structure, the roof diaphragm behaved as flexible in the E-W direction whereas the same diaphragm behaved rigid in the N-S direction. The E-W direction has an approximate stiffness of $1149 \mathrm{k} / \mathrm{in}$, about 13 times stiffer than the N-S direction. The in-plane stiffness of the diaphragm in the E-W direction is approximately $544 \mathrm{k} / \mathrm{in}$. The diaphragm behaved differently in each direction because the N-S direction is $53 \%$ less stiff than the N-S in-plane stiffness of the diaphragm while the E-W direction provides $211 \%$ more stiffness than the E-W in-plane stiffness of the diaphragm. As a result of the stiff lateral system, the diaphragm was engaged in the apparent E-W mode and thus behaved flexibly. The in-plane stiffness of the roof diaphragm was estimated by conducting a parametric study in accordance with the Steel Deck Institute (SDI) where the experimentally determined E-W frequency was used as a basis for comparison to the hand calculated results.

The type of side lap connections between the roof steel deck panels have a significant effect on the in-plane stiffness which then effects the natural period of the translational modes. During an on-site inspection there were no visual or physical evidence of the type of connection between the steel deck panels. The roof diaphragm connections that were considered in the parametric study were button punch, seam welds, and screwed connections. It was analytically determined that a welded side lap connection resulted in an E-W natural frequency of $15 \mathrm{~Hz}$ (a $65 \%$ error), whereas the button punch connections resulted in a frequency of $11.5 \mathrm{~Hz}$ (a $26 \%$ error). The 
parametric study concluded that the steel deck panels were inter-linked with no physical connection other than friction, producing a $22 \%$ percent difference from the experimentally determined natural frequency. Note that the parametric study did not account for the additional flexibility from the missing restraints between the steel deck panels and their supporting beams. It was experimentally determined that a portion of the gravity roof beams were fully attached to the metal deck while some were partially attached. The lack of interlocking mechanism between the steel deck panels in combination with the lack of restraints of the steel deck to the gravity beams produced a highly flexible diaphragm. As a result, the ratio of the lateral stiffness to the diaphragm in-plane stiffness is approximately 2 in the E-W direction versus 0.65 in the N-W direction.

A vertical anomaly on the floor diaphragm was consistently detected in the apparent $\mathrm{N}-\mathrm{S}$ mode. The structure was excited in the N-S direction where its primary motion was N-S; however, vertical accelerations up to 2 times greater than the lateral floor accelerations were experienced on the east end of the floor diaphragm. The vertical flexibility of the floor arose from the influence of a vertical mode resulting from the lack of connection between the floor diaphragm and the floor beam at the east end of the building.

\subsubsection{Foundation Flexibility}

The soil and the concrete foundation piers significantly contributed to the translational response in the E-W direction; however, the contribution was negligible in the N-S direction. Furthermore, the peak lateral roof to floor acceleration ratio was about 
2.7 in the E-W mode and about 9.8 in the N-S direction (4 times more in N-S than in the E-W direction).

The concrete piers are no different than a cantilevered beam and the stiffness is a function of its length, thus the different pier heights would typically result in different lateral stiffness. Torsion arises when a variation of lateral stiffness occurs; however, the results of the apparent E-W mode shape proved otherwise. The concrete piers have about $10 \%$ more lateral stiffness (based on ideal soil spring stiffness of $130 \mathrm{k} /$ in) than the surrounding soil. The ratio of lateral frame stiffness to soil spring stiffness is about 2.2 in the E-W direction and about 0.15 in the N-S direction; thus, the soil bearing against and on the concrete piers is not sufficient to engage the piers in bending, causing concrete piers to rock, more so in the apparent E-W mode.

\subsubsection{Frequency Shift Due to Thermal Effects}

The Bridge House was experimentally determined to be sensitive to the measured temperature range of $55^{\circ} \mathrm{F}$ to $120^{\circ} \mathrm{F}$. Throughout the day as ambient temperature progressively increased, the natural frequency of the N-S translational mode decreased from $4.5 \mathrm{~Hz}$ to $4.2 \mathrm{~Hz}$, a $7 \%$ decrease.

To computationally model this thermal phenomenon, an analytical model of the Bridge House was created where a $65^{\circ} \mathrm{F}$ temperature change was applied to the steel columns and girders of the LFRS on the west face of the structure (the side most susceptible to sun exposure in the experimental N-S mode). As The Bridge House heats up the steel expands against the structure and its supports, causing elements in the LFRS 
to undergo compression. From the analysis, a $65^{\circ} \mathrm{F}$ temperature change can induce compression stresses of up to $20 \%$ of the approximate yield stress. In the case of the apparent N-S mode, the P-delta effect causes the flexural stiffness in the N-S direction to decrease, thus also decreasing the natural frequency.

This phenomenon was determined to only affect the frequency of the experimental N-S mode. However, in order to globally understand the thermal phenomenon, other modes should be evaluated to determine if other modes are more, equally, or less affected. To better understand why the natural frequency is sensitive as the temperature of the structure increases and insensitive as the temperature decreases, additional research is recommended.

\subsection{Computational Modeling}

Analytical modeling of the Bridge House's dynamic behavior was an iterative process that began as a simple hand analysis and ended as a complex analytical model. Throughout the analysis process, the changes made to the computational model were based on the understanding of structural dynamics theory, modeling assumptions, and experimental structural behavior.

The final computational model generated a natural frequency of $4.10 \mathrm{~Hz}$ in the N-S direction and $8.20 \mathrm{~Hz}$ in the E-W direction, a $7.86 \%$ error and a $9.89 \%$ difference from the measured natural frequencies. The computational model included a hybrid roof diaphragm utilizing both in-plane and out-of-plane stiffness elements to allow for flexibility in the E-W direction while preserving the stiffness in the N-S direction. Soil 
springs $(\mathrm{K}=130 \mathrm{k} / \mathrm{in})$ were also included in the computational model in order to properly capture the foundation flexibility.

\subsubsection{Diaphragm}

The first analytical model was a hand analysis assuming a rigid roof diaphragm with a fixed base. Assuming a rigid diaphragm and a fixed base resulted in a $99 \%$ overestimation of the natural frequency in the E-W direction. Conversely, the same model resulted in an $11.68 \%$ overestimation of the natural frequency in the N-S direction. The diaphragm flexibility significantly impacts the natural frequency of the structure in the E-W direction, thus applying a hybrid roof diaphragm with in-plane and out-of-plane stiffness elements creates the needed flexibility in the E-W direction while preserving the in-plane stiffness in the N-S direction. When compared to the experimental results, the hybrid diaphragm decreased the natural frequency in the E-W mode by $40 \%$ and $11 \%$ in the N-S direction resulting in a percent difference of $16.04 \%$ in the $\mathrm{E}-\mathrm{W}$ direction and $0.90 \%$ in the $\mathrm{N}-\mathrm{S}$ direction. Internal braces mimicking the additional stiffness provided by the friction between the steel deck panels had a minor impact on the mode shapes; however, the additional stiffness increased the frequency by $10 \%$ and $1.5 \%$ in the N-S and E-W direction, resulting in a $7.86 \%$ and $9.89 \%$ difference, respectively.

\subsubsection{Foundation Flexibility}

Foundation flexibility was evident in the experimental mode shapes, particularly in the E-W direction. Hence, to accurately capture similar structural behavior, soil springs were applied to the computational model. Based on the original construction drawings 
and textbook values for the modulus of subgrade reaction, the minimum and maximum theoretical soil spring stiffness would be about $7 \mathrm{k} /$ in and $65 \mathrm{k} / \mathrm{in}$, respectively. However, based on good comparisons to the experimentally determines natural frequency, a soil spring with stiffness of $130 \mathrm{k} /$ in is considered ideal. Although the ideal soil spring stiffness is 2 times more than the theoretical stiffness, it can be justified by decreasing the average pier height from 5-ft-9-in to 4-ft-0-in or by increasing the width of the foundation concrete pads to 5-ft-6-in from 4-ft-6-in. Considering the uncertainty of both the onsite conditions and what is specified on the construction plans, a stiffness of $130 \mathrm{k} /$ in in each direction for an analytical soil spring is feasible. The finalized computational model generated a natural frequency of $4.10 \mathrm{~Hz}$ in the N-S direction and $8.20 \mathrm{~Hz}$ in the E-W direction, a $7.86 \%$ difference and a $9.89 \%$ difference from the measured natural frequencies.

\subsubsection{Comparisons of Analytical to Experimental Mode Shapes}

To directly compare "pure" experimental mode shapes to analytical mode shapes, the influence of other dynamic modes on an apparent mode shape was minimized through a process known as the sweeping procedure. The comparisons between the computational and experimental results were measured through a correlation tool known as the modal assurance criterion (MAC), a statistical indicator ranging from zero to unity, where zero represents inconsistent correspondence and unity represents a consistent correspondence. A total of 9 modes were experimentally recorded and as part of the purification process they were structured in order from purest to the most diluted. In order to effectively perform the sweeping procedure, all of the structure's dynamic modes should be 
experimentally captured; however, it was concluded that one essential apparent mode was not recorded. The apparent mode considered missing is a mode that is composed of only the out-of-plane deformations of the roof diaphragm in the apparent E-W mode. Thus, the apparent E-W mode was not effectively purified. However, for computational reasons, the apparent E-W mode was theoretically purified by artificially setting the out-of-plane roof deformations to zero just as they would have been if the missing mode was recorded. It is recommended that the missing mode be recorded in future research.

Apparent modes 1, 7 and 9 are defined as the N-S, E-W and rotational mode whereas modes $2,3,4,5,6$, and 8 are all defined as vertical modes, respectively. To perform the sweeping procedure the apparent modes were structured from purest to the most diluted. Judgment as to which experimental mode is considered most "pure" can be made by examining mode shapes, accelerations, and the shaker location. The arrangement of modes starting from what is considered most pure is as follows: apparent mode $1,5,2,3,8,7,4,6,9$.

Apparent mode 1 was chosen as the "purest" because the response was primarily strong translational motion in the $\mathrm{N}-\mathrm{S}$ direction with very minimal out-of-plane motion in the roof and floor diaphragms. Mode 5, a second order vertical mode, was chosen as the second purest as its response was the strongest out of all 9 modes. The peak acceleration of mode 5 was an out-of-plane acceleration of $0.1 \mathrm{~g}$ at the floor. Modes 2 and 3 follow because they are first order coupled vertical modes with well defined deflected shapes and accelerations up to $0.05 \mathrm{~g}$, about 6 times greater than the translational accelerations in a translational mode. Apparent mode 8 is a third order vertical mode and its response is 
also dominated by well defined roof and floor out-of-plane diaphragm; however, accelerations are about 4 times less than apparent mode 2 . Apparent mode 7 is influenced by a higher order vertical mode and is considered far from pure; however, its theoretical purification results in a better defined deflected shape than apparent modes 4, 6 and 9. Aside from apparent mode 9, apparent mode 4 and 6 were extremely diluted and are similar in shape. However, apparent mode 4 was chosen as more pure due to a mass weighted correlation number of 0.41 (see Table 6 on page 48) between apparent mode 6 and apparent mode 5. A value of 0.41 indicates a moderate correlation between the two apparent modes and being that apparent mode 5 is considered the $2^{\text {nd }}$ most pure, by default apparent mode 4 is regarded as more pure between the two modes. The computed MAC numbers for experimental modes $1-9$ are as follows: $0.98,0.93,0.89,0.76,0.94$, $0.00,0.86,0.85$, and 0.00 , respectively. MAC numbers for mode $1,2,3,4,5,7$ and 8 indicate that a good correlation between the experimental and analytical results is obtained. However, MAC numbers comparing experimental mode 6 and 9 show no correlation to the analytical model, thus indicating that there is a possibility that experimental modes 4 and 6 are not the real modes.

The Bridge House is a unique structure that poses dynamic properties observed in both buildings and bridges. Typically, the first three dynamic modes in low rise regular buildings are the first two translational followed by a rotational mode. However, because the structure spans $48 \mathrm{ft}$ over a seasonal creek, there are numerous vertical modes that have to be considered when analyzing this structure. Although not all of the vertical 
modes were experimentally captured, appropriate assumptions were made to generate a computational model that closely correlated with the experimental results. 


\subsection{REFERENCES}

Allemang R. J. "The Modal Assurance Criterion (MAC): Twenty Years of Use and Abuse." Sound and Vibration, 2003.

Bowles, Joseph E. Foundation Analysis and Design. Columbus, Ohio: McGraw-Hill, 1996.

Chopra, A. K. Dynamics of Structures, Theory and Applications to Earthquake Engineering, Third Edition. New Jersey: Pearson Prentice-Hall, 2007.

Davena, Ronald, et al. California Polytechnic State University, San Luis Obispo, 1966. San Luis Obispo: Cal Poly SLO, 1966. Print

Golub G.H. and Van Loan C.F. Matrix Computations: Second Edition. Baltimore: Johns Hopkins University Press, 1989.

Jacobsen, Erica Dawn, Forced Vibration Testing and Analysis of Pre- and Post-Retrofit Buildings. Diss. California Polytechnic State University, San Luis Obispo, 2011. San Luis Obispo: Cal Poly SLO, 2011. Print

Luttrell, Larry. Diaphragm Design Manual, Second Edition. Fox River Grove, Illinois: Steel Deck Institute, 1995.

McDaniel, C.C., and G.C. Archer. Improving Student Understanding of Structural Dynamics Using Full-scale, Real-time Excitation of Buildings. American Society for Engineering Education (ASEE) Annual Conference, 2010.

Medhekar, Manoj S., and D.J. Laurie Kennedy. Seismic Evaluation of Steel Buildings with Concentrically Braced Frames. Diss. U. of Alberta, 1997. Edmonton: UA, 1997. Print

Nelson, Chirs. Poly Canyon's Bridge House. www.chrisnelson.ca. 20 May 2005. Web. 19 August 2012.

Planas, Brian, et al. Rehabilitation of the Bridge House. California Polytechnic State University, San Luis Obispo, 2011. San Luis Obispo: Cal Poly SLO, 2011. Print

Rendon, Adam R., Determination of the Modal Parameters of a Five Story Reinforced Concrete Structure Using Ultra Low Level Excitation and Computational Analysis. Diss. California Polytechnic State University, San Luis Obispo, 2011. San Luis Obispo: Cal Poly SLO, 2011. Print

“San Luis Obispo, California.” Map. Google Maps. Google, Web 19 August 2012. 
The Structural Engineer Institute of the American Society of Civil Engineers. Minimum Design Loads for Buildings and Other Structures (ASCE-7-05). American Society of Civil Engineers, 2006.

Trembley, Robert, and Siegfried F. Stiemer. "Seismic Behavior of Single-Story Steel Structures with a Flexible Roof Diaphragm." Canadian Journal of Civil Engineering 23.1 (1996): 49-62. Print 


\subsection{APPENDIX}




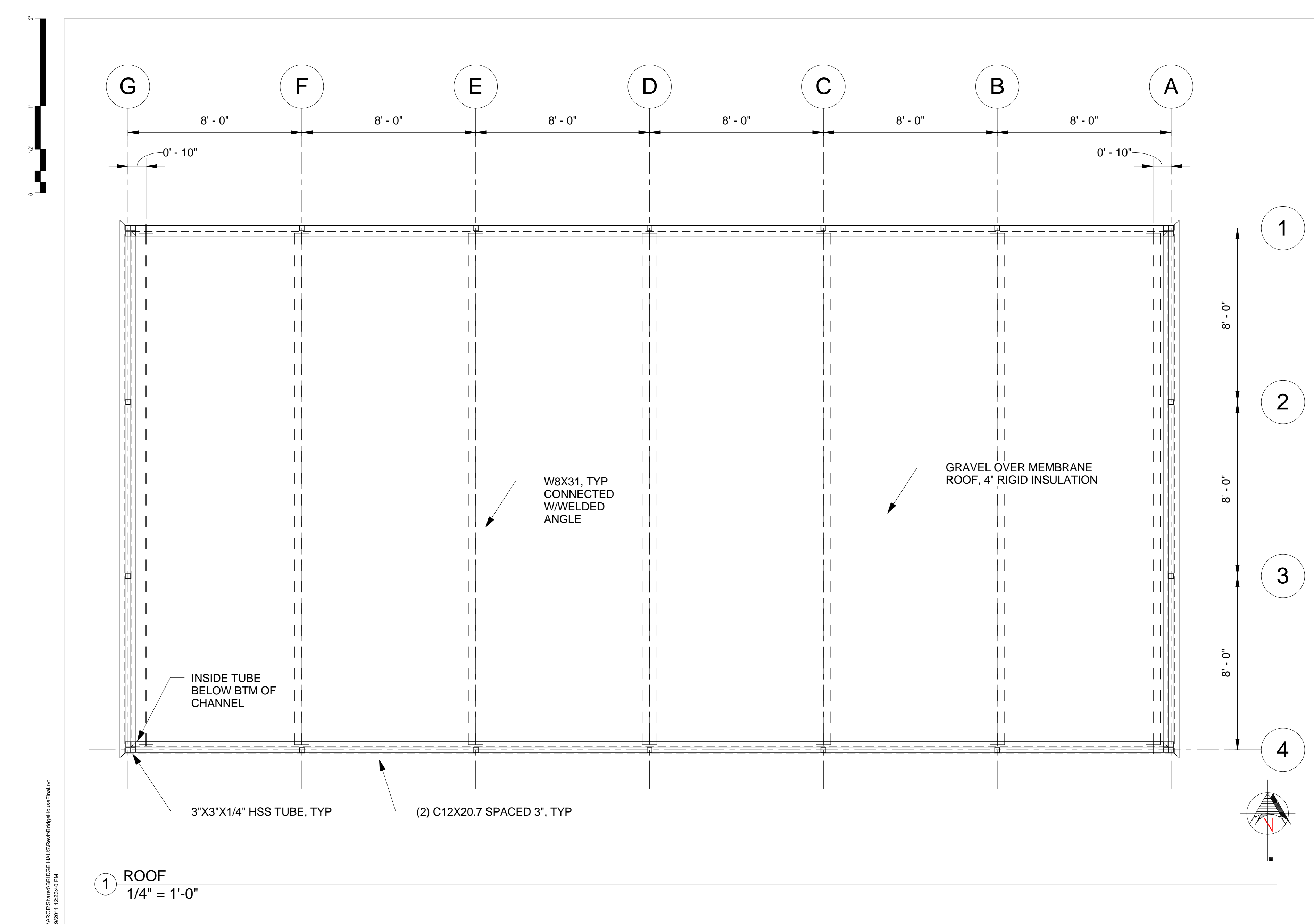




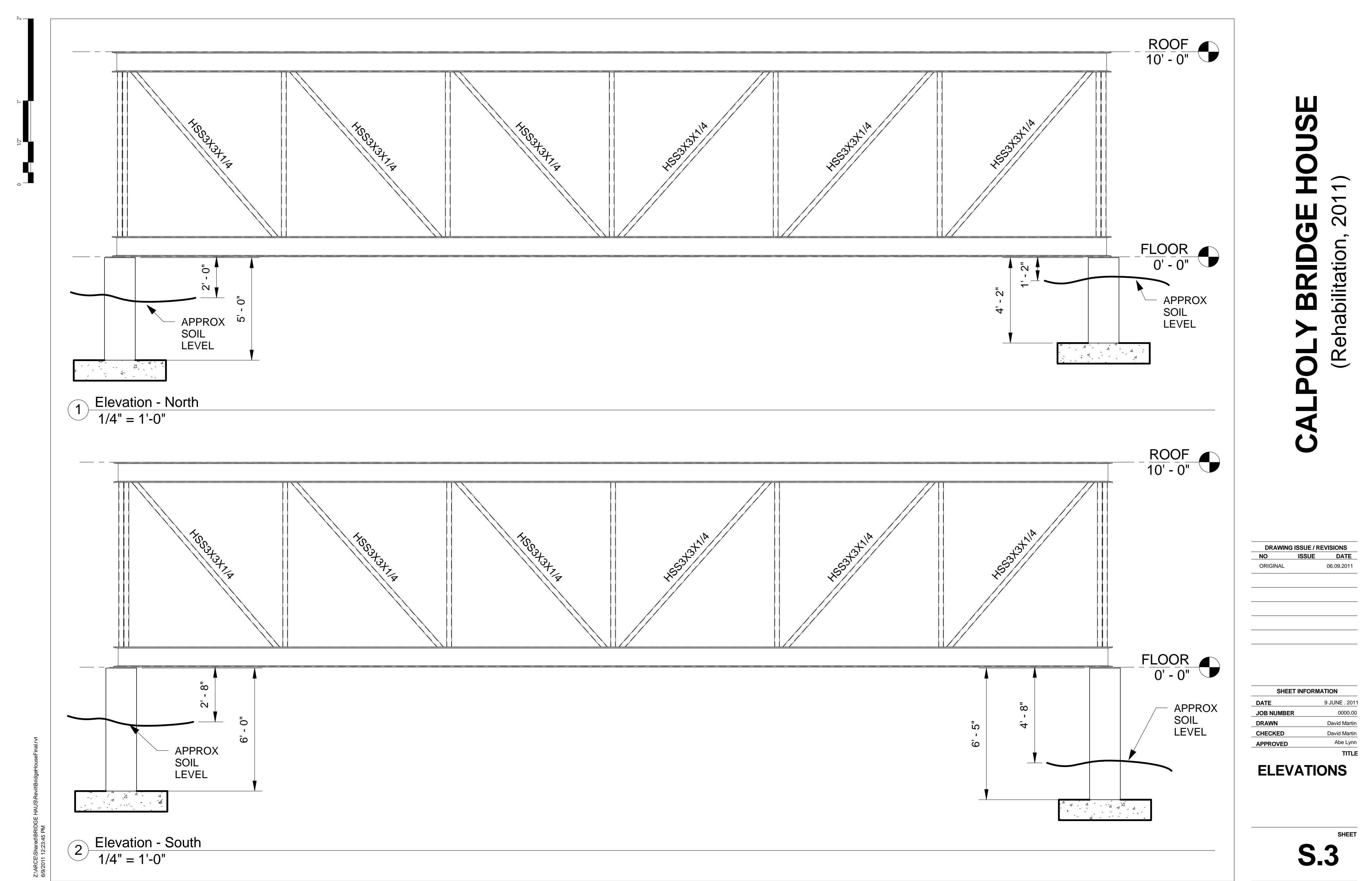




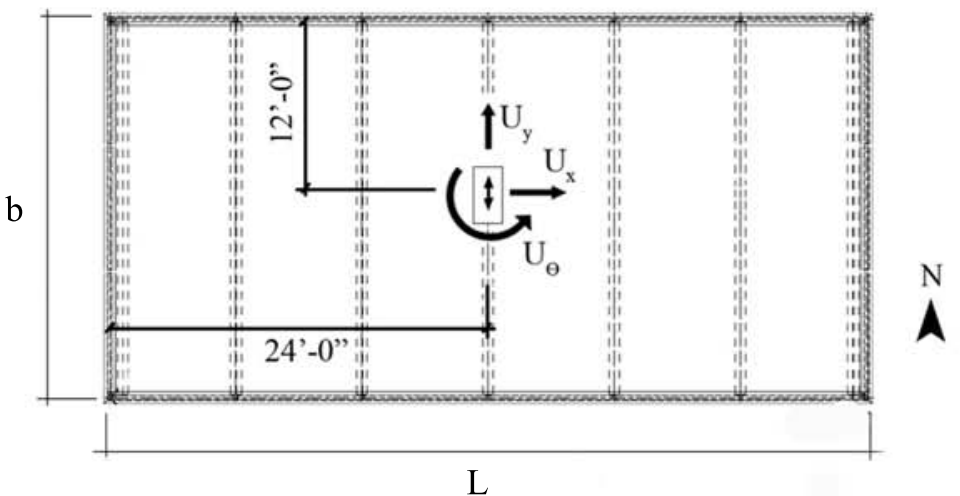

ROOF PLAN

$$
\begin{aligned}
& \mathrm{K}^{*}=\left|\begin{array}{ccc}
87 & 0 & 0 \\
0 & 1149 & 0 \\
0 & 0 & 31,036,608
\end{array}\right| \\
& \mathrm{M}^{*}=\left|\begin{array}{ccc}
34.3 & 0 & 0 \\
0 & 34.3 & 0 \\
0 & 0 & 1,185,18
\end{array}\right| \times \frac{1}{386}
\end{aligned}
$$

* Units are in $\mathrm{K}$, in, and $\mathrm{s}$.

$$
\begin{aligned}
\mathrm{K}^{11} & =\sum \frac{12 E I}{L^{3}} & \mathrm{M}^{11} & =m_{R} b L \\
\mathrm{~K}^{22} & =\sum \frac{E A}{L} \cos ^{2} \theta & \mathrm{M}^{22} & =m_{R} b L \\
\mathrm{~K}^{33} & =K^{11} \frac{L^{2}}{4}+K^{22} \frac{b^{2}}{4} & \mathrm{M}^{33} & =\frac{1}{12}\left(b^{2}+L^{2}\right) m_{R}
\end{aligned}
$$

\section{Acceleration Vs Time}

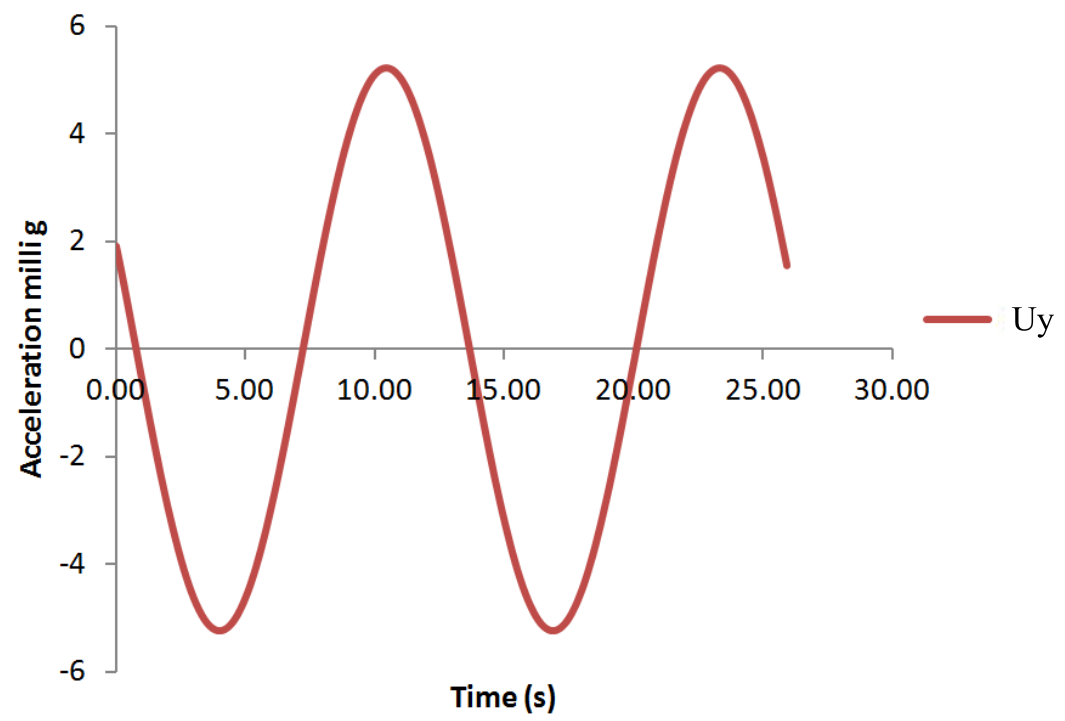

